\title{
Power factor typology through organizational and network analysis - Using environmental policy networks as an illustration -
}

\author{
Dissertation \\ zur Erlangung des sozialwissenschaftlichen Doktorgrades der \\ Sozialwissenschaftlichen Fakultät \\ der Georg - August - Universität Göttingen \\ vorgelegt \\ von \\ Nikolaos D. Hasanagas \\ aus Thessaloniki, Griechenland
}

Göttingen, 2004 
1. Gutachter: Prof. Max Krott

2. Gutachter: Junior Prof. Scott Gissendanner

3. Gutachter: Prof. Volker Müller-Benedict

Tag der mündlichen Prüfung: 27. Mai 2004 
Nicolas D. Hasanagas

\begin{abstract}
Power factor typology
through $O_{\text {rganizational and }} N_{\text {etwork analysis }}$
\end{abstract}

- Using environmental policy networks as an illustration -

Power $=f($ Organization, Network $)$ 


\title{
Bibliografische Information Der Deutschen Bibliothek
}

Die Deutsche Bibliothek verzeichnet diese Publikation in der Deutschen

Nationalbibliografie; detaillierte bibliografische Daten sind im Internet über <http://dnb.ddb.de> abrufbar.

\author{
$f$ \\ Gedruckt auf alterungsbeständigem, säurefreien Papier \\ Printed on acid-free paper
}

ISBN: 3-89821-386-2

(C) ibidem-Verlag

Stuttgart 2004

Alle Rechte vorbehalten

Das Werk einschließlich aller seiner Teile ist urheberrechtlich geschützt. Jede Verwertung außerhalb der engen Grenzen des Urheberrechtsgesetzes ist ohne Zustimmung des

Verlages unzulässig und strafbar. Dies gilt insbesondere für Vervielfältigungen, Übersetzungen, Mikroverfilmungen und elektronische Speicherformen sowie die Einspeicherung und Verarbeitung in elektronischen Systemen. 
To my schoolteachers Ms Filio Manoloutsiou and Mr Stavros Bletsas 



\title{
Power factor typology through organizational and network analysis - Using environmental policy networks as an illustration -
}

\author{
by Nicolas D. Hasanagas
}

Summary: This work is based on a doctoral research. Our main question is: who can be powerful and when. We assume that power is a function of network and organizational characteristics and thus not every actor can be powerful in every network. Power and institutional theories will be operationalized, completed and specified by the results. Five types of power factors will be proposed, which are combinations of organizational and network characteristics that combine to produce high power synergy and low inconsistency. The first dimension of power is trust: the trustee leads the one who trusts. The second dimension is financial incentive: the gift giver influences the gift receiver. The third dimension is irreplaceability. This is an operationalization of general system theory which operationalizes the exchange power model. Although the dependent variable (power) will be calculated by the systemic approach, the independent variables will be culled from New Institutionalism. For this purpose, a combination of the Theory of Organized Interests and Network Theory is necessary. These theories will be specified throughout our results. The typology of power factors (organizational and network characteristics) was derived from both inductive and deductive processes. The organizational factors have been deduced from certain theories: the "lawful" type from contingency theory and mobilization of bias, the "trustworthy" from the resource dependence model, the "little brother" from the transaction-cost and resource dependence model, the "omniscient" type from decisionmaking theory, and the "re-distributor" type from decision-making theory and hypotheses on the role of monitoring information. Afterwards, the deduced organizational factors of each type have functioned as a basis for the induction of network factors, which proved to reach highest power synergy with the organizational factors through stepwise regression.

Our methodology is a statistics-based vector algebra. We measured 108 indicators in 234 cases from 12 environmental policy networks in 8 European countries. In general, 'trust' makes up $82 \%$ of the power composition, while 'financial incentive' is only $8 \%$ and 'irreplaceability' only $10 \%$. Not all the network characteristics and organized interest models proposed until now have proven relevant to power, rather only some of them in certain combinations. We classified these combinations into five types: The "lawful" type: An actor with a multidisciplinary team that is lawful but not state-controlled has optimal chances in 'non crowded' and mono-sectoral networks with intensive state contacts, where the state does not play any important role. The "trustworthy" type: A trustworthy actor with a multidisciplinary team has optimal chances in a 'non-crowded' network with intensive state contacts and low importance of state. The "little brother" type: An actor who has powerful partners and various financing resources has optimal chances in a monosectoral network with 'equal chances', where many possible contacts remain unexplored. The "omniscient" type: A powerful actor who implements its power by imposing general or scientific information as "important" on a network with little material needs. The "redistributor" type: A powerful actor who receives occasional general information and reconstructs it in order to provide 'important' general and scientific information. It has optimal chances in a network with no scientific links.

The equilibrium between the advantages and disadvantages of the method of complete network analysis has motivated thoughts about future research questions regarding the quality of regression and the insights of Heckman on the weakness of self-selection. A combined strategy of qualitative and quantitative research is necessary in order to make policy consulting applicable to politics and further theorizing more accurate. 

1 Introduction

\section{Contents}

1.1 Questions and aims $\quad 7$

1.2 Concept, design and output $\quad 7$

2 Theoretical framework 13

2.1 A concise form of our research concept 13

2.2 Power: our dependent variable $\quad 15$

2.3 Operationalization of power for political networks: trust, incentive, irreplaceability 20

2.3.1Trust as a dimension of power 20

2.3.2 Incentive as a dimension of power 22

2.3.3 Irreplaceability as a dimension of power 23

2.4 System theory and the exchange model: applying our

2.5 New Institutionalism: trying to find relevant independent variables 25

2.5.1 Theory of Organized Interests 29

2.5.2 The deficit of network models: rather descriptive than explanatory 33

2.5.2.1 Understanding the logic of the institutionalists 33

2.5.2.2 Empirical institutionalist models: searching for definitions with properties 36

2.6 Five types of power factors: How they emerged and why they are necessary

2.6.1 Building typology 38

2.6.2 Why a typology is necessary 41

2.6.3 Theoretical bases of the types 41

3 Methodology and illustrative examples 49

3.1 Applying quantitative network analysis 49

3.2 Advantages and disadvantages of a complete network analysis: our strategy for improvement 51

3.2.1 Advantages of a complete network analysis 51

3.2.2 Disadvantages of complete network analysis 52

3.2.3 The strategy of "many" indicators 55

3.3 Operationalization of variables 58

3.4 Measurement of power $\quad 59$

3.5 Measurement of information-related variables 63

3.6 Measurement of organization-related and network variables $\quad 65$

3.6.1 Organization-related variables 65

3.6.2 Network variables 66

3.7 Data 67

4 Presentation and qualitative analysis of the results: Anatomy of power and the five power types 75

4.1 Anatomy of power 75

4.2 The five power types $\quad 78$ 
4.2.1 The three types of power accumulation factors

(or structure-related factors) $\quad 80$

4.2.1.1 The "lawful" type 80

4.2.1.1.1 Analysis of organizational factors 82

4.2.1.1.2 Analysis of network factors $\quad 84$

4.2.1.1.3 Empirical case of "lawful" type 86

4.2.1.2 The "trustworthy" type 88

4.2.1.2.1 Analysis of organizational factors $\quad 89$

4.2.1.2.2 Analysis of network factors 90

4.2.1.2.3. Empirical case of "trustworthy" type 91

4.2.1.3 The "little brother" type 92

4.2.1.3.1 Analysis of organizational factors $\quad 94$

4.2.1.3.2 Analysis of network factors 95

4.2.1.3.3 Empirical case of "little brother" type 96

4.2.2 The two types of power activation factors
(or communication-related factors)

4.2.2.1 The "omniscient" type 98

4.2.2.1.1 Analysis of organizational factors 100

4.2.2.1.2 Analysis of network factors 106

4.2.2.1.3 Empirical case of "omniscient" type 107

4.2.2.2 The "re-distributor" type 108

4.2.2.2.1 Analysis of organizational factors 109

4.2.2.2.2 Analysis of network factors 111

4.2.2.2.3 Empirical case of "re-distributor" type 112

5 Discussion: What is expected to be "original" on this work 114

5.1 Integration of the new results into the existent theory 114

5.2 Methodological aspects: strengths and weaknesses of

this work 118

5.2.1 Heckman' s contribution to the self-selection weakness $\quad 119$

6 Conclusions 120

6.1 Theoretical conclusions $\quad 120$

6.2 Suggestions for the political practice 121

6.3 Open questions for future research 123

7 Appendices 125

8 References 143 


\section{Introduction}

\subsection{Questions and aims}

Power analysis and assessment is one of the greatest challenges for social scientists because of the universal character of power and its critical role for success in every activity. The guiding question is: (a) who can be powerful and when ? $^{1}$. Another question (b) discussed in this framework is: through which processes is power accumulated and implemented?. The answers to these questions are expected to make a theoretical and empirical contribution, which can be useful for more accurate policy consulting and further theoretical discussion. The theoretical contribution consists in specifying abstract theories like New Institutionalism and hypotheses about processes of power accumulation and implementation. The empirical contribution lies in quantitative results on the relevance of power dimensions, and the operationalization of previous qualitative models.

\subsection{General concept, design and output}

\section{- General concept}

Based on the approach of New Institutionalism, we assume that power depends on certain organizational characteristics of an actor and certain characteristics of the particular policy network (system of interactions around a particular issue) in which it is involved. Thus, not every actor can be powerful in every network. We are going to examine what characteristics an organization should have in order to have the chance to develop power within a network with certain characteristics (which will be examined too). Models from the Theory of Organized Interests and Network Theory will be operationalized and specified in the results.

We will examine the main theories of power (Arendt, Bachrach/ Baratz, Foucault, Stone, Popitz etc). We will argue that the "power to" (Arendt) that seems to assure

\footnotetext{
${ }^{1}$ Predicting power before joining a network, an actor can avoid a useless conflict with a more powerful actor or a cooperation with only much more powerful "friends" that can lead up to its exploitation and no profit at all (Markovski et al. 1988: 225 in YAMAGUCHI 1996).
} 
the cohesiveness of a network is not a separate power, but a result of interactions between several "power over" relatio nships. This assumption is based on the Weber's initial approach and becomes more understandable through deepening our knowledge with Bachrach/ Baratz and Stone theories and finally connects Foucault's approach with our methodology ${ }^{2}$. Simultaneously, Arendt' s descriptive approach is used here in order to understand the "power to" effect, which seems to keep a network cohesive, and it will not be further used as an explanatory approach.

We will propose an operational power model with three dimensions; The first dimension is trust. The second one is (offering) financial incentive. The third one is irreplaceability (the pressure exerted by formal and informal institutions). These dimensions take the form of exchange relations (one gains trust, gives financial incentives, and gains dependence of other actors because he/she is irreplaceable for them in formal or informal procedures).

\section{- Design}

The above three power dimensions will be measured through complete network analysis. This is nothing but an operationalization of the general system theory which in turn operationalizes the exchange model of power. Although the dependent variable (power as an aggregation of the above three dimensions) will be calculated by the systemic approach, we will try to discover relevant independent variables using the approach of New Institutionalism. For this purpose, a combination of the Theory of Organized Interests and Network Theory is necessary. Models of these two research areas, namely organizational potentials as well as descriptive network dimensions, suggested by several authors will be discussed, operationalized and analyzed through cross-sectional analysis in relation to power. Our quantitative methodology is a statistics-based vector algebra (complete network analysis with cross-sectional analysis). In 2002 we measured 108 variables in 234 cases (power values) from 12 environmental policy networks in 8 European countries.

\footnotetext{
${ }^{2}$ Complete network analysis practically consists of the calculation of the effect of several dyads together and aims at assessing their aggregated effects.
} 
The answer to the guiding question (a) is a quantitative typology of power factors (certain organizational and network characteristics). Each type is an ideal type ${ }^{3}$ of actor with certain organizational characteristics (e.g. high multidisciplinarity, powerful partners) which can produce optimal power in combination with certain characteristics of the network in which this actor is involved (low oligarchy, low intersectorality etc). The main property of each ideal type is the optimal power synergy ${ }^{4}$ of organizational and network factors. A typology is necessary because of the need to isolate factors that combine to produce the highest possible power synergy (significance for power) and the fewest possible inconsistencies ${ }^{5}$.

As said, the organizational factors for these types are generally based on models of Theories of Organized Interests and the network factors are based on descriptive Network models suggested until now. However, the first grouping of organizational factors has been deduced from certain theories, on which the respective types are based. These are: contingency theory combined with the mobilization of bias for the "lawful" type, resource-dependence model for the "trustworthy" type, transactioncost model combined with resource-dependence model for the "little brother" type, decision-making theory with focus on coordination for the "omniscient" type and decision-making theory with focus on monitoring for the "re-distributor" type. Afterwards, the network factors were induced on the basis of the respective organizational factor groups through stepwise regression. The first three types try to

\footnotetext{
${ }^{3}$ These ideal types can hardly appear in the political practice in their whole form; the empirical examples presented in section 4 are the best possible real approaches to these types which we found in our empirical material.
}

${ }^{4}$ Synergy is a property of the components of a system to produce together a higher effect (here power effect) than the sum of their separate effects. This is a system property of major practical importance. The combinations of organizational and network factors are systems of factors which present strong synergy which is statistically expressed by the significance level of the factors (independent variables) for the power (dependent variable). This is a reason which makes the building of typology necessary.

${ }^{5}$ Inconsistencies here mean negative correlations between factors which are both favorable $(+)$ or both unfavorable (-) for power or positive correlation between factors which are the one favorable and the other one unfavorable for power. 
show how power can be developed (power accumulation types), while the last two types show how existing power can be implemented (power activation types). There are five types in this particular research (and not more or less) because this number has derived from employing the above theories (from which the organizational factors have been deduced). What we present here is an example of typology building that combines deductive and inductive processes to aim for more accurate policy consulting (more types can emerge in future research with a larger empirical basis or different theories). The indicators which have been used in this typology and their correspondence to previous qualitative models are presented in the two relevant tables in section 5 .

The five types are briefly presented as follows:

The "lawful" type: An actor with a multidisciplinary team that is lawful but not state controlled has its optimal chance in ,non-crowded“"and mono-sectoral networks with intensive state contacts, where the state does not play any important role.

The "trustworthy" type: A trustworthy actor with a multidisciplinary team has its optimal chance in a ,non-crowded“ network with intensive state contacts and low state importance.

The "little brother" type: An actor wi th powerful partners and various financing resources has its optimal chance in a mono-sectoral network with „equal chances“ where many possible contacts are still unexplored.

The "omniscient" type: A power actor can implement its power by imposing general or scientific information as "important" within a network with little material needs. The 're-distributor" type: 'The powerful actor does not need to 'learn' but rather 'reconstruct". A powerful actor receives occasional general information and reconstructs it so as to provide "important" general and scientific information. It has its optimal chance in a network with no scientific links.

The answer to the question (b) raised above is that in policy networks, trust contributes $82 \%$ to power composition while incentive only $8 \%$ and irreplaceability $10 \%$. One could say that these empirical findings seem to be of high importance because they show the strong relevance of trust (which is an unofficial dimension) and the weak relevance of financial and institutional pressure in policy-making. Accumulation processes of power are discussed: trust seems to produce irreplaceability and suitable conditions for offering financial incentives. Irreplaceability seems also to produce suitable conditions for financial incentives. 
Financial incentives are not expected to produce any of the other two dimensions. The role of information (general and scientific) seems to also be very relevant to power implementation. Information seems to be used as a driving force by powerful actors and not as a power source ${ }^{6}$.

Secondary results also include the connection of theoretical models (e.g. transactionmodel) with network dimensions through the combination of the above described deductive and inductive processes. This procedure may also serve as a possible method for building typologies in future research.

\section{Summary:}

Power analysis and assessment is one of the greatest challenges for social scientists because of the universal character of power and its critical role for success in every activity. Our main question is: who can be powerful and when. We assume that power is a function of network and organizational characteristics and thus not every actor can be powerful in every network. We are going to examine what characteristics an organization should have in order to successfully participate in a network with certain characteristics. Power and institutional theories will be operationalized, completed and concretized by the results. The information will be also examined separately and its role in power development will be discussed.

Five types of power factors will be built which are combinations of organizational and network characteristics that combine to produce high power synergy and low inconsistency. First, we will use deduction to group organizational characteristics (factors) and induction (stepwise regression) to combine network characteristics with the organizational ones.

${ }^{6}$ S. below decision-making theory (SIMON 1981) 


\section{Theoretical framework}

\subsection{A concise summary of our research concept}

Now, we are going to summarize the relation between the selected theories and the independent variables that we have operationalized and measured. We will discuss in more detail in section 4. (Analysis and operationalization of them is available in appendix I.) Our typology may be characterized as an atheoretical one. However, the five types are not exclusively results of induction. Below (2.6) we will discuss the types in more details and we will see that their first aspect (organization factors) has been deduced from and pre-designed on the basis of existing theories, and has functioned as a basis for inducing the second aspect (network factors). Why have we used a partly atheoretical approach? The answer is that inducing of the network factors (atheoretical part) may be the only way to integrate them in power theory, in so far as the network models suggested until now have an atheoretical and descriptive rather than an explanatory character. Moreover, what they describe is not so much power status but rather the interactions and behavior of actors. Through our method of induction by stepwise regression we have extracted a more restricted number of network variables which present the highest power synergy with organizational factors derived from theoretical models. This was the only solution we could think of in this research in order to avoid the trap of inventing ad hoc new hypotheses while simultaneously connecting descriptive atheoretical network dimensions with existing theories (perhaps these types can be useful for network theorization in the future).

At this early point, we should briefly clarify the role of information; Information "importance" (closeness centrality), capability of controlling (betweenness centrality) and monitoring it (indegree) are considered here to be organizational (actor-related) factors. Although these factors are certainly not internal structures of an organization, they are still a property assigned to organization by network interactions ${ }^{7}$ and thus they will be regarded as organizational characteristics.

\footnotetext{
${ }^{7}$ The relation of information to the power is not simple and we will discuss it in details in the omniscient and re-distributor type. The operationalization and measurement of information (simple differentiation of general from scientific information by cross-assessment) has been practiced quite simple in this work, and an in depth analysis of the information content did not pertain to our aims. Thus we will not develop any discussion about its content in the theoretical part (2).
} 
A wider applicability of the results to other sectors apart from the "environmental policy" (external validity of variables, BRYMAN 2001, p.30) is expected, as the general system theory filters through standard structures (polities like latent or manifest hierarchies) that have similar structures and properties in sectors beyond policy specialties or processes $^{8}$. The New Institutionalism has been used as a wider intellectual framework in order to improve the probability of finding out relevant independent variables from the Theory of Organized Interests and Network Theory and build integrated combinations out of them: such as our five types of power factors.

\section{New Institutionalism

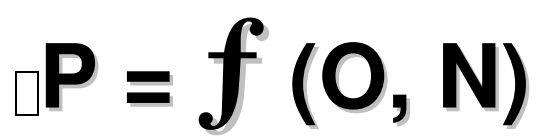

\begin{tabular}{|c|}
\hline Organizational factors (O) \\
- Trustworthiness \\
- Partner strength \\
- Radicalism \\
- Expertise \\
- State character \\
- Financial resources \\
- General image (closeness \\
centrality of general information) \\
- Scientific image (closeness \\
centrality of scientific information) \\
- Capability of controlling general \\
information (betweenness centrality \\
of general information) \\
- Monitoring (indegree of general \\
information) \\
\hline
\end{tabular}

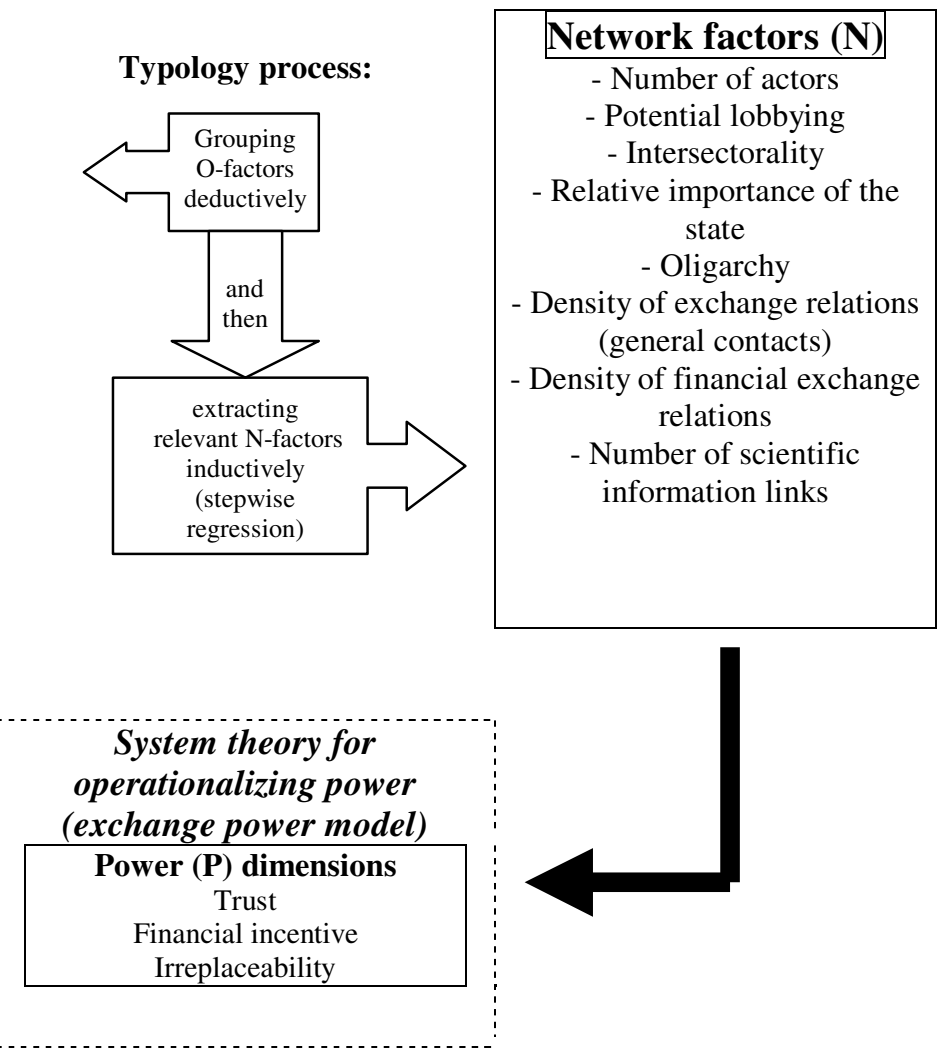

Figure 1. Concise research concept

\footnotetext{
${ }^{8}$ The system theory is a homologous theory in political science to the structuralism in cultural anthropology. Both want to filter stable social structures beyond time, "zeitgeist", language, particular bureaucratic procedures or ecological conditions.
} 


\subsection{Power: our dependent variable}

WEBER (1922: I §16) perceived power as the chance to impose one's will, even if violence is necessary against the will of another ${ }^{9}$. Thus, power is most easily realized when a resistance is overwhelmed (ETZIONI 1975). Scarcity of resources creates the necessity of violence-based power (HOMER-DIXON 1999). Resistance against any re-distributive policy is an illustrative example: a pluralistic world with scarce resources (money, reputation etc) offers considerable resistance to any re-distribution (KROTT 1990, WINDHOFF-HERITIER, A. 1987). However, though this classical definition is still very practical and useful to understand basic power phenomena, it is applicable only to dyads of actors and it is not operational enough for larger networks. Apart from that, new conceptions of power have been suggested in political power theory; ARENDT (1967, p.192, 1970, p.42) perceives power as the opposite of violence, namely as the capability of speaking, negotiating and acting. She suggests that power is not only the capability to achieve a goal, but it also maintains the public sector and thereby the basis of social existence (living together: cohesion and production of common potential). Thus, political institutions are manifestations of power and collapse when the power of people no longer supports them. This approach may go beyond the dyadic conception of Weber, but takes the acceptance of a governmental system for granted and has a clearly normative character. However, it was a decisive step to advance from the classical concept "power over someone" to the new one, "power to" do something ${ }^{10}$. PARSONS (1963, p.101) and LUHMANN (1975) have further elaborated the concept of power to, analyzing power as an exchange and communication means in politics (exchange of

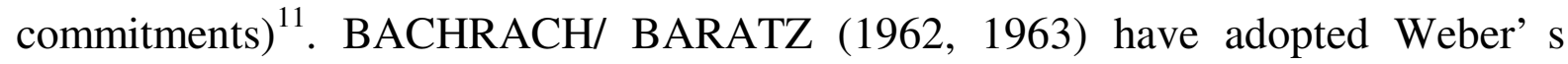

\footnotetext{
${ }^{9}$ Original citation in German: "Macht bedeutet jede Chance, innerhalb einer sozialen Beziehung den eigenen Willen auch gegen Widerstreben durchzusetzen, gleichviel worauf diese Chance beruht" (Weber 1922: I §16).

${ }^{10}$ The "tradition power" of Weber could also be a way to conceive the "power to" but Weber had rather insisted on the interest-oriented use of power between dyads.

11 An NGO e.g. provides the government with support and guarantee of public acceptance and receives financial, institutional support or information. This is a mutual accumulation of power which produces profit for both parties and maintains their favorable cooperation.
} 
conception of power over and have distinguished between threat-based power and trust- or value-based influence ${ }^{12}$. When the dominant values or power relations between actors effectively prevent grievances from developing into full-fledged issues that call for new decisions, then they call it a nondecision-making situation. Specifically, such values are nothing more than well-established bias which may be favorable to certain actors that are based on these bias ${ }^{13}$. This mobilization of bias is suggested by BACHRACH/ BARATZ (1962) as the other face of power, namely the intangible one. What one could note here is that although the mobilization of bias is a power over, the existence of bias is a basis of power to, as several actors become centralized around these beliefs (norms) to constitute a network ${ }^{14}$. This is the first connection between power to and power over, which implies that the former I based on the latter and thus the "common potential" suggested by Arendt is perhaps not so legitimate or "common" as expected, but rather the result of an hierarchization.

STONE (1980) has further elaborated on power phenomena in networks. In his view, power over is increasingly rare in networks, while conflicts and overt threats ("direct power") result in the dissolution networks, while hierarchy is based on common goals. These "common goals" may in turn be based on or dictated by nondecision making process or the "imperatives" of the situations. In this case, he speaks of "indirect power" (influence) ${ }^{15}$. The same author has tried to look deeper into the

${ }^{12}$ If the rules of a policy network are generally acceptable, then they talk about authority (influence of the system as a whole).

${ }^{13}$ E.g. for an environmental organization named "Bird Protectors" (hypothetical example) which is involved in a network ruled by a bird protection directive. There, the necessity of a bird protector is indisputable and it can never be discussed in the agenda whether it should be perhaps a secondary or no priority at all.

${ }^{14}$ S. also SABATIER (1998) about "deep core beliefs".

15 This form of power corresponds to what we here have measured as "trust", and indeed in our survey it has here proved to be the largest part of the power exerted in networks (about 82\%), while the rest is overt threats (possible deprivation of financial incentives and irreplaceable support) and only about $7 \%$ of the total relations of an actor to other ones have proved to be conflicts at average. 
mechanisms of developing indirect power, distinguishing between intentional and situational indirect power.

The nondecision-making influence may look frictionless but intentional as well; It is used by a "leader" in order to exclusively influence the agenda setting of possible "followers" in the political arena. So, this successful leader excludes other competitor from influencing the orientation of its followers, as different items for the agenda may be inconsistent with the established ones, or the available space for the followers' agenda is limited. This is a very possible mechanism initiated by the organizational factors ${ }^{16}$ of our types, which have proven to be strongly related to trust and will be discussed analytically in the relevant sections. These factors are related to the superior resources used by the leader to influence the agenda setting of followers, resources that its competitors do not have or have less of.

Concerning situational indirect (as well as direct) power, this corresponds to the network factors of our types which function as "imperatives of situation". These dictate (or force) certain patterns of political acting (e.g. more control and less trust, institutional pressure due to irreplaceability etc) and thus may function as constraints to power development. These constraints may correspond to the network factors ${ }^{17}$ of our five types.

After the above arguments, it should be clear that even frictionless indirect power is still a competitive leadership relation ${ }^{18}$. Thus, in a wider view it still can be

\footnotetext{
${ }^{16}$ Here we can briefly mention them. These are the multidisciplinarity, independence from state (minimal state character), system conformity, trustworthiness, financing resources, and partner strength, namely the organizational factors of the three types of power accumulation (lawful, trustworthy and little brother). The organizational factors of the two types of power implementation (omniscient and re-distributor) that are mostly related to or rather based on trust is the "importance" of information (closeness centrality). As it will be discussed, the trust makes information "important" and so the "important" information is used in order to impose nondecision-making and exclude possible competitors.
}

${ }^{17}$ Briefly, these are: actor number, intersectorality, relative importance of state, potential lobbying, oligarchy, (general) density, relative density of financial incentives, number of scientific links. For example, we will show that the high intersectorality impedes the development of trust, the low potential lobbying constraints the possibility of being irreplaceable to other actors etc.

18 Apart from that, a leadership which is based on nondecision-making and strong persuasion is automatically associated with suppression of pluralism (e.g. through propaganda). 
considered as a case of power over. So, the existence of indirect power it is rather questionable, if the "production of common potential" is as legitimate and frictionless as Arendt has implied, as long as a hierarchy is necessary for coordinating of social capital. This hierarchy is unlikely to satisfy every participant or be changed without conflict.

So, does power to exist at all and if not what maintains a network? We can find one answer in Foucault's work; FOUCAULT $(1980,1982)$ has tried a more illuminative analysis of the power to that in Arendt's view maintains 'together -living". He has asserted that the cohesion of a network is held together by on a multitude of complex power over relationships, which may vary from intellectual argumentation (influence) to overt violence. Namely, the power to exists but only as a macroscopic effect of the whole interaction between such subtle power over relationships. A is obliged by a direct or indirect reason(s) or pressure to cooperate with B and B with $\mathrm{C}$ etc, in order to maintain the chance (or perhaps the hope) to maximize their interests regarding a particular issue. Generally acceptable common goals set the general framework and norms for political action. In this sense, all of them stay in the network and the network just seems to be maintained by a separate power to.

The main substance of the above approaches for our research is that there is no power to as a separate form of power. This is the result of several power over (competitive) relationships which interact. The unit of a power over relationship is the dyad but an analysis should go beyond the dyadic level in order to explain complex and enlarged power structures in a network. Namely, the network should be examined as a system of dyads, which are interconnected and interacting, and thus produce an effective 'power to' which keep all these dyads together in a network. In our analysis, we have distinguished between direct and indirect power over, because the costs and the strategy that an actor should follow depend on these two categories (the distinction between situational and intentional power is only of restricted relevance to our research) ${ }^{19}$. A direct power is based on violence (e.g.

19 Apart from nondecision-making (intentional and indirect power), STONE (1980) has distinguished three more case of power relationships in a network: decisional relationship (intentional and direct power, e.g. an environmental NGO that threats a paper industry with market boycott), anticipated reaction (situational and direct power, e.g. a strong formalized chamber of agriculture which evokes formal norms and procedures in order to impose a decision), and systemic relationship (situational and indirect power, e.g. when a formalized or traditional procedure is regarded by all the actors as self-evident and there is no try to deviate from this). With the concept 
police intervention) or the threat of violence and corresponds to institutional procedures that objectively exist. An indirect power (influence) is based on internalized control and does not induce such costs and risks.

Finally, POPITZ (1992) has named indirect power "authoritative power" and direct power "instrumental power" (namely control by a plausible threat of action power) ${ }^{20}$. Popitz has practically differentiated the authoritative from the instrumental power as follows: if the actor who is merely a plausible threat-sender (e.g. a reputable law attorney who warns a client of the undesired result of his statements in the court), exerts authoritative power, while the threat-executor (e.g. the judge or the law maker) exerts instrumental power.

We are going to use this categorization of Popitz not only because it is compatible with the above approaches and make them more operational for our research but also because it enables an analysis of power accumulation processes; Popitz distinguished internal from external power accumulation; when a certain form of power produces power of the same form, this is an internal accumulation of power. When it produces

of systemic power relationship, the power has definitively ceased to be an exclusively dyadic relation and has been regarded as result of systemic interaction (which however, as above discussed, is still based on a multitude of complex power over interactions).Obviously, in a network every kind of this power relationships can appear. In our analysis we have distinguished between direct and indirect power. We have already shown a possible relevance of the categories "intentional" and "si tuational" to our results (actor-related and network factors respectively). However the distinction between situational and intentional power is only related to specific motives, which only each actor or perhaps only its chairperson is aware of. Additionally, one can accuse even a well formalized or 'lawful" actor of "false" interpretation of a rule or of accepting to implement an "unfair" rule, while it could have abandoned the network or even resisted. Thus, it is questionable whether this distinction is empirically researchable or subjective, and whether it differentiates the policy impact in a given network. Therefore it is not directly relevant to our analysis.

${ }^{20}$ Aggregating the existing literature, he has held that the authoritative power is an internalized control, based on various resources like reputation, identity, tradition, charisma or symbols. The instrumental power is an external control, which is based on a the repeatability of sanctions, that can even ultimately come to physical intervention (violence, social exclusion, deprivation of resources). When the threat of a physical intervention is not plausible enough, and thus needs to be implemented, the this is action power and practically may mean the failure of control by instrumental power. 
power of another form, it is an external accumulation of power $^{21}$. This distinction is useful for understanding phenomena and processes of power accumulation. In our five power factor types, we are going to see cases of external accumulation that can be useful for planning more effective power strategies.

\subsection{Operationalization of power for political networks: trust, incentive, irreplaceability}

We have operationalized the authoritative power as trust, and the instrumental power as incentive and irreplaceability. These forms are directly applicable to network analysis and also functional for our data capture technique (telephone interviews).

\subsubsection{Trust as a dimension of power}

Trust corresponds to authoritative power. The trustee leads the trustor: When A lets B make a decision for A, then B may favor or disfavor A without any previous conflict between them. An everyday example of trustor-trustee relation, is the relation between patients and doctors ${ }^{22}$ (persuasion, ETZIONI 1975, p.78).

The stronger trust is, the less control is exerted on the trustee by the trustor, and consequently the easier it becomes for the trustee to guide the trustor's actions (e.g. mobilization of bias). Especially the symbol policy (ideology) is used to justify acts of the powerful actor and is very strongly connected with political power (GIDDENS 1997, p.339). Through environment-related, abstract and therefore widely accepted ideologies (e.g. the empty formula of sustainability, the "value" of biodiversity), certain actors (normally non-profit organizations of conservationists) gain the trust of

\footnotetext{
${ }^{21}$ For example, a ministry of agriculture that exerts instrumental power on a farmer organization by financing can press this organization to accept state representatives in its board. In this way, the instrumental power is accumulated itself. This is an internal accumulation. When an environmental group gains the trust of a ministry (authoritative power) and be incorporated in a ministerial committee that influences the selection of protection areas, then this environmental group can threat farmers and forest owners with restrictions on the exploitation management of their areas (instrumental power). This is an external accumulation.

${ }^{22}$ The patient is as a rule persuaded to take the medicament without controlling the examination carried out by the doctor, because the former believes in the formal qualification or the widely disseminated reputation of the latter. Similar is the relationship between client and attorney. An example of strongly persuasive organizations are the religious ones.
} 
many other actors (and of course the public). This mostly applies to actors who do not have a market interest that is directly affected by environmental ideologies.

The eminent value of trust as a power dimension relates to two basic functions of interest groups: These organizations play a corrective role for state actions as they provide it with monitored information on the population they represent. They can also help the state or private actors become politically acceptable, exerting a persuasive influence on their own members. In return for these services they gain the dependence of their partners. Simultaneously, these organizations are also believed by their members and other people to mediate their interest to the state more flexibly than elected political organs with limited office terms (cf. KROTT/TRAXLER 1993). If an organization supplies reliable services, then this supplier-actor gains the trust of other actors that demand its services, and can thus impose its will concerning an issue. The mostly trusted organization has thus the upper hand in this service market (cf. ARNDT 1974, p.128, 132, HORSTER 1997).

Trust sustains conditions for rapid development of (unofficial) cooperation in social networks (BUSKENS 1999). Obviously, for this reason trust is extremely important in policy networks (as said about $82 \%$ of total power). It is generally regarded as indispensable to achieving coordination and interest satisfaction, especially between close-knit and autonomous groups of actors (NEE 1998, p.86), when there is neither output control (control of shirking) nor behavior control (control of cheating) between partners (VOGT 1997, p.239).

Trust essentially finds its ultimate expression in the form of "generalized exchange" (EISENSSTADT 1995, p.212). The generalized exchange of "gifts" (services, institutional support etc.) is distinct from a "specific" market exchange (balanced reciprocity), where gifts should be paid back in concrete form, value and time (HAVILAND 1999, p.205, 206) ${ }^{23}$.

General exchange seems to be non-utilitarian, but in reality it is highly structured and based on elaborate rules of reciprocity fostering a cohesive form of social integration like informal long-term coordination within a policy network; The trustor continues to collaborate with the trustee, just by maintaining the hope that its (trustor's) contribution will be "paid back". Both of them have potential motivation to develop a

\footnotetext{
${ }^{23}$ In environmental policy networks, both forms of exchange can appear and here we will analyze two examples of them: trust and financial incentive respectively (s. 4.2.2.1).
} 
trust-based cooperation: The trustor enlarges its possible range of partnerships (cooperation choices- or "action potenti al" according to LUHMANN 1987, p.180). Thus, it has the chance to improve its chances of achieving a desirable policy impact (e.g. to be heard, to gain information or to advertise itself in the network). In this way, the trustee gains leading potential over the trustor. Nevertheless, the profit of the trustee is much more direct and controlled by the trustee, while the profit of the trustor is mostly potential and not as controlled by the trustor.

Thus, trust may pass as a form of power to, aimed at common welfare, while it is actually a well-established, obscure power over; If an actor gains the total trust of the others, then it can totally formulate the content and form of their services, or make a decision, or implement a plan on behalf his trustors or possibly even against their plans.

\subsubsection{Financial incentive as a dimension of power}

The (financial) incentive corresponds to instrumental power to the extent that it is based on the giving (or depriving) of economic resources. LUHMANN (cf. 1987, p.300) defined the incentive of one organization to another one as the realization of a chance to use new resources through the structures of the new system (in our case a network or another organization partner). More specifically, incentive is defined here as gaining the dependence of an actor by providing it with favorable material support (like money, equipment, or staff time).

It is self-evident that the process of incentive is gift giving, and for every gift the gift giver expects a return that satisfies its own demand (balanced reciprocity). This return may consist of votes, intermediation, political support, information or other services. Thus, 'incentive' has a double effect: it restricts certain opportunities on the side of the committed gift receiver (restriction on free decision-making, political positioning etc) but also opens up new ones. Similar double effects are evident for the gift giver too (obligation to finance and receive a return). The party that gains the most relative advantages from this process depends on who has the most alternatives (the gift giver may select the gift receiver, or inversely) ${ }^{24}$. It is, however, a common assumption in

\footnotetext{
${ }^{24}$ Therefore, the incentive is the most uncertain power dimension; As we will see, its quantitative role is relatively restricted in comparison to the trust.
} 
policy networks that as a rule the potential gift giver are fewer than the potential gift receivers. Thus, the givers have the chance to monopolize the material support and to gain the incentive of the receivers who may desperately want to sell their services.

A hypothesis suggested by HEIDENHEIMER (1970, p. 18-9) is that the more developed and complex an economy is (like in a big urban center), the less specific the gift is likely to be. In contrast, in a simple and small community (like a mountainous rural area with farmer familist unions), the dependence on gifts (of symbolic or substantial nature) is more direct and not so "discrete". Generalizing these cultural differences, HEIDENHEIMER/ JOHNSTON (2002, p. 140) later formulated the following hypothesis:

"...as one moves from the traditional to the modern...communities, actions and exchanges that are objectively similar come to be more severely coded and often punished".

This assumption also implies something that Heidenheimer had clearly discussed in 1970: the blind trust (acceptance) and the consequent lack of control over a person leads to over-concentration of competencies and power over him (boss oligarchy). Not only the complexity but also the acceptance of a leader is something that makes gift giving more likely. This will be also illustrated by our quantitative results (s. omniscient and re-distributor type). Because of trust concentration or irreplaceability, in modern societies single gift giving actions are more intolerable and punishable as "corruption", but also more difficult to be realized as such when detected.

In the 12 networks that we have examined, we have enlarged the concept of 'gift giving' to consist not only of sponsorships, favorable loans, or equipment but also of staff time or any other form of material support.

\subsubsection{Irreplaceability as a dimension of power}

Irreplaceability also corresponds to instrumental power. Irreplaceability here seems to be the most accurate term for expressing a crucial position that an actor possesses in a fixed procedure (official or unofficial institution) by which it can influence the result and thus drastically favor or disfavor the interests of other actors. An actor A is irreplaceable for an actor $\mathrm{B}$, if the actor $\mathrm{B}$ cannot exclude the actor $\mathrm{A}$ from a procedure without a serious loss in the satisfaction of its (B) interests. For example, in Finland due to the eminent importance of forest production for the national 
economy, the forest industry federation may acquire a key position in a ministerial committee that makes all relevant decisions about the "certification of sustainability". This federation will then be irreplaceable for many actors interested in this issue $\mathrm{e}^{25}$. A generalized reciprocity - as in the case of trust - may also be based on irreplaceability. But with a difference: in case of irreplaceability, generalized reciprocity and the consequent patience of the weak actor, has been imposed due to a lack of other institutional alternatives (no alternative contact person etc.) and it is not based on internalized control as in the case of trust.

\subsection{System theory and exchange models: applying our power dimensions}

System theory ${ }^{26}$ is the most appropriate theory for the operationalization of power because we need an operational power definition, applicable in the widest possible range of policy arenas regardless of particular policy content (technology, agriculture, energy etc). Namely, we must regard power as a structural phenomenon (SKVORETZ/ WILLER 1993, KAPPELHOFF 1993, HORSTER 1997) that mainly depends on and can be explained through polities (official or unofficial hierarchies, general relations between state and private actors like lobbying accessibility etc) and not on politics or policies. The politics, namely the processes through which a decision is made, will be discussed in part at a micro-level in our work, but only to better understand the five power types and not to explain power itself. Finally, policies (environmental issues) have served only as empirical material. Only if we regard power as a structural and not content- or process- related phenomenon, we can abstract normative contents (goals) and changeable processes and correlate power to

\footnotetext{
${ }^{25}$ This forest industry association could be irreplaceable perhaps even for actors like environmental associations whose interests diverge from those of forest industry, if this is the only possible intermediator to the ministerial committee (in this case even the environmental associations should achieve a conciliation with the forest industry association).
}

${ }^{26}$ At first place we should here clarify that the New Institutionalism is the preferred theoretical framework in which power (dependent variable) is connected with organizational and network factors (independent variables). It functions namely like our general guiding hypothesis. But in order to understand and operationalize power the general system theory, particularly the exchange model is the most appropriate approach. 
heterogeneous empirical material (various issues, organizations with different orientations etc).

Moreover, COOK/ EMERSON (1978, p.721) have argued that for power and equity to be studied effectively, analysis of systems larger than the dyad is needed. We have already clarified above that power is not restricted to single dyadic relationships, but it is a result of multiple interactions between interconnected dyads (systemic interactions) which lead to network cohesion (s. above Arendt, Foucault, and Stone). Thus, system theory is a quite operational theory for studying power. System theory regards a network as a system ${ }^{27}$, namely a composite of exchange relations (money, information, trust, etc.) between actors (parties, industry association, etc.). An actor (component of system) does not determine its identity and position within a network hierarchy simply by itself but rather through interactions with a multitude of other participants in the network. The operational conversion of a system in power theory is the exchange model of power. In the exchange model, power means an unequal sharing of resources (trust, financial and institutional support are also resources in the widest sense) between actors and power relations are measured as asymmetries (SKVORETZ/ WILLER 1993). Thereby, within a network, an official or unofficial hierarchy is developed. The position of each actor in this hierarchy depends on the other factors involved as well as on its own potential.

An operational definition of a system which we have employed for networks is that of LUHMANN (1987): a system is defined by the time (when the randomly selected issue has taken place), the participants (found through snowball technique) and the content of the exchange relation (trust, financial incentive, irreplaceable support and information) measured separately from power.

\subsection{New Institutionalism: trying to find relevant independent variables}

New Institutionalism works as a general guiding hypothesis that connects power with actor- and network-related factors. The analytical efficiency of the policy network approach in influence relations between participants and thereby in policy outcome

\footnotetext{
27 A social system can hardly be a closed one, but in our research we have practiced complete network analysis with snowball technique. Thereby, we have at least achieved a self-bounding, namely a bounding defined by all the participants. This is as complete and acceptable as possible bounding at least at the time of survey.
} 
assessment has been recognized in the social sciences. However, it has also been remarked that merely explaining the structure of a network as an independent variable has a more descriptive than explanatory value for policy outcomes and power. Thus, the need of considering the characteristics of the participant actors has been emphasized (BLOM-HANSEN 1997). In particular, the power in a policy network should be understood as a function of network and actor variables (WANG/ VAN KOOTEN 2001, p.17-18). New Institutionalism has taken a substantial step towards such an integrated model. Before the Second World War, institutions were considered to be the main driving force in policy making while the "old institutionalists" merely tried to describe and categorize structures. Behavioralism was a reaction to this "old" theoretical stream. According to behavioralism, individual properties and behavior constituted the main explanatory variables of political actions. The last ones were regarded as a mere aggregation of individual actions. Afterwards, the "new institutionalists" incorp orated institutional factors that shape homo sociologicus (socialized actor) and individual factors that shape homo economicus (rational being) (BLOM-HANSEN 1997). In this way, they aimed not merely to describe institutions but also to explain them as "dep endent variables" (PETERS 1996, p.206). Apart from that, it enabled research into not only of formal but also informal institutions (PETERS 1999), which however proved a challenge for empirical social research.

A criticism of New Institutionalism was that it disregards the social-integrative behavior of individuals. However, this criticism should be read with scepticism, because the so-called "methodical individualism" applied in new -institutionalist analyzes has practically, examined not individuals but rather units of collective action (services, coalitions etc) (PAPPENHEIM 2000, p.249). In this research, we follow a similar strategy: we consider an organization that interacts within a network, according to formal and informal rules, analogous to the concept of homo sociologicus, while another immanent aspect of the same organization is considered to be the homo economicus with its own identity, needs and interests. The networkconditioned factors $(\mathrm{N})$ that bring about homo sociologicus and the organizational factors $(\mathrm{O})$ that constitute the aspect of homo economicus, should be considered together in order to assess power (P) (formula 1).

\section{$P=\boldsymbol{f}(\mathbf{O}, \mathbf{N})(1)$}


For this purpose we must analyze and operationalize factors that have been suggested as power-relevant in the Theory of Organized Interests and Network Theory. The operationalization and quantification of these variables will be described in the methodology section. Many studies have been carried out about the role of organizational potential and network factors separately but very few studies have been written about their synergy in power development ${ }^{28}$.

One analysis that has intensively employed such a combination is that of MEIER/ OTOOLE (2001). They considered the pass rate of pupils (public education performance) to be dependent variable. Independent variables were managerial factors (like experience of teachers, salary, hierarchy) and environmental factors (like the percentage of black or poor pupils in the classroom). They have thereby derived operational managerial models where hierarchy has played a decisive role in the impact of environmental factors and thus has supported hypotheses that the same authors had posed in the past (O' TOOLE/ MEIER 1999).

However, the main difference between our analysis and the modeling approach of OTOOLE/ MEIER is that their dependent variables were not an actor-related

\footnotetext{
${ }^{28}$ A characteristic but single example of a qualitative hypothesis about a possible synergy between them is this of homogeneity of an organization and its negotiation potential in the corporatist network (where the private actor is incorporated in the decision-making of the state) (KROTT 2001, KROTT/ TRAXLER 1992). It is namely supposed that an organization can only be reliable enough to join a state decision-making structure (e.g. a committee defining conservation areas and sustainability standards in exploitation of natural resources), if it is capable of quickly achieving an internal compromise between the individual member interests and so taking a single position to each issue. There more homogeneous an organization is (namely the homogeneous the interests of its clientele are), the more able the organization is supposed to be to join a corporatist network). This was a practical-valuable approach (policy-consulting) but it is only one of the many possible power factors.

Another seldom example was a field experiment by KIESSLER/ SCHOLL (1976, p.509); they have ascertained that the conditions of the environment affect the internal structure (particularly, participation model) of the participating group. They have spoken of "pressing character of the environment". Both external and internal factors influence the fulfilling of a task by the group. However, this fulfilling was no clear definition of political or social power.

Another example of interaction between network and actors features is the work of LEENDERS (1995, p.14) but it is confined only on the interaction of this two sides (considering actor features as an independent variable) and does not deal with their synergy to a third independent variable (like power).
} 
variable but system variables (education system performance). The managerial factors were also system-related averages and not features of specific actors. Finally, the environmental factors did not express any bounded structures and institutions but rather population characteristics. The only structural characteristic that could be considered as an institutional one was the hierarchy. This was measured as crosssectoral contacts between services and as oligarchy within the network, while network analysis was not been applied at all. Thus, latent structures of power could not be detected (and this was obviously not the goal of their research). However, the conclusions and hypotheses of OTOOLE/ MEIER will be relevant to our work as a basis for one of our power types (s. below 'little brother').

OSTROM (1999, p.3-4, et al. 1994) also carried out a combined analysis of organizational and network conditions, considering a network as a common-pool of resources. She has considered both resources and users (actors) characteristics that should be combined in order to enable self-governance of a network. According to the same author, a favorable condition for self-governance is that the improvement of the resource (e.g. rights of land use or lobbying in a network) should be feasible, measurable and predictable. Apart from that, the whole network ("spatial extent") should be small enough so actors are aware of boundaries and of internal microenvironments and are able to monitor procedures and interactions. The actors should also be homogenous and have a common understanding of the resources and their use. They also should be autonomous (not state-dependent) in order to establish their own rules within the network. An additional hypothesis of OSTROM (1999, p.9) is that the actors of a network may be privileged, when the more powerful actors take on the higher initial costs of organizing. Besides that, trust between actors (generalized reciprocity) is also of importance for long-term coordination and selfgovernance.

This common-pool model makes assumptions about actor decision-making and the generation of a network but not so directly on the power that actors develop. In this sense, it differs markedly from our approach. However, OSTROM points out the importance of homogeneity and size of a network for its sustainability and its independence from the state for its self-governance. Her assumptions will help us understand the "little brother" type (s. below) and the role of intersectorality, as well as the role of the state and state control in the "lawful", "trustworthy" and "re distributor" types. 
There still exist points of further improvement for suggested abstract or middle-range models. In this work, we have tried to improve these models through operationalization and completion. By completion, we mean our five types. Namely, the additional factors that should be combined with each particular factor in order to achieve optimal power synergy.

\subsubsection{Theory of Organized Interests}

The theory of Organized Interests is a wide and heterogeneous research area rather than a coherent theory. Until now, in this area abstract models about the role of the organizations have been suggested concerning how organization work in civic society and how they exert influence. Short-range hypotheses are also suggested in particular cases by practitioners (lobbyists and politicians). Applied political scientists ${ }^{29}$ have tried to formulate middle-range hypotheses that are more general than particular explanations and more operational than the basic theoretical discourses. These have been based on empirical data derived from interviews, (participant) observation, and document analysis. However, these are still fragmented as they are related to specialties in particular policy areas, and fall short of claims to universal generalizability. Such hypotheses posit certain organizational characteristics as power factors ('influence potentials" KROTT 2001, p.72-76, ALEMANN 1996, BURKOLTER-TRACHTEL 1981, NOLLERT 1997, BUSKENS 1999, HENNING/ WALD 2000): such as expertise, lobbying and relation to the state, partner strength, financial resources, reputation. Below, we will discuss some of these organizational factors which have proved to condition the power status of an organization.

An organization can be defined as a union of resources (money, knowledge, contacts etc), which is characterized by a certain hierarchy and aims to satisfy certain interests (in our case the interests of its members) (BUESCHGES/ ABRAHAM 1997). This union tries to develop internal power (towards its own members) so as to coordinate the internal resources and to convert them to external power (towards other actors) in order to satisfy its interests using its resources (cf. TUERK 1995, p.288). Here we will only discuss external power.

Various factors have been suggested as relevant to external power development by organizations (Duke in BURKOLTER-TRACHTEL 1981, p.97): high legitimization,

\footnotetext{
${ }^{29}$ Environmental, forest or industrial policy-analysts etc.
} 
unity of all social forces, social stability, adequate resources etc. However, the multitude of power resources that have been suggested in the organizational literature are not always described in an operational form. Apart from that, not every factor is power-effective under any network conditions. KROTT (2001) has tried to specify organizational factors that maximize to external power development ('influence potentials").

One factor is the right of assembly and coalition as well as the right to petition. At least in the EU countries, these rights are protected by the basic code of law. They provide the formal basis for education, training and activities offered by associations (BOEHRET et al. 1988, p. 60). Special legal actions enable those with organized interests to participate in the work done by parliament and government. The standing orders of the ministries provide for the participation of associations in drafting bills, as well as expert advisory services and the formation of advisory committees. Another factor is the invitations to cooperate (e.g. in a corporate committee or an umbrella association). Through these invitations special acts are enforced, where in a few varying cases chosen associations are to be informed, given a hearing, or even involved in the decision-making process. The associations may so acquire the right to nominate representatives to advisory committees. An alternative form of cooperation with the state is when private organizations have state representatives appointed in its board or general assembly, or its existence is demanded by state law (ALEMANN 1996). So, it acquires a state character that can inspire a feeling of security to the organization. This state character that a private association may acquire through the above means is first of all expected to strengthen the status of an organization within a network, especially in corporatist networks where the state plays a dominant role by definition and thus it could function as a powerful "friend". However, this state character does not foster power development, at least according to our definition (trust, incentives, irreplaceability). KROTT (cf. 2001) argues that right of selfadministration plays a key role in the participation of associations in wider structures (such as the chamber of agriculture). Legally, it is fully integrated into environmental decision-making and enforcement. At the same time, the internal expression of its will highly depends on the associations themselves, since its decision-making bodies are appointed via elections where associations successfully participate as campaign groups. For instance, the Farmers' Association dominates the Chamber of Agriculture. However, the possible existence of state representatives in these chambers can impede the chambers' power development. Internal staff 
representatives are also considered to be of great significance to associations, particularly worker syndicates (cf. SCHWARZER 1996) ${ }^{30}$.

There are also other potentials that are more difficult to operationalize because of their informal or abstract form. One example is expertise (BURKOLTERTRACHTEL 1981). A form of organizational expertise which has proven relevant to power in our survey is multidisciplinarity (existence of multidisciplinary team which cooperates with the board). A classic characteristic of any organization that hopes to improve its goal-effectiveness in its environment is the horizontal differentiation of functions (HALL 1996). Multidisciplinarity amounts to such a differentiation at the level of expertise (organized expertise, s. ETZIONI 1969). By (organizational) expertise, we will forthwith mean multidisciplinarity.

The exact role of expertise varies depending on the level of interaction (national, international). At the supranational level like the EU bureaucracy, the expertise of the private organizations is employed to influence the assessment of a natural resources situation, providing appropriately selected factual judgments (HASANAGAS 2003, NOLLERT 1997). In national political-administrative systems, the state possesses sufficient expertise to competently make an assessment. For this reason, private expertise makes an impact on national policy-making, if only for suggesting solutions. The function of expertise in this case lies in emphasizing decision-making and evaluation processes or introducing new ones, which are favorable to the interests of each private actor as well as in preventing unfavorable reforms proposed by the state (KROTT 2001, p.72). In general, using expertise, organizations try to defend and intervene in their environment. On the one hand, the question is how to emphasize those processes that favor one's interests, as well as to defend "established practices" against possibly disadvantageous reforms suggested by the state, which may adversely influence particular interests. On the other hand, the associations also try to introduce new processes that are better suited to forward their interests than in the past. The more "Innovative" the associations are in their argumentation, th e more political influence they can attain. Practical solutions like economic-technical ones and those involving material resources (like more available agricultural areas or compensations) improve the performance of a program and can solve an interest

\footnotetext{
${ }^{30}$ Personnel committees in public service, and works councils in private companies, have widescoped rights to information and codetermination regarding personnel issues and the regulation of working conditions.
} 
conflict without effecting the interests of the participants (KROTT 1990, p.72). In this case, no (instrumental or authoritative) power is necessary for any re-distributive policy.

An additional informal potential is lobbying. Generally, lobbying can be defined as influencing decision-making by providing relevant information (STRAUCH 1993, p.19). It is characterized by four aspects (cf. NOLLERT 1997, p.109): a. an organized and consistent effort to influence, b. the addressees are political decision-makers in the widest sense (politicians and bureaucrats), c. informality, and d. lack of transparency. For example, in Brussels as well as in the EU member states environmental activist groups, agricultural unions, wood industry federations etc. have their own spokesmen in government organs (ministerial committees, parliaments etc.). Ideally, the association' s reliable contacts are expected to fulfil their political functions responsibly and independently, i.e. independent of the association' $s$ direct influence (cf. COLEMANN 1986). However, their immediate knowledge of the association's issues and the speedy exchange of information promote the interests of the association to which they are most closely connected. Small sized sectors like forestry often engage in joint lobbying with larger sectors, e.g. agriculture, or larger associations, e.g. farmers associations, the unions and the alliance of civil servants, and play also an important role regarding personnel transfer of forestry experts into political institutions. In our survey, opportunities to develop (potential) lobbying have proven a very relevant factor to power development.

System conformity (opposite of radicalism) improves the acceptance of an organization because it integrates them into the image of common welfare (cf. RUDZIO 1996, p. 96) ${ }^{31}$. CUBBAGE et al. (1993) has also conceptualized system conformity as an organizational factor that improves power potential. Mostly lawful organizations (system conform) are those that use scientifically grounded arguments or have a market orientation (exploitation), in contrast to political-oriented actors (often conservationists) that have the highest average of radicalism. This factor has proved relevant enough to be included in our power definition.

\footnotetext{
${ }^{31}$ Even the self-seeking groups (exploitation groups) like worker syndicate, or landowners often realize this and try to adopt a non-profit image (e.g. labelling their coalitions with conservation titles like Forum Natura 2000 in 1999 in Brussels) (HASANAGAS 2001). This is only indirectly power-relevant to the extent that it is significant for the trustworthiness of an actor.
} 
Financing resources are of essential importance for the continued existence and influence of an association. On the one hand, they provide the material basis to sufficiently build up the internal administrative body to actively take part in politics. On the other hand, associations generally employ financial resources to directly support other politicians, in particular political parties, thus winning over cooperative partners (KROTT 2001).

The benefit of coalition partners and other circumstantial cooperative partners is also of great importance. Cooperation and unity with such partners is as a rule strongly emphasized by cooperatively acting associations. They often claim that their particular interests (either as industry or landowners or conservationists) are only sufficiently strong as a united force to attain political power (cf. NIESSLEIN 1995).

\subsubsection{The deficit of prior network models: more descriptive than explanatory}

\subsubsection{Understanding the logic of the institutionalists}

Most network models until now have still had a descriptive rather than explanatory value. DOWDING (1994) argued that power theory lacks an explanatory analytical framework and thus suggested that network analysis could and should better develop an explanatory and no more a descriptive focus. Moreover, he emphasized the relevance of organizational factors like BLOM-HANSEN (1997). Additionally, MILLS/ SAWARD (1994) believe that the problem of explanation within network models of politics is a problem of levels of analysis (micro, meso, macro); this does mean using a different level of analysis; that level, though, must ultimately be one of theoretical depth rather than of empirical breath so as to answer the question: who possesses power. This is a main challenge of power theory and corresponds to our questions at the beginning of our research ${ }^{32}$.

\footnotetext{
32 Other topics are: how the networks come about, how they change, which their policy-impacts may be. However, these are not relevant to the aims of this work. These present a certain research interest for the policy analysis and the Theory of Organized Interests but only from historical, sociological and procedural point of view, and they don't examine power as structural phenomenon (polities). Even the historical Institutionalism that was supposed to pay more attention to the role of the structures in governance and explain the power as a structural phenomenon has rather focused on historical processes and decisions (politics and policies). For the historical institutionalists the policies are "path -dependent” (KRASNER 1984).
} 
The forerunner of New Institutionalism ${ }^{33}$ was the normative Institutionalism (PETERS 1999). This held that political actors more closely reflect the values of the institutions with which they are associated and that they are embedded in collectivities and complex series of interactions (GRANOVETTER 1985) (e.g. the action of a federation of agricultural industries reflects the values of a liberal party, a group of farmers and forest owners may be associated with a conservative party etc). This may be in part useful in order to understand the action of certain types (e.g. why the a "little brother" organization chose the particular powerful "friends").

The choices of the actors and the consequent power status they achieve can be analyzed in New Institutionalism through a complete analysis of their exchange relations (trust, incentive and irreplaceability). MARCH/ OLSEN (1996) criticized exchange theories (largely related to rational choice) because they apparently employed the simplified egocenteric model of the rational choice Institutionalism which mainly focuses on the existence of rules and incentives (WEINGEIST 1996) and ignores the values and the many heterogeneous organizational potentials. The influence of values and potentials make a political network something much more than the sum of predictable rules (like a court of justice in its ideal form).

However, below we have combined complete network analysis in order to examine latent structures and hierarchies which shape rules and acting (incl. incentives) in a network and we have also taken organizational factors into account.

A further approach to institutions which tries to make the logic of rational choice more realistic and seems to be the closest approach to BLOM-HANSEN' $s$ conceptualization of New Institutionalism and to our guiding concept, $\mathrm{P}=\mathrm{f}(\mathrm{O}, \mathrm{N})$, is that of actor-centered Institutionalism (MAYNTZ/ SCHARPF 1995, SCHARPF

33 The Old Institutionalism has exerted a strong influence in the Political Science for longer than two millenniums; the oldest stream was the empirical Institutionalism (from the comparative governance patterns of ARISTOTLE in ancient world until network patterns in 90s like these of van WAARDEN. These four streams (normative, historical, empirical and rational-choiceInstitutionalism) that PETERS mentioned in 1999 as new varieties of Institutionalism, rather aggregate directions of the Old Institutionalism (Structuralism, Legalism, Holism, Historicism) rather than create a cohesive "New Institutionalism" as he also accepts. The most concise formulation of a "New Institutionalism" theory has been suggested by BLOM -HANSEN (1997). In our this was the initial hypothesis, that has been proved to be of high explanatory value and has led up to our formula $P=f(O, N)$. 
1997). It differs from the classical rational choice model in that it does not take for granted the existence of a field of tension between normative imperatives of institutions and rational motives of actors. It accepts that the actor's orientations may be compatible with its institutional environment and even influenced by this. It rather conceptualizes the institutions as collections of rules and incentives that establish then conditions for bounded rationality, and therefore a "political space" within which many interdependent political actors can function (PETERS 1999, p.44). This model does not accept that political institutions determine the behavior and capabilities of actors but rather bound their potential fields of actions and offer them a range of specific alternatives (MAYNTZ/ SCHARPF 1995, p.43). An actor selects one of them according to its orientation or adapts its orientation to them. Actorcentered Institutionalism began as a heuristic framework of analysis rather than a specific theory (MAYNTZ/ SCHARPF 1995). Until now, it has examined the political space using game theory, though the significance of the network approach is acknowledged by actor-centered institutionalists (MAYNTZ/ SCHARPF 1995 and SCHARPF 1997, p.231). Moreover, through it has also shown interest and potential in power research, it has focused almost exclusively on decision-making as a dependent variable. Here we have tried to replace abstract game theory with a more operational organizational and network analysis (independent variables) and the decision-making with power (dependent variable).

Finally, the oldest and a quite valuable form of New Institutionalism was empirical Institutionalism. This approach can be very useful for operationalizing the New Institutionalism, particularly actor-centered Institutionalism, using network analysis, because it has previously developed a very wide range of network patterns that may be tested as potential political space of an actor. This approach is quite descriptive and suggested various patterns of institutional systems (governance); for example, presidential or parliamentary democracy (WEAVER/ ROCKMAN 1993) or control points (IMMERGUT 1992). Various patterns from ARISTOTLE until VAN WAARDEN (1992) were expected to disclose some possible properties between many variables. Thereby, we already have a multitude of proposed categories which we had just to operationalize. 


\subsubsection{Empirical institutionalist models: searching for definitions with properties}

There is no "most recent" network dimension model which has been based on the empirical controls of all previous ones and thus could present the initial basis for our research. Several models that have been proposed consisted of separate dimensions, certain of which have proven to have explanatory value in our research. Thus, a concise discussion of these will take place here. The dimensions that have been derived from various models and have proven relevant to explaining power in our research are actor number, intersectorality, corporatist or pluralist character: relation between private and state actors (lobbying, dependence on the state), general oligarchy derived from the interdependence between all actors, exchange relations (financial means, scientific information). Aggregated labels like corporatism, pluralism, parentela relations etc. may be helpful to understand qualitative mechanisms of power within a network but have not proved to have a clear explanatory value for assessing the power of single actors. They have rather described behavioral patterns and interaction between actors. Their dimensions are to a large extent open to further specification, which we have partly achieved with our operationalization. Thus, we have carried out an analysis of these dimensions separately in relation to the power status of each single actor.

Authors that have recognized the above-mentioned weakness of the network models (:descriptive rather than explanatory models), have tried to improve the explanatory value of network modeling by increasing the number of variables. However, widening the variables range does not improve the explanatory function of a model, if this does not take place at an appropriate theoretical level (MILLS/ SAWARD 1994). On the contrary, with the mere proliferation of variables the models have become much more descriptive and qualitative and hence incapable of going beyond policyspecific and local differences and of extracting general and operational properties beyond these differences (EASTHOPE 1974). EVANS (2001, p. 544) has also suggested a dialectic discourse a comparison between all these proposed types in order to discover "useful" properties (e.g. micro -macro level, private-state, formalinformal etc). However, a dialectical discourse (thesis-antithesis-synthesis) depends on the subjective selection factor of each researcher (personal values, observation capacity). 
These extensively descriptive models have suggested a wide range of network factors, increasing the probability for future researchers to find some factors with power-relevant properties among them. The most concise patterns of network dimensions that have served as basis for operationalizing network variables in our research are the following: a. JORDAN/ SCHUBERT (1992) who spoke of Institutionalization (stability-instability), Policy-Making-Arrangements (sectoral/ intersectoral), Number of actors (openness), b. KRIESI (in BORZEL 1997) who spoke of Structure (corporatism/ pluralism), Relations between state and interest groups (concertation - pressure), and c. ATKINSON/ COLEMANN (1989) who spoke of Power concentration in the state, Capacity of the state to mobilize interests of employers. Finally, van WAARDEN (1992) proposed a more extensive system of descriptive criteria classified in seven categories: Actors, function, structure, institutionalization, rules, power relations, strategies (all aggregated all these criteria in three main categories: social actors, functions, power relations). These were afterwards further divided in more concrete criteria (actor number, type etc). In this model he has included many criteria of the above-mentioned models while he has excluded some others (e.g. the intersectorality) ${ }^{34}$. In our research, this model has also led to several power-relevant network variables.

Moreover, a three-part model and a more concise model is the following: the form of each network swings between ,policy community“ and ,issue network“ depending on the stability of the participants, the closeness and the dependence of the actors on resources (e.g. state support) within the network (PETERSON 1994, MARSH/ RHODES 1992). These dimensions have also proved explanatory enough in our research.

\footnotetext{
${ }^{34}$ His model has presented the basis for many further research and discussion, as it has combined elements both of the American School (focusing on Interest Intermediation) as well as from the German School (focusing Governance) (BORZEL 1998, MAYNTZ 1991). Moreover, it has both adopted Old Institutionalist and Behavioralist elements (like pressure pluralism) and thus it has further improved its explanatory value, functioning as a bridge between Old and New Institutionalism.
} 
Finally, a very promising model with empirical illustration was that of HENNING/ WALD $(2000)^{35}$. They applied a calculation technique (matrix analysis) which enables the aggregation of multiple data to concise structures. The dimensions are: number of state actors, number of private actors, paths of private actors to the state actors (segmentation in regional or national categories), and relations among private actors (cooperation or conflict) ${ }^{36}$. However, this model tries to explain the policy output and not the power status of each single actor.

In general, all network approaches until now tried to answer why and how a network emerges and how it changes, but they do not explain who holds the power in the network. An exception was the work of LAUMANN/ PAPPI (1973) about groups of influential actors (elites) in Altneustadt (a community of former west Germany). They tried to explain which actor holds power, considering as an independent variable the sector where an actor belongs. In order to answer this question, it is necessary to research the features of an actor and not only the network characteristics. LAUMANN/ PAPPI have taken a decisive "quantitative" step in this direction, but they focused only on the sectoral and not on the organizational characteristics of the actors.

\subsection{Five types of power factors: How they emerged and why they are necessary}

\subsubsection{Building a typology}

By power factors we mean both internal organizational structures and resources that can be activated by the organization in order to develop or implement the power and network conditions under which these organizational characteristics can be used optimally (power synergy). Now we will explain how our types have emerged ${ }^{37}$. For

\footnotetext{
35 This model has been elaborated after a critical discussion of the previous models, but it added relevant dimensions to our research but it could not replace the previous models, because they included different dimensions which in part have proved here relevant to power.
}

36 The dimension of cooperation has proved indirectly relevant to power as relation to powerful partners, but this is here regarded as an actor-related factor.

${ }^{37}$ Although these explanations are related to methods and techniques, it is purposeful to take place in this section, because they are much more strongly related to theoretical models, modeling processes (induction, deduction) from which the types have derived. 
each type, the organizational (actor-related) factors have been deduced by theoretical models of organizational and political power theory (mainly contingency theory and mobilization of bias, resource-dependence theory, transaction-cost theory, Simon's decision-making theory and elements of Ostrom's common-pool resource theory). We can thus say that we have produced a type, quasi for each theoretical model. 2-3 organizational factors have been derived for each type. The 2-3 factors were selected so as to correspond to one or more of the above theoretical models. When the factors corresponded to a single theoretical model (like the trustworthy type, which is based only on the resource-dependence model), they were selected so as to have as few autocorrelations as possible or at least as few inconsistencies as possible. The combination of factors corresponding to more than one theoretical model has also been accepted in our typology, if it was possible to develop a qualitative discourse that connects these models with each other (for example, the little brother type combines transaction-cost theory with resource-dependence theory).

Afterwards, these 2-3 initial organizational factors for each type were given in the SPSS with all 8 network factors together, and through stepwise regression the network factors which presented the highest power synergy (statistical significance) in combination with the initial organizational factors were selected. This procedure has been repeated 5 times and thereby thus 5 types have emerged. The relations between actor and network factors are further analyzed using logic, experience and partially with theory. We can thus claim that the first part of each type (organizational factors) has been to a large extent deduced, while the second type (network factors) has been purely induced through stepwise regression.

In this particular research, these types are five because there are five theoretical characteristics which differentiate them (differentia specificas); The lawful type is mainly based on contingency theory (and secondarily on the mobilization of bias), the trustworthy type is based on the resource-dependence model, the little brother type is mainly based on the transaction-cost model (and only secondarily on the resourcedependence model), the omniscient type and the re-distributor type are mainly based on Simon's decision -making theory (the powerful actor defines which information is 'important") but they are differentiated by their secondary specifications: the former is additionally based on the coordination potential (s. SIMON 1981) (communicative control based on betweenness centrality), while the latter is based on the monitoring 
potential; that is the reception of information measured by the indegree (s. mainly self-governance of common-pool resources in OSTROM 1999).

Certainly, these are not the only possible types ${ }^{38}$. By employing more variables or theories we can extract many more types with optimal synergy and minimal autocorrelation or inconsistency in another survey. More types could perhaps emerge through the results of this survey too, by 'diving' into the network characteristics in several categories according to new criteria and applying stepwise regression for each one separately etc. Thus, we do not present these five types as a definitive account but rather as an example of typology building and illustration and operationalization of existing abstract theories and models.

We have specified 18 factors (s. following table) derived from the organizational and network theory by testing 108 indicators and choosing those which have proven significant enough to power accumulation or implementation (s. also methodology 3 ).

Table 1. Factors for accumulation and implementation of power

\begin{tabular}{|c|c|c|c|}
\hline \multicolumn{2}{|c|}{ Power accumulation factors } & \multicolumn{2}{|c|}{ Power implementation factors } \\
\hline Organizational factors & Network factors & Organizational factors & Network factors \\
\hline $\begin{array}{l}\text { Multidisciplinarity } \\
\text { MULTIDIS }\end{array}$ & $\begin{array}{l}\text { Number of actors } \\
\text { ACTORS }\end{array}$ & $\begin{array}{l}\text { Closeness centrality of } \\
\text { (importance) of general } \\
\text { information CCGI }\end{array}$ & $\begin{array}{l}\text { Relative density of } \\
\text { incentive } \\
\text { RELDENINCE }\end{array}$ \\
\hline $\begin{array}{l}\text { Radicalism (opposite of } \\
\text { system conformity) } \\
\text { RADICALI }\end{array}$ & $\begin{array}{l}\text { Intersectorality } \\
\text { INTERSEC }\end{array}$ & $\begin{array}{l}\text { Closeness centrality } \\
\text { (importance) of scientific } \\
\text { information CCSI }\end{array}$ & $\begin{array}{l}\text { Number of scientific } \\
\text { information links } \\
\text { SILINKS }\end{array}$ \\
\hline $\begin{array}{l}\text { State character } \\
\text { STATECH }\end{array}$ & $\begin{array}{l}\text { Potential lobbying } \\
\text { POTLOBB }\end{array}$ & $\begin{array}{l}\text { Betweenness centrality } \\
\text { (control) of general } \\
\text { information CBGI }\end{array}$ & \\
\hline $\begin{array}{l}\text { Trustworthiness } \\
\text { TRUSTWOR }\end{array}$ & $\begin{array}{l}\text { Relative importance of } \\
\text { state RELIMPST }\end{array}$ & $\begin{array}{l}\text { Indegree (need of receiving } \\
\text { occasional information) } \\
\text { GINEEDIN }\end{array}$ & \\
\hline $\begin{array}{l}\text { Alternative financing } \\
\text { resources FINRESOU }\end{array}$ & $\begin{array}{l}\text { Power inequality } \\
\text { (Oligarchy) POWERINE }\end{array}$ & & \\
\hline $\begin{array}{l}\text { Strength of partners } \\
\text { PARTNSTR }\end{array}$ & $\begin{array}{l}\text { Density } \\
\text { DENSITY }\end{array}$ & & \\
\hline
\end{tabular}

Thereby, we formulated and used 18 concrete factors as independent variables for further typology building. These 18 factors are practical indicators which specify the abstract variables suggested by the above discussed authors (s. also the tables in 5.1.1). Concisely, the selection of the abstract variables that were supposed to condition power were carried out deductively but were specified inductively. Afterwards, we used deduction to make the first grouping of organizational factors which was the basis of the five actors and then induction again in order to associate

\footnotetext{
${ }^{38}$ The relatively high constants in these types (s. regressions in section 4) show that many other factors may play a role that they simply have not been measured here, and the formulation of a "complete" theory (which is in any case impossible) did not pertain to the aims of this work.
} 
the network factors with the respective organizational factors groups. So, the types were completed.

\subsubsection{Why a typology is necessary}

The necessity of typology is derived from the fact that not every factor can co-exist or produce the highest power synergy with every other factor. Finding out optimal combinations is a challenge for both quantitative research and theories.

The disadvantages of a bivariate regression or a multivariate regression including all the 18 variables are three: a. certain variables appear to be insignificant, since after the stepwise regression their power synergy in certain combinations have been disclosed, and $b$. in a multivariate regression including all variables there are many more autocorrelations in which more inconsistencies appear as well, which make policy consulting more controversial.

Indeed, in appendix V (s. underlined values), we can observe that in the bivariate regression the potential power synergy of 4 variables is ignored, while in the multivariate regression the potential power synergy of 13 variables is ignored. In appendix VI, we can see that between all the 18 variables a total of 72 autocorrelations in the multivariate regression appear. 21 of them were proven inconsistent in political practice (s. underlined values). Only 7 of these inconsistencies are in our typology (s. values in dashed frames).

\subsubsection{Theoretical basis of the types}

Each type we have found has been based on and named according to a basic characteristic that differentiated it from the other types. Each basic characteristic corresponded to and specified an appropriate abstract organizational theory which was the initial basis for developing the respective combination of factors (synergy with factors corresponding to other theoretical models and hypotheses). The first three types ("lawful", 'trustworthy" and "little brother") are types of power accumulation factors, while the last two ("omniscient" and "re -distributor") include factors which help an actor implement power that it already holds. This differentiation between power accumulation and power implementation types is based on SIMON's decision-making theory which regards information importance as a result and not as a source of power and is supported by the empirical findings and their discussion (s. 4). 
At this point we should clarify that the difference between our types and other common types is that they are multidimensional. While common typologies include types consisting of two dimensions ( $\mathrm{x}$ and $\mathrm{y}$ axes), each of our five types consists of 5-8 dimensions ( $\mathrm{x}, \mathrm{y}, \mathrm{z}, .$. incl. power axe).

The "lawful" 39 type has been derived from contingency theory (LAWRENCE/ LORSCH 1967). An organization should be flexible enough in order to adapt itself to its dynamic environment. Communication strategies, symbols and arguments are what has to be adapted in order to open up new resources and contact points as well as "mobilize bias" and socia 1 capital (e.g. volunteers and new members). This flexibility requires compatibility (system conformity) (-RADICALI) with the rules and norms of its cultural and institutional environment rather than radical (subversive) actions. The ability of an actor to construct plausible arguments is of great importance for adapting in information networks. Thus, multidisciplinarity (MULTIDISC) drastically improves the adaptability and organizational efficiency in communication. The independence of an actor from the state (-STATECH) also improves the adaptability of an actor, as this actor can be more open to new rules and arrangements (s. also OSTROM 1999). The potential fields of action are also improved through maximizing the lobbying chances in a network (POTLOBB). In addition, a small network (-ACTORS) is simpler and thus an actor can more easily adapt to possible changes. When the state does not play a very important role (RELIMPST), then the private organizations can make new arrangements with each other more easily. When all organizations belong to the same sector (e.g. environmental protection) (-INTERSEC), then they have a common understanding of the resources at their disposal, and can agree more quickly to common resolutions and also be more willing to adapt themselves to these resolutions (s. OSTROM 1999).

The "trustworthy" type is based on the resource-dependence model (ALDRICH/ PFEFFER 1976, PFEFFER/ SALANCIK 1978). This model holds that an

\footnotetext{
39 One could name the "lawful" type "adaptability" type too because of its connection to the contingency theory. However, we have here preferred the label "lawful" for practical reasons; we believe that it is more understandable for policy consulting, as it relates to radicalism which is directly perceivable (more perceivable than the "flexibility").
} 
organization does not generate its own resources but acquires them by generating trust within its environment. These may be short- or long-term, material (money, personnel) or immaterial (institutional support and acceptance, particularly trust). Often it is combined with the above contingency model but it is not identical (HALL 1996, p.289), since the resource-dependence model emphasizes the active role organizations play in their environments and not just passive adaptability. Indeed, this type only partly includes the factors of the "lawful" type and thus it is feasibl e to be practiced by more actors (even for those that are state dependent or participate in networks with great intersectorality). However, the presentation of the "lawful" type as a separate type also makes sense, because it clarifies the role of radicalism and state character.

The basic feature of this type is the trustworthiness (TRUSTWOR), as only a "trustworthy" organization can open up sufficient resources in an informal network (VOGT 1997). The resource-dependence model focuses on the strategic choice of an organization (CHANDLER 1962, CHILD 1972), the range of which increases with its multidisciplinarity (MULTIDISC). Multidisciplinarity obtains an eminent importance in a network without access to scientific information and official rules and this is only a network where the state is unimportant (-RELIMPST) but there is however a large potential for lobbying (POTLOBB). So, a multidisciplinary and trustworthy organization can use its quick-wittedness and develop its own rules with other private organizations (OSTROM 1999). Nevertheless, trustworthiness can hardly be maintained in big networks with many actors (-ACTORS) (SCHARPF 1997).

The "little brother" type is based on the use of external power (power of "friends") (PARTNSTR). An actor has to develop relationships to other actors in order to use their power. In other words, it has to build up a sub-network for its own profit. This action corresponds to the transaction-cost model (WILLIAMSON 1985, WILLIAMSON/ OUICHI 1981). Although the transaction-cost model has been at first place introduced as an economic model, it has also found great resonance in the social sciences. A model of transaction costs, whether or not the costs are economic or social, is best used in combination with other models (as Williamson has noted). The "little brother" type is a combination of the transaction -cost and resourcedependence models. 
The transaction cost model assumes that actors act in their own self-interests. Simple transactions take place in a free marketplace. Gradually, the simple markets are replaced by more complex and uncertain networks. In our case, networks can be regarded as markets, where organizations exchange services, resources and institutional or social support. Occasional promises based on trustworthiness are not enough in very complex and uncertain networks. Thus, the actors build up specific network structures in order to decrease uncertainty and transaction costs like timeconsuming rearrangements, fruitless co-operations and conflicts. An example of this structure is the cooperation relationship where powerful actors share the transaction costs and help their "little brothers" overcome uncertainty. In return, the powerful actors expect their "little brothers" to provide specific services and other $\mathrm{k}$ inds of support, when it is possible and necessary. In other words, the "little brother" type describes building (in)formal coalitions and simultaneously presents a managerial behavior that is necessary when hierarchy is lacking; According to OTOOLE/ MEIER (1999) management is necessary when hierarchy is lacking and participants try to maintain the system within they participate and decrease transaction costs and uncertainty (entropy). Indeed, the "little brother" type is an optimal way to develop power when oligarchy disappears (-POWERINE); Apparently, this occurs only when the necessity of managing through powerful "friends" increases (PARTNSTR), but also because accessing power actors and making them "friends" is easier in low oligarchy than in high oligarchy, where a strong power monopoly is established and the very few power holders tend to look down on the many "useless" powerless actors. O'TOOLE/ MEIER (1999) have observed that mutually reinforcing or non conflicting goals can also be used to generate stability in the absence of hierarchy. Policy subsystems e.g. in the USA composed of interest groups, bureaus, and relevant congressional committees are known to arrive at a set of agreements that allows each actor to achieve its goals by facilitating the goal achievement of the other actors. As discussed, the main differences between the "little brother" type and OTOOLE/ MEIER's model are that the 'little brother" tries to assess power of single actors and not the performance of the whole system (like e.g. the performance of public education) and - concerning the independent variables - we have operationalized hierarchy as oligarchy and not as intersectorality like these authors ${ }^{40}$. According to

${ }^{40}$ O' TOOLE/ MEIER regarded intersectorality as a (negative) indicator of hierarchy: the more intersectoral contacts, the less the hierarchy and the more the uncertainty in the system. 
the same authors, strong hierarchy (meaning low intersectorality according to them), is an effective buffering mechanism for (external) environmental shocks. In a network where a "little brother" - actor dominates, we may possibly consider its particular sector as a system (sub-network), e.g. wood producers, and other sectors around this can be regarded as environmental shocks (INTERSEC), e.g. bio-diversity protectors, ramblers, hunters, farmers. According to the "little brother" model, both the wood producers and their "environmental shocks" may interact with each o ther within the same network (e.g. an environmental protection policy program). The environmental shocks increase uncertainty because the members of its other sector are not only interest groups, agencies and enterprises but also journalists, researchers, and analysts. They have, therefore, both the will and the potential to transpose their ideas and values to the "central" sector (wood producers) (DUDLEY/ RICHARDSON 1997). The complexity and uncertainty of the network also increase with the relative number (percentage) of possible relationships (DENSITY) that have been developed between the actors. According to the "little brother" type, an actor has optimal chances and need to be based on powerful "friends" in order to overcome transaction costs and uncertainty in a network with low oligarchy (-POWERINE), where only one single sector is involved (-INTERSEC) and where the complexity (relationships) between the actors is as little as possible (-DENSITY).

Apart from powerful partners, an actor can also improve its power position and alleviate uncertainty through a multitude of alternative financing resources (FINRESOU) (resource dependence model). In this way, it can support its own and others' programs and also remain important to other powerful partners (in order to make powerful friends in policy networks, one should also be able to make a substantial contribution).

The "omniscient" type has been derived from SIMON's decision -making theory (1981); An actor that already holds power can impose its own arguments (information) as "important", or alternatively expressed, other actors believe this actor possesses "Important" information that may make them powerful as well. Thus, they wish to be informed by the powerful actor as directly as possible. In this way, the powerful actor not only monopolizes the general or scientific information "Importance"(CCGI and CCSI), but also the control of information channels (CBGI), as it excludes many other possible competitors as "unimportant". In this way, the powerful actor persuades the others to adopt a single decision at the same time; in 
other words it achieves coordination of the network, based mainly on trust. The question of under which network conditions such a use of information most effectively take places should be answered in reference to the institutional-economic argument that where clear relationships of financial incentives play a weak role in general, then there is sufficient "political space" for developing trust and compromises (VOGT 1997) in order to achieve a quick coordination. Thus, the optimal network under which the "omniscient" type may come about is a network where the relative density of incentives is low (-RELDENINCE).

The "re-distributor" type has been derived from the SIMON's decision -making theory and the assumption about the role of receiving information. On the one hand, the powerful actor normally does not need to "learn" from and imitate the less powerful ones but rather the opposite (DIMAGGIO/ POWER 1983). On the other hand, authors like OSTROM (1999, p.4) and GILL (1994), for different reasons, point out the need for every actor, even of the most powerful ones, to receive monitoring information. OSTROM (1999) emphasizes that all actors, including the powerful should receive certain monitoring information, because the common understanding of an issue is a prerequisite for the sustainable self-governance of the network. Even if actors do not understand this function of monitoring information or do not perceive any need of self-governance and sustainability for the particular network, it is evident that such a function exists de facto to certain extent, as long as the network has been and is being further developed. GILL (1994) specifies the relevance of receiving information (GINEEDIN) to the development of power. He says that intelligence agencies and similarly intelligence departments in private organizations (or lobbyists who carry out such a function) play two roles: an "offensive" one, namely to persuade other actors, and a "defensive" on e. The defensive role consists of monitoring actual power relations, possible risks and threats and finally the weaknesses of other actors. In other words, the powerful actor also has to be aware of the current situation, if it wants to remain powerful, and it has to be supplied with actual information from its environment. On the basis of monitored information, it (re)constructs its arguments and distributes in turn its own 'important" information (CCGI and CCSI).

The question of under what conditions the "re-distributor" type can optimally implement its power will be answered just on the basis of everyday experience; It is a common assumption that science is connected with a critical approach to any 
argumentation. Thus, the "propaganda" of the "re -distributor"type which is based on occasional and actual information can find optimal resonance in networks where science has a very weak presence (-SILINKS).

\section{Summary:}

We have examined the main theories (Arendt, Bachrach/ Baratz, Foucault, Stone, Popitz etc) proposed until now and we have aggregated them in a 3-dimensional power model that is operational for quantitative analysis of policy networks. The first dimension is trust (authoritative power): the trustee leads the trustor. The second dimension is financial incentive (instrumental power: providing favorable material support): the gift giver (like a sponsor company) influences the gift receiver (e.g. sponsored landowner association). The third dimension is irreplaceability (instrumental power: physical violence as the basis of institutions, social exclusion). These three dimensions are exchangeable (trust, incentive, and recognition of irreplaceability) and so power can be calculated through a complete network analysis. This is an operationalization of general system theory which operationalizes the exchange power model. Although the dependent variable (power) will be calculated by the systemic approach, the independent variables will be culled from New Institutionalism. For this purpose, a combination of the Theory of Organized Interests and Network Theory is necessary. These theories will be completed and specified throughout our results.

The typology of power factors (organizational and network characteristics) were derived from both inductive and deductive processes. The organizational factors have been deduced from certain theories: the "lawful" type from the contingency theory and mobilization of bias, the "trustworthy" from the resource -dependence model, the "little brother" from the transaction-cost and resource-dependence model, the "omniscient" type from SIMON's decision -making theory, and the "re -distributor" type from decision-making theory and hypotheses on the role of monitoring information. Afterwards the deduced organizational factors of each type have functioned as a basis for the induction of network factors which proved to achieve highest power synergy (significance) with the organizational factors through stepwise regression. The first three types are types of power accumulation factors, while the last two are types of power implementation. This differentiation is based on SIMON' decision-making theory which regards the information importance as a result and not as a source of power. 


\section{Methodology and illustrative examples}

\subsection{Applying quantitative network analysis}

The New Institutionalism resembles the case-oriented Mill's method of agreement. This is a quite straightforward method (RAGIN 1989, p.36): if an investigator wants to know the cause of a certain phenomenon, he/ she should identify instances of the phenomenon and then attempt to determine what circumstances invariably precedes its appearance. Our instances are the networks and the invariable circumstances are the five combinations of actor and network factors. Firstly, this is a descriptive method (as is every case-oriented method) and is based on few cases and many variables. However, in our research design we have also tried to make it more explanatory by extracting (in part atheoretically) as few variables as possible through cross-sectional analysis (variable-oriented models). The technique of stepwise regression (s. appendix III) has been used (order "forward" in the SPSS) in order to extract the optimal combinations (our five power factor types). This technique extracts optimal combinations even if no internal interaction (causality) occurs between the independent variables. Thus, the employment of qualitative analysis is inevitable in order to assess real and to avoid spurious causalities ${ }^{41}$. The variables have been measured using a complete quantitative analysis of 12 issue networks in 8 European countries. These will be described in the relevant paragraph (3.7).

The survey has taken place during 2002. The variables have been operationalized on the basis of expert interviews (September 2001-March 2002) and measured by means of standardized telephone inquiries and in part document analysis as well (April 2002-December 2002). The interviewees were directors, experienced lobbyists, chairpersons and campaign officers so as to improve the access to the relevant information. All these networks included 234 actors (cases: observation of power), which have been analyzed through the cross-sectional method that regarded 108 indicators $(234 * 108)$. From these 234 actors, 163 are private and of these 91 are private associations that formed the basis on which the lawful, trustworthy and the

\footnotetext{
41 These are theoretically relevant because we are interested in understanding the mechanisms through which power is accumulated (e.g. external or internal accumulation) and implemented. Relevant hypotheses and authors will be discussed in the relevant paragraphs (4).
} 
little brother types have been built ${ }^{42}$. The omniscient and re-distributor types have also been based on all of the 234 actors. The variables have been analyzed through cross-sectional design. Qualitative explanations based on Theory of Organized Interests and Power Theory are necessary because the cross-sectional method does not distinguish real causality (internal validity) from spurious causality between variables (BRYMAN 2001) ${ }^{43}$. Certain examples will be used as critical cases for better understanding the qualitative discussion.

In each network, the first actor contacted has been selected randomly by internet or catalogues of environment-related conferences. The initial question was "please, mention an environmental issue within the last 2 years where you were successful". And the next question was "please name all actors that you have contacted in the context of this issue". Afterwards, we contacted and interviewed the actors they pointed us to and other new actors, which they had contacted in the context of the same issue etc. In this way, through successive referring and contacting (snowball effect) we have opened up the whole network in each issue (s. appendix II). Thus, this quantitative network analysis was a complete network analysis. We carried out snowball sampling until the network could not further grow, and not simply until we reached a certain number of actors that we would consider to be sufficient.

We have selected environmental issues because they include a great variety of actors and interests (developmental organizations, industry federations, landowner associations, workers syndicates, environmental activists, scientific units etc) (ENGLISH et al. 1998). Also there is a certain polarization and conflicts between groups over exploitation and conservation of natural resources (e.g. landowners and environmentalists respectively) (HOBERG 2001, WAPNER 1996, cf. WEBER 2002). The environmental networks are supposed to produce empirical evidence

\footnotetext{
${ }^{42}$ However, the relationships of trust, financial incentives and irreplaceability have been measured between all the 234 actors for the measurement of power as dependent variable in all the five types.

43 A quantitative method that further clarifies causalities is the longitudinal design but in case of policy network analysis it could take many years and the same informants may not be always willing to cooperate. Moreover, the whole networks could have vanished after some years. In any case, the longitudinal methods require enough money and time and also diachronically accessibility to relevant data. If these three factors miss, then the only way to disclose causalities (in particular to avoid spurious causalities) is a combined qualitative approach. Thus, in our analysis the network and actor variables are considered to be constant over the time.
} 
applicable to a very wide range of policies: from education policy (e.g. environmental education project) to cultural policy (like protection of natural monuments) to technology and industrial policy (water management, wood production etc). It is thereby understandable that an environmental network contains features from many heterogeneous sectors and it is thus a representative sample for these and the actors that are active in these. It is quite difficult to find networks in other policy fields that are "different" from environmental networks because an environmental network already includes so many heterogeneous interwoven fields. For example, the distinction of FALKNER et al. (1999, p.509-510) between so-called "environmental" and "social" policy network seems to not be applicable because environmental policy very often includes interests (and conflicts) directly related to "social" policy (e.g. a conflict between forest worker syndicate which demands more logging work places and insurance from a forest industry, and a nature conservation organization who claims that it represents the cultural needs of a local community). Apart from that, the independent variables are related to polities (structures) which can appear in any sector rather than to specific policies (programs) or politics (procedures) that depend on each specific sector.

\subsection{Advantages and disadvantages of a complete network analysis: our strategy for improvement}

\subsubsection{Advantages of a complete network analysis}

Practically speaking, the complete network analysis is the concretization and application of general system theory, examining the whole of interactions between actors. The advantage of a complete network analysis is that one can measure the relative position of each actor in a network (power, "importance" and control of information exchange, radicalism, trustworthiness and other subjective characterizations that one is assigned in a network through cross-assessment) and disclose latent structures (like informal hierarchies) ${ }^{44}$. Moreover, the bounding that

\footnotetext{
44 This method also improves the chance to minimize the effect of "tactical" and ,misleading" answers, as an actor expresses a comment (even a negative one) on a third actor much more freely than on itself. Additionally, in the complete network analysis there is also the advantage of the mutual verification and of the general overview (it is improbable that all actors lie).
} 
takes place by this snowball procedure is quite close to reality and not arbitrary or dependent on the personal feeling or observation of each surveyor (we will argue below that the bounding of a network plays a very important role for making conclusions in social research and very often takes place in a very normative way).

\subsubsection{Disadvantages of a complete network analysis}

On the other hand, a network analysis presents the disadvantage of a small sample size $^{45}$. Each network usually includes between 15 to 35 actors. The ideal "solution" for this would be to open up and survey a much larger number of networks but this would require extensive qualified personnel, communication costs and naturally a vast number of existent networks to open up. Nevertheless, even if the technicaleconomic difficulties had been overcome, it would have still remained debatable whether we could find an acceptable number of networks that could make up a special research terrain (e.g. European agricultural policy). For example, in EU environmental policy fields regarding exploitation and conservation of natural resources, it is questionable whether we could find many more actual networks that included many more relevant actors.

And though the final conclusions may have a general application, at the beginning one should set a specific policy area as an empirical case for such a survey. As we have already analyzed in section 2 , the systemic approach we follow concerns only polities and not processes and policies. The approach of New Institutionalism (Organized Interests and Network theory) are generally applicable on any policy field. However, before the application one should operationalize the dependent variables of the systemic theory as well as the independent ones of the network and the organizational models considering the specifications of the respective policy contents; for example, financial resources could be different between European environmental networks and a bank network or in American or Eastern environmental networks.

Another disadvantage of network sampling is self-selection (Heckman, ROYAL SWEDISH ACADEMY 2000, p.2). With self-selection Heckman meant a non-

\footnotetext{
45 This is not a problem if we regard the particular networks as the whole population which we want to make generalizations on, but it is problematic if we try to apply the derived types outside of these networks.
} 
random sample that depends on the individual decisions by the agents under study (participant actors that point the surveyors successively at each other), or depend on administrative rules or decisions on the part of surveyors (selection of initial actor and successful character of the policy issue). In this sense, no sample should be considered "random" according to the strict definition of statistics because even with random selection the whole population is ultimately defined by the samplers (KUEHNEL/ KREBS 2001).

In network sampling (snowball sampling) the sample does not only depend on the (at any rate) arbitrarily defined population (environmental-related actors) but on the individual decision of the actors to participate. In other words, we encounter the problem that we can measure the power-synergy of organizational and network variables only for the actors that participate and not for those who could potentially participate in future.

We have tried to overcome these shortcomings that snowball sampling is considered to have as follows: The basic goal of randomness is to assure the independence of data capture from the subjective preferences or personal observation capacity of each surveyor and thus to increase the reliability (reproducibility) of the results. As in the so defined "random" sampling, we had had a defined population. This was the actors that have been involved in the environmental networks and the networks they had built together in our selected countries (which were independent of the will or the observation capacity of the samplers). We may have not known the exact names of all these actors from the beginning, but exactly the same process is followed in the so called random sampling: the population is defined and delineated as a whole and not in its single units. When a "random" sampler says that he has defined his population, he means that he has bounded a certain group of units that present specific general properties, like a graduating class of pupils at a secondary school. The population is in this sense already an independent variable that simply does not appear as such in the multivariate analysis because it is stable. The sampler does not know about each single unit with "all" its peculiarities separately. In contrast, he is aiming to measure certain of these peculiarities in order to see if they appear frequently "enough" to be considered correlated to each other.

In a similar way, we have tried to increase the randomness of the snowball samples (networks) in this analysis by two steps: The first one was to select an actor in a random way per internet (e.g. first actor of a web page). Then, this actor was contacted and interviewed. The environmental issue was not selected by the 
researchers but by this actor ("please, mention an envi ronmental issue that you have been successful ${ }^{46}$ in the last two years"). Afterwards, with successive contacts and references ("please, tell us who else you have contacted in the context of this issue") the whole network was opened up. Thus, we have also achieved a bounding independent from the arbitrary definition of the researchers or of another single actor $^{47}$.

Moreover as we will discuss in 3.4, even the weakest actor participating in a network is considered to be more powerful (POWER $=1$ ) than an actor that does not participate at all (therefore, POWER $=0$ is not defined in our analysis). Namely we have measured the power for the actors that at least hold enough power to participate. This methodical problem (self-selection) resembles many statistical problems mentioned by Heckman (ROYAL SWEDISH ACADEMY 2002, p.2): working hours and wages are observed only for those who have chosen to work; earnings of migrants are observed only for those who have chosen to move; earnings of university graduates are observed only for those who have completed a university education, and so on. This is, however, a general phenomenon in any sampling - even in so called "random" sampling.

In our analysis, the power of participating actors in a network was only measured for those that decided to participate. The improvement suggested by Heckman takes into account the propensity of missing actors to participate as well. This requires implementation of the probability theory and can only be a theme for a separate analysis. In this doctoral thesis, it will only be discussed in section 5.

\footnotetext{
${ }^{46}$ We have asked the initial actors to mention a issue where they were successful according to their self-evaluation in order to encourage the answering. After a test we have ascertained that almost none was willing to accept a defeat and to mention an issue where it was "unsuccessful".

47 Additionally, we have examined a dimension of policy, the intersectorality, as an independent variable, which finally has proved relevant to the power development The "environmental" networks offer a good chance for measuring intersectorality because they are very cross-sectoral networks.
} 


\subsubsection{The strategy of "many" indicators}

What we could do in our survey in order to at least outweigh the disadvantage of the 'small' size samples was on the one hand the theoretical grounding and on the other hand the substantial empirical material (indicators). Specifically, our strategy was to examine as many indicators as possible (108 totally) which were specifying the organizational and network factors discussed in section 2, then to reduce (funnel) them on the basis of existing hypotheses and models and try to illustrate these hypotheses with them (s. 4). Only 18 of them have been selected for further use those that presented significant correlations (Pearson) to power. After the earlier discussion in 2.6, this should not be regarded merely as an atheoretical multidimensional description, but rather as an attempt to specify the restricted number of most explanatory variables that have been extracted on the basis of existing theoretical models ${ }^{48}$. The question of what exactly are these specified variables and

48 An expected criticism on this strategy is that it is an atheoretical one, because the main characteristic of a theory with considerable explanatory strength is to be based on as little variables as possible that should be applicable to as many cases as possible (variable-oriented model). Otherwise the model is a case-oriented one and rather has a descriptive function (RAGIN 1989). However, the employment of "many" indicators in this analysis does not impedes its explanatory aims; Its main aim is not to produce new theories (theorizing) but rather to specify and improve existing long-range hypotheses and so to make them more useful for further theoretical discussion and simultaneously more applicable to policy consulting. On the basis of these long-range hypotheses, the 108 indicators are finally restricted to only 18 power-relevant concrete factors which specify these hypotheses and improve so their explanatory value.

At this point, one could pose the question, how you had formulated 108 indicators and how do you justify them? We here should clarify that these 108 indicators were just various dimensions of the abstract organizational and network factors that we discussed in the theoretical part (2). As usual in quantitative research, each of them (e.g. actors, expertise, coalition, lobbying, information, power relations between state and private actors etc.) had to be specified and measured in more than one form (namely with more than one criterion). Most theorists and practitioners accept that information exchange, for example, plays a role in power phenomena. But this is a too abstract concept: Which information? The general or the scientific? The "image" of information importance or its control? The absolute number of scientific information links or its standardization (division) by the whole number of general information links or to the whole contacts in the network? Almost everyone discusses also the expertise and knowledge of an organization as power-relevant factors but in which specific form do they produce power as multidisciplinarity or as human capital (qualified members)? etc. The relations between state and private sector should be considered as the 
what authors have suggested them is answered as concisely and clearly as possible on the two tables of paragraph 5.1.1 ${ }^{49}$.

In this way, we have improved the possibility of finding out as many significant relations as possible with relatively low autocorrelations and inconsistencies (between the independent variables).

The existence of autocorrelations between independent variables enlarges the confidence interval of the dependent variables, because under this condition the independent variables are not fully distinct from each other (there is conceptual overlapping). Only after many cases can the clear (or overlapping) relation between independent variables be further confirmed. Or if as many as possible variables are measured and tested in a systematic way, then we can have a better chance of discovering multivariate relations (like our five types) with low autocorrelation between independent variables and high significance of them to the dependent variables. Furthermore, in the stepwise regression, if we steadily remove all independent variables that have high autocorrelation to others within a certain model, then the whole model will change. Moreover, the autocorrelations that appear in our five types do not make such an enormously negative impact on the practical value of these models, because their realistic aim would not be to precisely calculate the power of an actor in a network (this is not yet feasible in an immediate way); Their realistic value lies rather in a more accurate comparison of the power factors between various actors and thus a more accurate assessment of the relative power position that one can expect in a network (namely policy consulting in qualitative terms).

ratio of the respective actor number (as HENNING/ WALD suggested) in order to be power relevant or as the ratio of their average irreplaceability in each network (as we have done)? In the relevant literature, the discussion is confined on abstract level or various specifications are suggested. We had thus, to test a wide range of specification alternatives. These were first 47 as described in appendix I. Afterwards we have combined them with each other or standardized them (e.g. the relative state importance is the possibility of state monopoly divided by the possibility of private monopoly). So, we had tested totally 108 indicators until to find the most relevant specifications to our power definition that should simultaneously fit the long-range hypotheses. Thus, the author does not believe that it is necessary to present all the 108 specification tries and confines himself to the appendix I.

${ }^{49} \mathrm{We}$ found purposeful to present these tables in one of the last sections (5) because they include all works of all authors we have cited meanwhile. This would be the only possible way for the reader to get an overview of the variables specified. 
In this work we have purposefully avoided any reductive techniques like factor analysis. This decision is based on two reasons:

a. Theoretically, we had to test as many as possible - and not as few as possible relevant indicators in order to discover the most subtle and operational form (specification) of the few explanatory variables that are relevant to power and use the abstract models we have worked with (s. 2.5). For these reasons, we have tried to specify these abstract hypotheses.

Autocorrelations in the five types still exist but we have tried to justify and comprehend them theoretically (through qualitative discussion). Moreover, we should not forget that even if two independent variables (e.g. CCGI and CBGI as seen below) are strongly correlated, they are in no case identical. Thus, if we remove one of them, we also remove the not-overlapping part. That amounts to rejecting a useful piece of information in order to call another piece more "clear" and "explanatory". Such a simplification can only take the attentio n of future research away from real causes of specific phenomena. Some argue that the "social" sciences have to account with much more complicated phenomena than the "natural" ones. However, it is questionable to what extent the basic natural sciences (like physics or biology) have developed a more accurate mode of theorizing due to their abstraction and simplification; to all appearances their methods continue to produce not so unambiguous results even nowadays.

b. Practically, it would be in any case misleading for a client (e.g. a lobbyist), if the consultant omitted relevant factors that may explain his/ her "problem".

What we can - and should - do in our case is the following:

The overlappings (autocorrelations) are rather inevitable in network analysis because the networks de facto consist of relatively few cases (small sample). We can take these overlappings into account in order to assess the capacity of each type for an exact prediction of power in a future try, and in order to use relevant qualitative discourse.

Namely, complete network analysis is a middle epistemological way between description (that improves the chance to find definitions with properties) and explanatory design (that examines properties) that should be regarded as legitimate and would satisfy many different epistemological directions (s. MARSH/ SMITH 2001, p.538, RAAB 2001). We will try to pick out the advantages of explanatory, positivist, objectivist, deductive, and quantitative methods ("hatural sciences") that 
are variable-oriented in order to test theories and the advantages of the descriptive, constructivist, inductive and qualitative methods ('interpretivism") that try to generate theories. Thus, we can test and improve existent theories. A clear example of the first category of methods is pure statistics. A clear example of the second category is the hermeneutic methods of historical or empirical Institutionalism (deepening interviews, unstructured observation, qualitative document analysis). Our statistic-based network analysis swings between these two epistemological orientations.

\subsection{Operationalization of variables}

The main task of empirical social research is the precise operationalization of variables so that (cf. BRYMAN 2001, ATTESLANDER 1995):

- They become measurable through the techniques of the empirical social research (e.g. interview, observation, standardized inquiry, network analysis etc)

- They measure what should be measured (measurement validity)

- They can produce the same results when, measurements are repeated by other surveyors (reproducibility, also described as reliability too)

- The whole research procedure is replicable step-by-step for other researchers

This task becomes much more challenging if the variables are latent like trust (in contrast to manifest variables). In that case the researchers have the responsibility not only for the operationalization (in our case formulation of the standardized queries) but also for clear defining the variables. The clearer the definitions and the more integrated in the social theory they are, the more objective and transferable knowledge they produce. Simultaneously, empirical social research is also confronted with possible "tactical" or insincere answers from certain interviewees or with their ignorance, subjectivity and misunderstanding (KROTT/ SUDA 2001, p.7,8). A solution to the first problem (misconduct) can be approached by employing indirect indicators that come to surface in the course of intensive qualitative interviews (e.g. our economic indicators). Faulty, answers due to ignorance or misunderstanding can be prevented by selecting interview partners with access to the relevant information and by previous testing of the query. 
A basic mathematical entity for the following formulas is the link from an actor $i$ to the actor $j$. If there is a link (e.g. information exchange ${ }^{50}$ ) from the actor $i$ (e.g. forest service) to the actor $j$ (e.g. a certain environmental group), then this link is defined as: $Z_{i j}=1$.

If there is no exchange in this direction $(i \diamond j)$ then: $Z_{i j}=0$.

A link (e.g. trust exchange) can also be valued: $Z_{i j}=1,2,3 \ldots$.

The total number of actors participating is defined as $N$.

\subsection{Measurement of power}

The power $(\mathrm{P})$ of each actor has been measured as the summa of the trust that an actor gains, the incentives it gives and the irreplaceability that it is supposed by the other participants to have (appendix I). Power was first measured in a 5-level scale $(\mathrm{P}=1$ to 5$)$ where $1^{51}$ means no trust at all and 5 total trust (3), incentives (1), and irreplaceability $(1)^{52}$. Afterwards power was converted into a percentage variable $(\%)$

50 Other exchange relations we are going to measure are exchange of trust, recognition of irreplaceability, and incentives, namely the three dimensions of power. In 2.2.2 we have emphasized that in our analysis, power has been expressed though asymmetric relations: power is to concentrate trust, to give incentives and to be regarded by the others as irreplaceable (exchange of recognition). So, power cannot practically exist without (asymmetric) exchange. The information links can also visualize power centers: the most powerful actor imposes its own information as "important" and controls to large extent the communication too (s. five types below). But information is a means to implement power rather than a power source (we will discuss it below).

${ }^{51} \mathrm{P}=0$ has been not defined for technical and measuring-theoretical reasons; 0 means in Visone (our network analysis software) "ho relation". However, there is a relation of weakness, which should also be measured so that the totally weak actors $(\mathrm{P}=1)$ are also included in the status calculation. Otherwise, the whole network structure and the relative power position of all actors and the oligarchy would have been deformed. If we had defined also $\mathrm{P}=0$, would have meant no existence of the actor of the network and this would be deceptive, because the actor, even with quite little power $(\mathrm{P}=1)$, still exists in the network. In other words, "weak participation" means for us more power than "ho participation" at all.

52 There are two equivalent medium situations:

- When an actor gains only full trust $(\mathrm{P}=3)$ 
through the formula for "status" ( KATZ 1953) (T) using special software for quantitative network analysis, "Visone". Status illustrates an inform al or formal hierarchy, which is based on power relations. In the case of Ireland the oligarchy is much more noticeable (sharp pyramid) as in Finland (s. below). The formula of "status" (formula 2) includes matrix multiplication:

$$
T=a C+a^{2} C^{2}+\ldots+a^{k} C^{k}+\ldots=(I-a C)^{-1}-I
$$

where $\mathrm{T}$ is a matrix that includes the status values of all elements, $\mathrm{C}$ is the matrix presenting the real network (of power exchange), and a the value of the exchange $\mathrm{z}$. In our case, a is not constant. Thus, this algorithm becomes more complicated and is only calculable using the software.

The status practical sense is that if an actor $\mathrm{X}$ gains power from an actor $\mathrm{Y}$, the actor $\mathrm{Y}$ from an actor $\mathrm{O}$ and an actor $\mathrm{O}$ from an actor $\mathrm{J}$, then the actor $\mathrm{X}$ indirectly gains power from the actors $\mathrm{Y}, \mathrm{Z}$ and $\mathrm{J}$. In so far, actor $\mathrm{X}$ presents a certain 'skill' in this kind of exchange (in this case, an aptness in concentrating trust, incentive or irreplaceability recognition.). Through this dependence chain, the actor $\mathrm{X}$ can (mis)lead all the others. In other words, the (power) status of each actor expresses its position in the formal or informal hierarchy that is generated in the network through this power exchange. Thanks to "Visone" ${ }^{53}$, this hierarchy can be visualized as a pyramid and the oligarchy (namely power inequality) can also be calculated (s. BAUR et al. 2002). The meaning of each power value form 1-5 is presented on the appendix IV.

As we will discuss below, the oligarchy $(\mathrm{O})$ (from 0 to indefinite) is the concentration of power on a few actors and it affects the individual power status of each actor. Mathematically, it can be defined (formula 3):

- When an actor gains only incentive and irreplaceability $(\mathrm{P}=3)$

53 The algorithms used by "Visone" are presented in this work in relevant paragraphs: the "status" with which power and its components separately have been measured is formula 2 . The closeness and betweenness centrality as well as the indegree which have been applied to the information are formulas 4, 5, and 6 respectively (s. below). 
Oligarchy $=\frac{\text { Status } \max -\text { Status } \min }{\text { StatusAverage }}$

The higher the $\mathrm{O}$, the sharper the pyramid is in a network. Examples of three networks can be seen on figure 2 . The highest oligarchy was recorded in the Irish network and the lowest oligarchy in the Finish network.

The practical meaning of the status coordinates (vertical $\mathrm{y}$ and horizontal $\mathrm{x}$ ) can be critically discussed at this point; The practical meaning of the coordinate $\mathrm{Y}$ is clear: the higher an actor is layered, the higher its status. Namely, $\mathrm{Y}$ is a vector size (oriented distance from 0 to $100 \%$ ). However, $\mathrm{X}$ coordinate is not a vector but a scalar size. Consequently the horizontal placement of each actor does not give any direct information about the status or any other property of the actor. BRANDES et al. (2001, p.12) have recognized this deficit in the status graphic of "Visone". They have clarified that the only logic for horizontal positioning is the ergonomic optimization of the graphic: the actors are positioned in horizontal layers so as to ensure that long lines run vertically as much as possible and so that the number of crossings is reduced as much as possible. In this way, the graphic obtains a clear form.

However, $\mathrm{X}$ has a practical value for the political interpretation of the network (s. figure 2): Considering a network in a certain scale, then we should compare the $\mathrm{Xmax}$ with the $\Delta Y \max$. Then, we will extract a coefficient a, where $\mathrm{Xmax}=\mathrm{a}^{*} \Delta Y \max$. The higher the coefficient $a$, the higher the proportion of the actors that are placed on the respective status layer. Also, the shorter the distance $b$ of the layer Xmax from the bottom of the pyramid, the sharper the pyramid ${ }^{54}$.

Concerning the general form of network (the three polygons in figure 2), the order of the actors around it has no practical meaning for policy analysis. But what is very

\footnotetext{
54 Consequently, another indicator to assess oligarchy could be Oligarchy= $\Delta \operatorname{Ymax} *(a / b)$. This indicator would have the advantage that it includes the horizontal distance $\mathrm{Xmax}=\mathrm{a}^{*} \Delta Y \max$. On the other hand, such an indicator would not be so easy measurable because it needs geographical characteristics ( $a$ and $b$ ) and a standard scale of the graphics and it is not always so clear to be measured (e.g. in Finland). For this reason, we will continue to use the formula 3. However, it is noticeable that $\Delta$ Ymax=Statusmax-Statusmin. Thus, if in a future research one proves that the quantity $(\mathrm{a} / \mathrm{b})$ is equal or analogous to the (Status average $)^{-1}$, then the two indicators will be homologous to and replaceable by each other.
} 
significant to the power analysis, as we are going to see in our results, is the density of the network (how many (\%) of the possible diagonals exist). The "darker" the network in its general (polygonal form) is, the higher its density. We observe that Ireland is a "lighter" network (density=25\%) in comparison to UK and Finland (34,7\% and $32,4 \%$ respectively).

Apart from that, the polygonal form is useful for visualizing a network, and making it understandable at first glance to every reader.

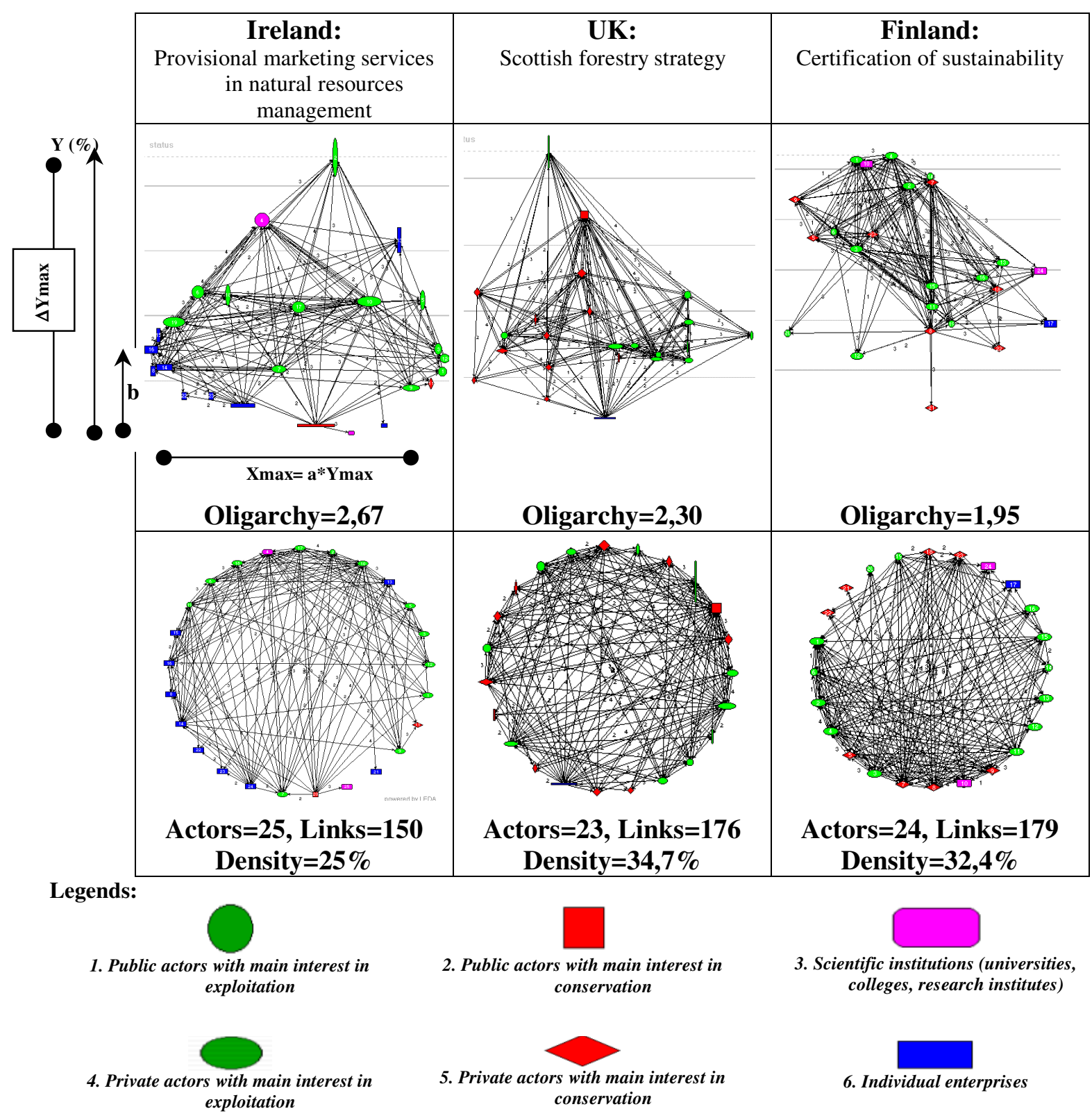

Figure 2. Examples of networks with different status oligarchies and pyramid sharpness 


\subsection{Measurement of information-related variables}

In our definition of power we have not included the asymmetry of information exchange. This is going to be separately measured. Then its qualitative relation to power will be discussed (4.2). Based on the idea of HENNING/ WALD (2000) of the distinction between scientific and general information, we will distinguish them too, based on a cross-assessment of the interviewees (s. appendix I). Scientific information is a specific part of general information that is supposed to be characterized by a higher degree of objectivity.

We will measure five information variables in all:

- “importance" (imag e) of:

a. general information and

b. scientific information

and

- control of:

a. general information and

b. scientific information

The fifth information variable is the occasional reception of general information.

The "Importance" of information is quantified through the closeness centrality and the control through the betweenness centrality. Because of their critical role in the quantification of the information they will be discussed more extensively.

The closeness centrality (\%) of general or scientific information (CCGI and CCSI respectively) is defined as follows:

$C C_{(i)}=\left\lfloor\sum_{j} d(j, i)\right\rfloor^{-1}$ (formula 4)

where $\mathrm{d}=$ distance (shortest path) from $\mathrm{j}$ to $\mathrm{i}$.

Practically, this means, how directly the others want to receive information from an actor (without middle paths) (cf. BRANDES et al.1999); the more directly the others seek to receive information from a certain actor, the more "important" they consider it for a specific kind of information. 
The betweenness centrality (\%) of general information (CBGI) is mathematically defined as follows:

$C B_{(i)}=\sum \frac{\left|P_{i}(i, j)\right|}{|P(i, j)|}$ (formula 5)

where $P(i, j)=$ set of all shortest paths between $\mathrm{i}$ and $\mathrm{j}, P_{i}(i, j)=$ set of shortest paths passing through $\mathrm{i}$.

Practically, this refers to the number of communication paths where an actor plays the "go -between" and thus they will be cut off if the actor leaves the network (cf. BRANDES et al.1999).

Examples of betweenness and closeness centrality of information are presented in the figure 3 .

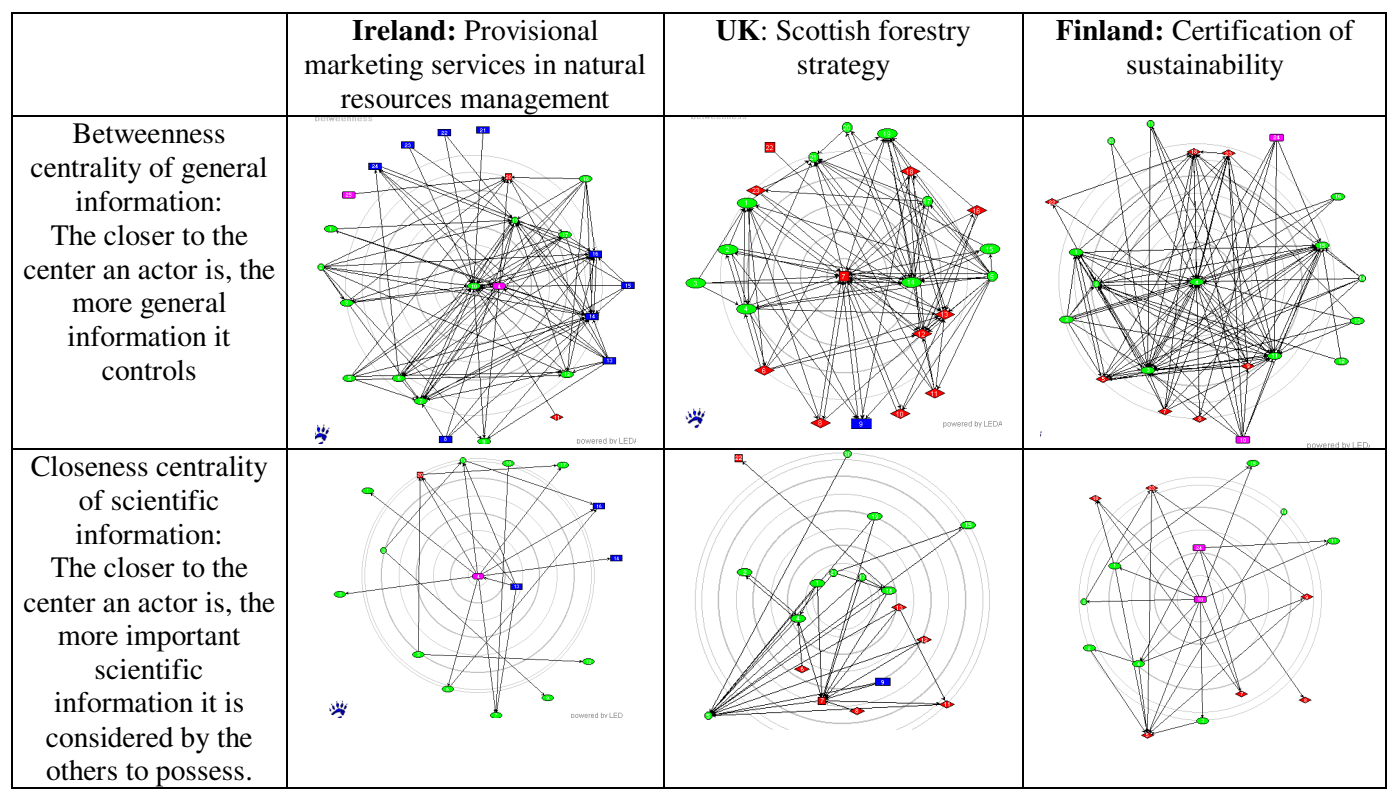

Figure 3. Examples of visualization of information betweenness and closeness centrality

The occasional reception (\%) of general information (or abbreviation of indegree of need for general information GINEEDIN) is expressed as an indegree of each actor in general information (KNOKE/ KUKLINSKI 1982).

$I n \operatorname{deg}$ ree $_{j}=\frac{\sum_{i=1}^{N} Z_{i j}}{\sum_{i=1}^{N} \sum_{j=1}^{N} Z_{i j}}$ (formula 6)

where $\mathrm{Zij}$ : the information being sent from $\mathrm{i}$ to $\mathrm{j}$ and $\mathrm{N}$ : the total actors of the network. Namely, this variable expresses how much information an actor receives from the first contacted actors in comparison to each other. 
It is named "occasional" because it is only a percentage of the first contacted actor and not for example a dependence chain like the power status that shows a 'hierarchy".

\subsection{Measurement of organization-related and network variables}

\subsubsection{Organization-related variables}

- Multidisciplinarity (MULTIDIS)

This refers to the number of disciplines included in the expert team of an organization (s. appendix I). It has been measured with self-report.

- State character (STATECH)

This expresses to what extent the existence of an organization is demanded by state law and if state representatives participate in the decision organs of the organization (s. appendix I). It has been measured with self-report and it fluctuates from 1 to 5 on an ordinal scale.

\section{- Radicalism (RADICALI)}

This expresses to what extent the organization uses legal and system-conform means or follows extreme practices like those of Greenpeace. This has been measured using cross-assessment (each one has characterized each other) (s. appendix I). It fluctuates from 1 to 3 on a metric scale.

\section{- Trustworthiness (TRUSTWOR)}

Trustworthiness has nothing to do with the trust status. It is only the average of the characterization of the first contacted actor to a certain organization regarding trust (cross-assessment) (s. appendix I). It fluctuates from 1 to 3 in a metric scale.

- Alternative financing resources (FINRESOU)

This is the number of alternative financing resources an organization has (stability). It has been measured with self-report.

\section{- Partner strength (PARTNSTR)}

This is the average of the power of the partners that a particular organization has. 


\subsubsection{Network variables}

- Number of actors (ACTORS)

This is the number of actors that participate in the network.

\section{- Intersectorality (INTERSEC)}

This is the number of sectors that are involved in the network; or in other words the number of the sectors to which the involved actors belong. It has been measured using a standard sector list (s. appendix I).

\section{- Potential lobbying (POTLOBB)}

This expresses the percentage (\%) of the whole existent relations $\mathrm{Z}$ that have contacts among private or state actors and can thus increase potential lobbying (s. appendix I).

$$
P O T L O B B=\frac{\sum Z_{\text {privateActors } \rightarrow \text { stateActors }}^{N}}{\sum_{i}^{N} \sum_{j}^{N} Z_{i j}} * 100 \quad(\text { formula } 7)
$$

-Relative importance of the state (RELIMPST)

This is the ratio of the possibility of state monopoly to the possibility of private monopoly ${ }^{55}$ and can fluctuate from 0 to indefinite (s. appendix I). This way, the role of state and private actors does not depend on the absolute number of the actors and a comparison across all networks becomes possible (cf. RAAB 2002, p.619). (The possibility of state monopoly alone without this standardization did not prove significant to power.)

$$
\text { RELIMPST }=\frac{\text { pos.st.m. }}{\text { pos.pr.m }}(\text { formula } 8)
$$

\footnotetext{
55 The possibility of state monopoly is the average irreplaceability of a state actor, namely the sum of the irreplaceability assigned by all the other actors to state actors, divided by the number of sate actors. (This can fluctuate from 0 to $\mathrm{N}$-1.) Namely, it has been measured by cross-assessment. Similarly, we have measured the possibility of private monopoly.
} 


\section{- Density (DENSITY)}

The density just means how much percent (\%) of all possible contacts has already been used and is an indicator for the complexity of a network or of the extent to which all possible contacts have been exhausted (KNOKE/ KUKLINSKI 1982).

Density $=\frac{\sum_{i}^{N} \sum_{j}^{N} Z_{i j}}{N^{2}-N} * 100$ (formula 9)

where $\mathrm{Z}$ and $\mathrm{N}$ are as defined above.

- Oligarchy or power inequality (POWERINE)

s. above, formula 3 in 3.3

- Relative density of incentive (RELDENINCE)

This expresses the ratio of material support exchanges between the actors $(i, j)$ to the total existent links (cf. KNOKE/ KUKLINSKI 1982):

$$
\text { RELDENINCE }=\frac{\sum_{i=1}^{N} \sum_{j=1}^{N} \text { Incentive }_{i j}}{\sum_{i=1}^{N} \sum_{j=1}^{N} Z_{i j}} * 100 \% \text { (formula 10) }
$$

- Scientific information links (SILINKS)

This is the number of links of scientific information exchange.

\subsection{Data}

The 234 actors which have been measured are public institutions and private associations dealing with exploitation (101) or conservation of resources $(97)^{56}$, or are single enterprises $(15)^{57}$ and scientific institutions (21) (universities or other research units).

\footnotetext{
${ }^{56}$ Examples of public and private actors dealing with exploitation of natural resources are a forest service and a forest owner association (market-oriented association) respectively. Similarly, examples of public and private actors in conservation are an environmental protection agency and an environmental NGO (non-profit-association). The single enterprises are certainly exploitationoriented but they do not have structure and properties of associations. Thus, they have been measured separately.
} 
The networks that have been surveyed in 2002 can briefly be described as follows (visualized in appendix VII):

1. Denmark: Certification of sustainable management of natural resources

2. Finland: Certification of sustainable management of natural resources

3. Spain: Certification of sustainable management of natural resources

'Sustainability" is a normative and quite abstract term that finds an eminent acceptance nowadays as an elegant empty formula. In political communication, it means an ideal situation where every decision and action finds quite long-term (intergenerational) and wide (intersectoral and interregional) acceptability. The simplest sustainability principle is that each generation should take care of the next one and thus not exhaust any resource. The certification of sustainability in natural resources management is a very controversial issue. Principles and criteria set by Agenda 21, EU forestry strategy and other international resolutions or treaties must be implemented. These relate to social questions (e.g. employment), to ecological questions (e.g. $\mathrm{CO}_{2}$ emission) and to economic ones (e.g. marketing, regional development). These criteria often require interpretation. These are numerous implications for forestry. A common conflict exists between market-oriented groups (e.g. land and forest owner associations) and non-profit-oriented groups (environmental NGOs). These conflicts tend to become sharper in countries with private forestry. These groups follow different interpretation systems for sustainability. The former have adopted the criteria of Pan-European Forest Certification, which are believed to be more favorable for marketing and production, while the latter those of Forest Stewardship Council. Although sustainability is a normative rather than scientific term, scientific information is exchanged in these networks. The certification process also concerns various policy sectors: e.g. environment, agro-forestry, trade, industry, work policy (concerning land and forest industry workers).

\footnotetext{
${ }^{57}$ An industry has been measured as a single enterprise, while the a federation of industries as a private association.
} 


\section{Germany- Bavaria: Eco-account}

\section{Germany- Bavaria: Mapping of biotopes}

6. Sweden: Key biotopes

The two German issues involved, to a large extent, the same actors. Eco-account dealt with the assessment and mitigation of possibly forest exploitative impacts on the forest ecosystem (e.g. disturbance of bio-diversity, emissions, soil quality). The mapping of biotopes is a procedure for the classification of each forest area according to the "most important" function it can fulfil. Thereby certain forest may be characterized as conservation areas and this means constraints for the market-oriented forestry and land use. Both issues have been characterized by the reactions and stress on the part of landowners. The key biotopes controversy in Sweden was an issue of similar character. The only difference is that in this issue big companies have also exerted pressure (multinational forest industries have been involved)

7. Greece: Revision of constitution regarding environmental policy

8. Sweden: Governmental forestry strategy

9. UK- Scotland: Scottish forestry strategy

10. UK- Scotland: Loch Lomond and Trossachs National Park

These four issues have strongly concerned regulative instruments (lawmaking).

In Greece, the challenge was an "environment -friendly" revision of the constitution. New definitions have been given about what a "forest" is etc. There were many conflicts but not between market- and non-profit-oriented groups (forestry is at any rate to the largest extent public). The conflicts have taken place almost exclusively between non-profit-oriented groups about definitions, strategies, and power-sharing. The Swedish forestry strategy has been characterized by classical conflicts between market- and non-profit-groups.

The Scottish forestry strategy has focused on intersectoral coordination regarding forest management. A wide range of interests should be satisfied: water management, wood production, biodiversity conservation, cultural values, recreation etc. Only associations have been involved. The management of Loch Lomond Park was quite similar. One difference is that single enterprises have also involved. Both Scottish issues were relatively frictionless. Disputes were quite mild ones like whether native or commercial species should be planted in Loch Lomond. 
11. Ireland: Provisional marketing services in natural resources

This issue presents the least similarities to the others. It is related to "Improvement" and flexibility procedures for forest products marketing. Many companies have been involved. This network was quite frictionless because it was related to purely economic interests of enterprises (rather than not of non-profit ideologies). Thus, it was quite clear who the power holders and the rule-setters were (high oligarchy).

12. Spain: Research project castanea

This issue was a "purely scientific" one (research project on the species castanea). Public actors and universities have dominated and the issue had relatively few crosssectoral implications and centered on forest policy.

One can see the descriptive statistic for the 234 cases out of 12 networks on the following table. These values are useful for finding out specific cases that remained above or below the average of the respective organizational and network factors and thus illustrate the five types. 
Table 2. Descriptive statistic of all data

\begin{tabular}{|l|c|c|c|}
\hline $\begin{array}{l}\text { Descriptive statistic of all } \\
\text { networks }\end{array}$ & Minimum & Maximum & Average \\
\hline Organizational factors & & & \\
\hline POWER &, 00 & 15,62 & 4,9716 \\
\hline TRUST &, 44 & 13,84 & 5,0584 \\
\hline INCENTIVE &, 00 & 100,00 & 5,1276 \\
\hline IRREPLACEABILITY &, 00 & 40,00 & 5,1179 \\
\hline MULTIDISCIPLINARITY &, 00 & 9,00 & 3,3667 \\
\hline RADICALISM & 1,00 & 3,00 & 1,3202 \\
\hline STATE CHARACTER & 1,00 & 5,00 & 1,5275 \\
\hline TRUSTWORTHINESS & 1,00 & 3,00 & 2,3424 \\
\hline PARTNER STRENGTH & 1,97 & 13,66 & 6,3852 \\
\hline FINANCING RESOURCES & 1,00 & 9,00 & 3,7582 \\
\hline CCGI &, 00 & 23,08 & 5,0141 \\
\hline CCSI &, 00 & 60,00 & 5,0825 \\
\hline CBGI &, 00 & 75,00 & 5,0410 \\
\hline GINEEDIN &, 00 & 53,85 & 5,0496 \\
\hline Network factors & & & \\
\hline ACTORS & 11,00 & 38,00 & 23,2179 \\
\hline POTENTIAL LOBBYING & 4,73 & 63,16 & 21,9933 \\
\hline RELATIVE IMPORTANCE &, 35 & 4,21 & 1,7791 \\
\hline OF THE STATE & & & \\
\hline INTERSECTORALITY & 4,00 & 11,00 & 6,6197 \\
\hline OLIGARCHY & 1,20 & 2,67 & 1,9399 \\
\hline DENSITY & 19,76 & 52,73 & 28,6099 \\
\hline RELATIVE DENSITY OF & 2,63 & 23,51 & 15,6929 \\
\hline INCENTIVES & & & \\
\hline SCIENTIFIC & 4,00 & 38,00 & 21,9744 \\
\hline INFORMATION LINKS & & & \\
\hline
\end{tabular}

Before explaining the process of finding out empirical examples of power types, we should clarify that when we talk about types we basically mean ideal types of actors and not of networks. We can only speak of possible networks with certain characteristics that strongly favor a particular type e.g. the lawful one. In such a case, an organization with the organizational factors "provided" by the lawful type, can be strongly advised to join this network.

One can pose the question: how many organizations belong to each type in our networks. Or reformulate the question more precisely: how many organizations have the negative organization factors of a particular type (e.g. lawful type) equal to the minimum value (e.g. radicalism $=0$ ), along with respective positive organizational factors equal to the maximum value that appears in all in our data (e.g. multidisciplinarity=9), and finally simultaneously participate in a network with the respective negative characteristics equal to the minimum and the positive characteristics equal to the maximum that appears at all in our data (e.g. intersectorality $=4$ and potential lobbying $=63,16 \%$ ). 
We have already tried to discover actors that strictly fulfil all the respective positive and negative factors at the maximum and minimum values, and none have proven to belong to any type. Thus, it is almost impossible for these five ideal categories of actors to appear in their ideal form in political reality. The empirical examples that we present here for each type are only approaches to ideal types; namely, they are cases where actors have negative organizational and network factors under the general average of our data, while their positive factors are above the average ${ }^{58}$ (s. empirical examples for each type in section 4).

The following table includes the characteristics of each network separately, and it will be useful for discovering networks that are favorable for each type in exactly the same way: comparison of each value with the average. In each empirical example (s. section 4), the respective favorable networks are also discussed.

\footnotetext{
${ }^{58}$ Where this could not succeed, then we have tried to find out the actor having its negative factors as much low as possible than the maximum value of all date and its positive ones as much high as possible than the minimum value of all data. The wider the interval of acceptable values for each variable becomes, the more empirical approaches (cases of these 234 actors) can be found for each type.
} 
Table 3. Values of network factors

\begin{tabular}{|c|c|c|c|c|c|c|c|c|c|c|c|c|}
\hline & 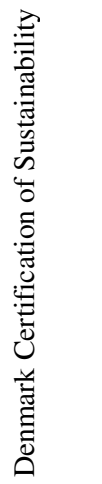 & 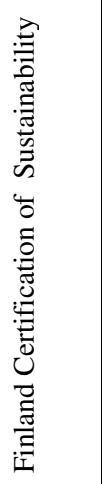 & 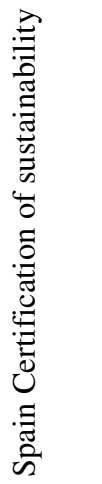 & 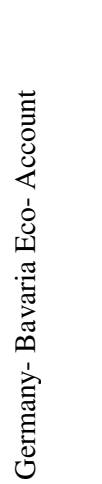 & 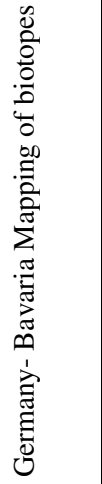 & 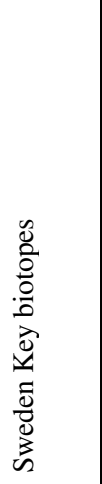 & 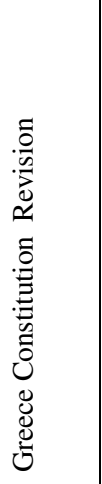 & 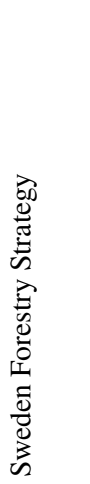 & 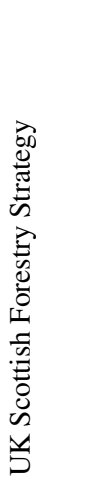 & 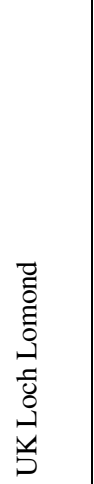 & 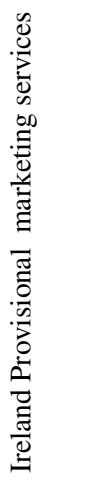 & 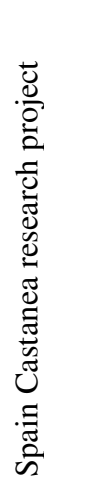 \\
\hline $\begin{array}{l}\text { INTERSECT } \\
\text { ORALITY }\end{array}$ & 6,00 & 11,00 & 9,00 & 5,00 & 5,00 & 5,00 & 6,00 & 5,00 & 5,00 & 7,00 & 6,00 & 4,00 \\
\hline $\begin{array}{l}\text { POTENTIAL } \\
\text { LOBBYING }\end{array}$ & 8,70 & 20,00 & 20,20 & 63,16 & 29,30 & 31,00 & 18,60 & 34,60 & 4,73 & 23,00 & 18,70 & 22,89 \\
\hline $\begin{array}{l}\text { RELATIVE } \\
\text { IMPORTANC } \\
\text { E OF THE } \\
\text { STATE }\end{array}$ & 1,63 & 1,20 &, 53 & ,66 &, 34 & 3,19 & ,62 & 2,81 & 1,56 & 2,85 & 2,07 & 4,20 \\
\hline OLIGARCHY & 1,89 & 1,19 & 1,85 & 1,60 & 1,28 & 1,45 & 1,48 & 1,67 & 2,30 & 2,40 & 2,67 & 2,45 \\
\hline ACTORS & 18,00 & 24,00 & 38,00 & 14,00 & 16,00 & 11,00 & 13,00 & 14,00 & 23,00 & 27,00 & 25,00 & 21,00 \\
\hline DENSITY & 37,58 & 32,43 & 21,48 & 20,88 & 24,17 & 52,73 & 37,82 & 26,92 & 34,78 & 26,78 & 25,00 & 19,76 \\
\hline $\begin{array}{l}\text { SCIENTIFIC } \\
\text { INFORMATI } \\
\text { ON LINKS }\end{array}$ & 10,00 & 28,00 & 38,00 & 4,00 & 8,00 & 13,00 & 6,00 & 9,00 & 32,00 & 30,00 & 21,00 & 17,00 \\
\hline $\begin{array}{l}\text { RELATIVE } \\
\text { DENSITY OF } \\
\text { INCENTIVES }\end{array}$ & 16,10 & 21,22 & 23,50 & 2,63 & 6,89 & 12,06 & 5,08 & 6,12 & 13,63 & 15,42 & 16,66 & 22,89 \\
\hline
\end{tabular}

\section{Summary:}

Our methodology is a statistics-based vector algebra. We measured 108 indicators in 234 cases (observations of power positions) from 12 environmental policy networks in 8 European countries. Out of 234 actors, 91 were associations. The correlation of organizational factors has been based on these associations. From the 108 indicators we have extracted 18 specifications of variables significant to power. The data was captured using standardized telephone interviews (self- and cross-assessment). We have analyzed them with cross-sectional design using the technique of the stepwise regression. The method of complete network analysis presents advantages and disadvantages. The advantages lie in disclosing latent structures (like informal hierarchies), measuring relative positions (like status), and achieving a complete and thereby bounding of the network (that at least does not depend on the personal perception of the researchers). The disadvantages lie in the relatively 'small size' and consequently many autocorrelations as well as the self-selection. In this work we have tried to mitigate the first two disadvantages by increasing the number of variables. The self-selection could be corrected with the methods of Heckman. 


\section{Presentation and qualitative analysis of the results: Anatomy of power and the five power types}

\subsection{Anatomy of power}

If we compute the status of trust (TRUSTSTA), incentive (INCENTIVE) and irreplaceability (IRREPLAC) separately with the formula 2, and we add them again, we observe that they explain the power status with different weights (standardized coefficients) (table 4). Comparing these standardized coefficients, we find out the percentage of contribution for each component:

Trust: $82 \%$

(Financial) incentive: $8 \%$

Irreplaceability: $10 \%$

Table 4. Power composition

\begin{tabular}{|l|r|r|r|}
\hline & \multicolumn{1}{|l|}{$\begin{array}{l}\text { Unstandardized } \\
\text { coefficients }\end{array}$} & $\begin{array}{l}\text { Standardized } \\
\text { coefficients }\end{array}$ & Significance \\
\hline (constant) &,- 022 & &, 840 \\
\hline TRUSTSTA &, 900 & $(82 \%), 864$ &, 000 \\
\hline INCENTIVE &, 026 & $(8 \%), 081$ &, 000 \\
\hline IRREPLAC &, 060 & $(10 \%), 106$ &, 000 \\
\hline
\end{tabular}

Dependent Variable: POWER

The overwhelming magnitude of the trust status in the power composition is remarkable. This eminent value of $82 \%$ is also in accordance with the self-assessment of the power position by the actors themselves (table 5). The cross-assessed trust status is the only significant variable to the self-assessed power position (PERPOWER: perceived power, measured from 1 to 3). Thereby, it seems that actors perceive the trust they feel they gain from other participants as power. This not only means that they see their arguments (general and scientific information) find resonance with others but also that other-s let the actors represent their interests to tertiary actors (e.g. state institutions) or adopt specifications (e.g. concrete formulation of programs) made by the actors. Additionally, as we can observe on table 6, the actors can, on average, assess their real power quite accurately, as selfassessed power (PERPOWER) has proven significant enough to cross-assessed power. 
Table 5. Self-assessment of power: the recognized relevance of trust

\begin{tabular}{|l|r|l|rr|}
\hline & \multicolumn{2}{|l|}{$\begin{array}{l}\text { Unstandardized } \\
\text { coefficients }\end{array}$} & $\begin{array}{l}\text { Standardized } \\
\text { coefficients }\end{array}$ & Significance \\
\hline (constant) & 1,740 & &, 000 \\
\hline TRUSTSTA &, 042 &, 213 &, 010 \\
\hline
\end{tabular}

Dependent Variable: PERPOWER

Table 6. Cross-assessed and self-assessed power

\begin{tabular}{|l|r|l|rr|}
\hline & \multicolumn{1}{|c|}{$\begin{array}{l}\text { Unstandardized } \\
\text { coefficients }\end{array}$} & $\begin{array}{l}\text { Standardized } \\
\text { coefficients }\end{array}$ & Significance \\
\hline (constant) & 3,066 & &, 001 \\
\hline PERPOWER & 1,151 & &, 211 &, 010 \\
\hline
\end{tabular}

Dependent Variable: POWER

There are also autocorrelations between all components. From a power-theoretical point of view, this means very extensive phenomena of external power accumulation (we will discuss them in relevant paragraphs).

Table 7. Autocorrelations and rsq values in power

\begin{tabular}{|l|r|r|}
\hline & TRUSTSTA & INCENTIVE \\
\hline TRUSTSTA & 1 & \\
&. & \\
\hline INCENTIVE & $\mathbf{. 3 3 6}$ & 1 \\
& $\mathbf{. 0 0 0}$ & \\
& Rsq=11,3\% &. \\
\hline IRREPLAC & $\mathbf{. 6 3 7}$ & $\mathbf{. 2 5 7}$ \\
& $\mathbf{. 0 0 0}$ & $\mathbf{. 0 0 0}$ \\
& Rsq=40,5\% & Rsq=6,6\% \\
\hline
\end{tabular}

The TRUSTSTA explains the 11,3\% of the INCENTIVE variance ( $r s q=, 113$ ) and the $40,5 \%$ of the IRREPLAC variance ( $\mathrm{rsq}=, 405$ ). The IRREPLAC explains only $6,6 \%$ of the INCENTIVE variance ( $r s q=, 066)$ (figure 4). Why we accept this causal direction and not inversely will be further discussed in the relevant paragraphs on the five types. In general, we can say that, as calculated above, trust is the most relevant (82\%) hierarchy component in the network of power exchange. This also makes it more understandable why trust is the power dimension most easily identified as power by power holders as well. Most power relations in informal networks, as institutional economists rightly hold, are based on trust. Or, in other words, trust is as a rule the first step towards developing a power relationship in a network. Second comes irreplaceability, which not everyone can develop (not everyone holds an irreplaceable position in a decision-making procedure, valuable contacts etc). Finally, offering incentive seems to be the most rarely practiced power dimension, because 
other actors are not always so strongly dependent on financial resources or are willing to receive them.

Thus, trust is better understood as the basis for more external development of incentive and irreplaceability than inversely. It also sounds reasonable that an actor that has gained the trust of others can be incorporated into a state committee (corporatism) and thus become irreplaceable to others. In contrast, there were many cases in our queries where an irreplaceable actor was not trusted at all. Concerning incentive, we are going to argue in the context of the "omniscient" and "re distributor" type, that a powerful actor can take the attention of other actors away from alternative sources of solutions (blinding) - e.g. other possible advisers, sponsors, contacts etc - or practically exclude these alternatives (monopoly) using trust and irreplaceability. Thereby, trust and irreplaceability create suitable conditions for uncontrollable offering of incentives which has a function practically comparable to "bribery" and can be regarded as normal or illegal and punishable depending on the cultural and political context of the network (HEIDENHEIMER 1970). On the other hand, trust and irreplaceability are accumulated in the first three types ("lawful", "trustworthy" and "little brother"), without parallel accumulation of incentive.

Concisely, we can say that trust is not only a very decisive power dimension by itself but also produces appropriate conditions for development of irreplaceability and incentive offering. This is a quite strong external accumulation of power: from authoritative power, one can produce two dimensions of instrumental power. Irreplaceability is a weaker but not negligible power dimension which can additionally produce incentive implementation (internal accumulation: instrumental power produces more instrumental power). An actor who holds this dimension has one more potential to anticipate an undesired reaction from others, to exclude undesired competitors and also to attract others by offering incentives. Finally, incentive is just a power dimension by itself but does not contribute to any internal or external accumulation of power. This analysis of the partial relevance of each power dimension and the hypotheses of external and internal accumulation processes can perhaps be regarded as a quite new and useful result which may help us understand the genesis and accumulation of power. The partial relevance and accumulation processes will be more analytically discussed in each one of the five types. 


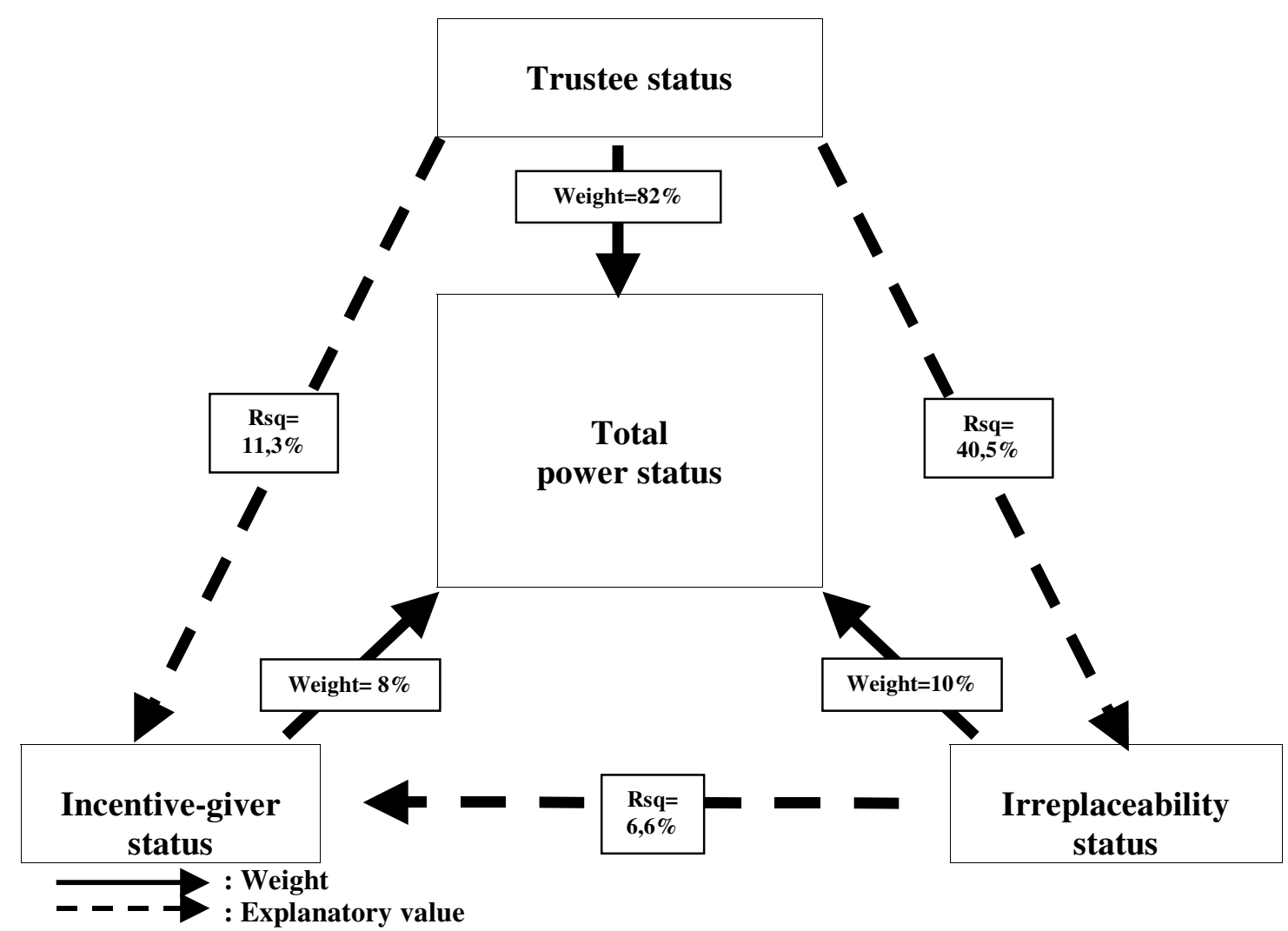

Figure 4. Average relations between power dimensions

\subsection{The five power types}

Using the technique of the stepwise regression ("forward" in the SPSS), we have found the following five types of power factors: I) the "lawful" type, II) the "trustworthy" type, III) th e "little brother" type, IV) the "omniscient" type and V) the "re-distributor" type. Each of these types expresses nothing but the combination of certain organizational and network factors that have proven significant to power and should meet each other in certain combinations in order to achieve the optimal power synergy for a particular organization. For example, by "lawful" type we mean an organization with the organizational characteristics described in this type, when participating in a network with the characteristics described in this type. Practically, we can conduct policy consulting either on the basis of network or on the basis of organizational characteristics. Considering certain characteristics of a real network that resemble this type better than any others, we can suggest that when an organization comes closer to the organizational factors provided by the "lawful" type than any other organization in this network, it has the best chance to develop power. 
Concurrently, considering an organization with certain characteristics, we can recommend the most favorable (or least unfavorable) network to this organization. We are going to divide the power factor types into two categories: a. Types of accumulating power and $b$. types of implementing power (power activation) ${ }^{59}$. This distinction is expected to be very decisive for effective policy-making because if an actor has at its disposal accumulating factors, this does not necessarily mean it has realized these as well as it knows how to activate them and so it may leave its potential unused.

Apart from the possession of such factors, an actor should also be aware of them and possess the "know how" to develop the appropriate mechanisms for activating its power. Information exchange is often such a mechanism that can be effective under certain network conditions. On the other hand, if an actor sees other powerful actors using information in order to implement their power, then it would be misleading to suggest that these powerful actors have accumulated their power through their information exchange: they only activate (implement) their power potential using information.

This typology is expected to answer these points: diagnosis of power position and optimal planning for power accumulation and activation. For reasons of practical communication, each type has been named according to the organizational factor that plays the most important role (highest absolute value of a standardized coefficient) in power development or activation and simultaneously differentiates the particular type from the other types.

Each type includes at least one variable (factor) that concretizes middle-range hypotheses that have already been proposed and supported by qualitative argumentation in the area of political science that we call the Theory of Organized Interests. Using our quantitative results, these hypotheses are expected not only to

\footnotetext{
${ }^{59}$ The former are the lawful, trustworthy and little brother type. We have named them alternatively structure-related types, because each one includes at least one specific structure, e.g. multidisciplinarity, coalition (measured here as partner strength), which imply specific qualitative contents). As said in methodology, these types have been based on a more restricted sample of 91 private associations, because these structures appear only in private associations. The latter are the omniscient and the re-distributor type. We have named them alternatively communication-related types because they relate only to information and not any structure. These are adoptable not only by private associations but by every one (public actors, single enterprises and universities too). Thus they have been based on the whole sample of 234 actors.
} 
become more accurate and operational but also supplemented with more independent variables.

\subsubsection{The three types of power accumulation factors (or structure-related types)}

The accumulation factors are related to internal structures or external cooperation relations of an organization: multidisciplinarity, state control, system conformity, reputation, partner strength and financing resources. Thus, they can be alternatively regarded as structure-related factors. When these are activated under specific network conditions, then power emanates from them.

\subsubsection{The "lawful" type}

An actor with a multidisciplinary team that is lawful ${ }^{60}$ but not state-controlled has optimal chances in ,non crowded“and mono -sectoral networks with intensive state contacts, where the state does not play any important role.

Table 8. The "lawful" type

\begin{tabular}{|l|r|r|r|}
\cline { 2 - 5 } \multicolumn{1}{c|}{} & Unstandardized coefficients & Standardized coefficients & Significance \\
\hline Constant) & 14,266 & &, 000 \\
\hline Organizational factors & \multicolumn{5}{|c|}{} &, 000 \\
\hline MULTIDIS & -488 &, 284 &, 001 \\
\hline RADICALI & $-2,393$ &,- 261 &, 006 \\
\hline STATECH &,- 590 &,- 203 &, 000 \\
\hline Network factors & \multicolumn{5}{|c|}{} &, 000 \\
\hline ACTORS &,- 186 &,- 427 &, 000 \\
\hline POTLOBB &, 112 &, 394 &, 009 \\
\hline RELIMPST & $-1,003$ &,- 296 &,- 243 \\
\hline INTERSEC &,- 365 & & \\
\hline
\end{tabular}

Dependent Variable: POWER

${ }^{60}$ Lawfulness means in our analysis conformity to dominant formal or informal rules and norms of the policy arena (system). This system conformity is as the antipode (opposite variable) of radicalism regarded. What we have directly measured is radicalism. The (-) radicalism is lawfulness. 
- Relevance of each factor to the composition of accumulated power

Table 9. Power anatomy in the "lawful" type

\begin{tabular}{|c|c|c|c|c|c|c|}
\hline & \multicolumn{6}{|c|}{ Dependent variables: } \\
\hline & \multicolumn{2}{|l|}{ Trust status } & \multicolumn{2}{|c|}{ Incentive status } & \multicolumn{2}{|c|}{ Irreplaceability } \\
\hline & \begin{tabular}{l|} 
Standardized \\
Coefficients
\end{tabular} & $\mathrm{P}$ & $\begin{array}{l}\text { Standardized } \\
\text { Coefficients }\end{array}$ & $\mathrm{P}$ & $\begin{array}{l}\text { Standardized } \\
\text { Coefficients }\end{array}$ & $\mathrm{P}$ \\
\hline (Constant) & & , 000 & & ,169 & &, 000 \\
\hline MULTIDIS & ,326 & ,000 & ,238 & ,033 & ,093 & ,298 \\
\hline STATECH &,- 193 & ,014 &,- 089 & ,427 &,- 181 & ,049 \\
\hline RADICALI &,- 230 & ,005 &,- 043 & ,709 &,- 221 &, 020 \\
\hline INTERSEC &,- 228 &, 020 &, 017 & ,902 &,- 238 &, 038 \\
\hline POTLOBB & ,327 & ,000 &,- 057 &, 612 & ,367 &, 000 \\
\hline RELIMPST &,- 245 & ,003 &,- 063 & ,593 &,- 372 & ,000 \\
\hline ACTORS &,- 447 & ,000 &,- 172 & 200 &,- 241 & 028 \\
\hline
\end{tabular}

- Examination of autocorrelations: 5 out of 21 (25\%) overlappings

Table 10. Autocorrelations in the ,lawful"'ty pe

\begin{tabular}{|c|c|c|c|c|c|c|}
\hline \multirow{2}{*}{ MULTIDIS } & MULTIDIS & STATECH & RADICALI & INTERSE & POTLOBB & RELIMPS \\
\hline & 1 & & & & & \\
\hline STATECH & $\begin{array}{r}-, 019 \\
, 861\end{array}$ & 1 & & & & \\
\hline RADICALI & $\begin{array}{l}, 131 \\
, 219\end{array}$ & $\begin{array}{r}-, 310 \\
, 003\end{array}$ & 1 & & & \\
\hline INTERSE & $\begin{array}{l}, 177 \\
, 096 \\
\end{array}$ & $\begin{array}{r}-, 005 \\
, 960 \\
\end{array}$ & $\begin{array}{l}, 016 \\
, 808 \\
\end{array}$ & 1 & & \\
\hline POTLOBB & $\begin{array}{r}-, 067 \\
, 532 \\
\end{array}$ & $\begin{array}{l}, 152 \\
, 151 \\
\end{array}$ & $\begin{array}{r}-, 062 \\
, 348 \\
\end{array}$ & $\begin{array}{r}-, 151 \\
, 021 \\
\end{array}$ & 1 & \\
\hline RELIMPS & $\begin{array}{l}, 015 \\
, 887 \\
\end{array}$ & $\begin{array}{l}089 \\
, 401 \\
\end{array}$ & $\begin{array}{r}-, 076 \\
250\end{array}$ & $\begin{array}{r}-, 485 \\
, 000\end{array}$ & $\begin{array}{r}-, 005 \\
, 945\end{array}$ & 1 \\
\hline ACTORS & $\begin{array}{r}-, 011 \\
, 915 \\
\end{array}$ & $\begin{array}{r}-, 047 \\
, 659 \\
\end{array}$ & $\begin{array}{r}-, 094 \\
, 151 \\
\end{array}$ & $\begin{array}{l}\mathbf{, 6 1 7} \\
\mathbf{, 0 0 0}\end{array}$ & $\begin{array}{r}-, 319 \\
, 000\end{array}$ & $\begin{array}{r}-, 279 \\
, 000 \\
\end{array}$ \\
\hline
\end{tabular}

We observe that the state character of an organization prevents it from undertaking radical actions. Also, the more associations participate in a network, the less lobbying possibilities appear in competition with other. Simultaneously, as the actors proliferate, they outweigh the state importance. This could be attributed to the fact that among the proliferating actors, new ones appear that can replace the previous state actors and thus break their monopoly (HENNING/ WALD 2000). Apart from that, with the proliferation of actors the probability of involving interests from other policy sectors increases (water management, energy, development etc) increases too (intersectorality). Moreover, it is understandable that in an intersectoral and pluralist network, the mono-sectoral state services that normally act separately lose their importance in comparison to private actors. This occurs not only because of the parallel proliferation of private actors but also because the actions of the latter is less standardized than that of public institutions and can be more flexible. 


\subsection{Analysis of organizational factors}

- The relevance of multidisciplinarity

SIMON (1981, p. 164) regards organized expertise as an extremely important function of power development. As said, specialization is an important factor organizational efficiency, especially in a very active organization that is involved in heterogeneous and complex networks. The expertise of an organization (expert team) consists of policy-relevant knowledge (law, technical knowledge, ecology, etc) that makes an organization able to critically consider the suggestions from the state or private actors and thereby capable of resisting a "blind" trust to them. Simultaneously, expertise proves an effective factor for gaining trust of others (DOLATA 2000), by providing plausible fact-based and multifaceted ('innovative") arguments. This implies "quick-witted" answers to a respectively wide range of interest fronts (wood industry federations, farmers associations, land owners, forest employees, cultural associations etc) (MAJONE 1989) ${ }^{61}$.

As state institutions at national level (where we have carried out the survey) normally possess adequate expertise, the role of private expertise can thus only be strong enough in a network where the relative importance of the state is low so that it cannot intervene with its own expertise. Multidisciplinarity can also highlight the role of an actor in a mono-sectoral network because in this context multidisciplinary argumentation appears "innovative". Simultaneously, the plethora of lobbying possibilities make such multidisciplinary argumentation easier to disseminate in the political-administrative system. Furthermore, an organization with multidisciplinary arguments also has better chances in networks with a fewer actors, because in that case it has less partners to convince concerning its "innovative" character and argumentation becomes easier for a multidisciplinary team.

\footnotetext{
${ }^{61}$ MAJONE has emphasized that a really innovative argumentation and evaluation of a program by a multidisciplinary team, should be something more than merely the sum of the separate disciplines. However, even if the advisory team remains at the superficial level of the "sum of the separate disciplines", the information, data and instruments block is drastically widened by the multidisciplinarity and the chance to find out accurate and favorable evidences.
} 
- The relevance of the state character of an organization

Even a private organization can be officially controlled by the state. This happens through an interpenetration between state and organization: the organization penetrates into the political-administrative system and thus its behavior is strongly influenced by the state. Not only its behavior is influenced but also its structure is influenced. This means more complexity both for the state and the organization and the policy outcomes become more uncertain (LUHMANN 1987, p.290-2). However, this uncertainty seems more likely to negatively affect the organization than the state. The most 'innocuous' form of such control occurs through a specific law that demands the existence of the particular organization (e.g. certain chambers of agriculture), and thus its members cannot abolish the organization. A stronger form of state character is when the organization also has state representatives in its internal decision organs.

The regression shows that an organization should be administratively independent of the state (at least officially) so as to gain trust from other network participants. A chamber of agriculture defined as a "public institution with the official right of self administration" (KROTT 2001, p. 71) can be regarded at first glance as a key institution for the effective participation of private actors (e.g. land and forest owners) in state policy-making. However, it should actually be regarded as a statecontrolled corporate organ of private organizations (whether it is officially a legal person of "public" or "private" right does not play any role in state control). Namely, through such institutions the state actually has more chances for influence on private actors than inversely.

The negative impact of state control is rather tangible in networks with many lobbying chances that remain unused because of state control. Thus, the other private actors that remain state-independent can become more antagonistic. State control further impedes the power development of an organization in networks where the state is unimportant in comparison with the private sector, and hence an organization controlled by the state is restricted in its potential fields of action without profiting from its dependence at all. 


\section{- The relevance of lawfulness}

System conformity excludes any implementation of means, which are subversive to official or unofficial institutions (established patterns of acting in the political arena). Such subversive means are often implemented by certain environmental groups and are phenomena of action power (s. also 2.2) like a technical sabotage of a pipeline, market embargo, road blocking etc.

However, at least in so-called 'modern western' societies, the implementation of action power by private actors is not so acceptable in the political arena and by country not so usual (KROTT 1990, p. 54-55). Thus, if an actor uses action power, then it does not gain any trust or irreplaceability thereby. Additionally, if an actor implements action power, he is automatically incapable of exerting instrumental power (which is based on plausible threat of action power). System conformity seems to be especially important in a network with few actors and sectors, because under these conditions, radical actions become known much more rapidly and emphasized as 'unsociable' behavior.

\subsection{Analysis of network factors}

- The relevance of the actor number

'Crowdedness' appears to be the most relevant of the network factors that impedes the development of trust status. As discussed, it is supposed to impede the effective use of multidisciplinarity and lawfulness (and to mitigate the negative impact of radicalism).

- The relevance of potential lobbying

Potential lobbying fosters trust status and irreplaceability. As discussed, it seems to directly favor the use of multidisciplinarity and indirectly to aggravate the negative impact of the state character. 
- The relevance of relative importance of the state

The relative importance of the state impedes the development of trust status and irreplaceability of an organization. As discussed, in national networks where the state plays an important role, private multidisciplinarity loses its importance, because the state possesses enough expertise. However, when the state plays an important role, it can possibly be favorable for the organizations it controls. Thus, its importance can indirectly mitigate the negative impact of the state character.

- The relevance of intersectorality

Involvement of many policy sectors in a network makes a negative impact on trust status of an organization because it is more difficult for an organization to find common interests and develop strong cooperation relations with actors of other sectors. For example, a bird watchers association needs certain time until it becomes familiar enough with the interests, tactics and organizational culture of an artist association that is involved in a common issue (e.g. sustainability certification in Finland). In networks with temporary intersectoral issues it is much more difficult to stabilize any rules and trust relations (cf. JORDAN/ SCHUBERT 1992, p.27).

As analyzed, intersectorality is expected to decrease the value of multidisciplinarity and the need of lawfulness (or in other words, intersectorality mitigates the negative impact of radicalism).

The qualitative relations of the network to organizational factors can be summarized on the following table:

Table 11. Qualitatively analyzed relations between network and organizational factors

\begin{tabular}{|l|l|l|l|}
\hline \multicolumn{1}{|c|}{ Organizational factors } & MULTIDIS & RADICALI & STATECH \\
Network factors & & & \\
\hline ACTORS & - & + & 0 \\
\hline POTLOBB & + & 0 & - \\
\hline RELIMPST & - & 0 & + \\
\hline INTERSEC & - & + & 0 \\
\hline
\end{tabular}

(-): impeding positive or aggravate negative impact

$(+)$ : favoring positive or mitigating negative impact 


\subsection{Empirical case of 'lawful" type}

The nearest case of actor that develops power as a "lawful" type is the Swedish Federation of Forest Industries in its particular network (Swedish forest strategy). In this issue the federation should defend its interests in wood production (mostly pulp wood). There are conflicts with environmental activists who, however, had only 4,8 power. The federation had power $=7,70$. This is quite higher than the average $(4,70)$. It employs 4 disciplines (forest scientists, lawyers, economists, and industrial engineers). It is quite conform to the system (radicalism $=1$ ). The industry is always conform to the system (political norms, market standards and social hierarchies), because it builds or maintains its self this system to a large extent. For example, the industry may drastically influence the power relationship between employees and employers using unemployment as a threatening argument. Thus, the industry as well as other large-scale enterprises are apparently based on indirect and situational power ("systemic power" STONE 1980:982) and thus can mobilize bias in a network, evoke the "hame of the law", or even informal market c onditions or social traditions as long as they are favorable for their interests. The necessity of forest production, particularly pulp wood, is a very well established belief in a land like Finland, where the economy is strongly based on forestry. This belief favors the interests of forest industry. Lawfulness is indispensable in order to mobilize bias, because only a lawful actor can be embodied in the system. The industry federation employs the lawfulness quite effectively as it combines this with multidisciplinarity and state restrictions (no state character). Also, it exists only due to the initiative of its members, while it has nor state representatives at the board (state character $=1$ ).

It participates in a network of only 14 actors, quite many chances for lobbying $(34,60)$, where state institutions do not monopolize the decision-making but leave many open fields for law interpretation, evaluation and implementation or alternative contact points; The relative importance of the state is here 2,82 , namely higher than the average but still much lower than the maximum $(4,21)$. The intersectorality $(=5)$ is also relatively low in comparison to the average in all the networks. The involved sectors are: forestry, nature conservation, research policy, trade policy, and industrial policy. Thus, any multidisciplinary proposal is easily by the others as innovative and it is more difficult to become open to criticism. Although the federation has conflicts with decision-making centers of Greenpeace in Sweden as well as abroad, it has gained the trust of the Ministry of Environment and even of certain fractions of the 
Swedish Parliament. The wide fields for potential lobbying enables the federation to contact many actors and cooperate with them (Swedish Association for Nature Conservation, Swedish Environmental Protection Agency, Forest Owners Association). In this way, the federation can also provide all these actors with plausible arguments and understand their heterogeneous needs due to its multidisciplinarity. It is also evident that this capacity of networking and developing cooperation, could be much less flexible and more restricted, if the federation had state representatives in its decision-making organs. Apart from that, if the state held a disproportional higher value (irreplaceability) than the private actors, then "Innovative" multidisciplinary arguments would have been discouraged from the beginning or they would not have made a considerable impact on the power status (trust) of the federation.

Networks which are favorable for "lawful" type, are the two ones in Germany Bavaria (eco-account and the mapping of biotopes). Both of them have their 'lawful type"-relevant positive characteristic (potential lobbying) over than the average value of all the 12 networks and the negative ones (actor number, relative importance of state and intersectorality) lower than the respective averages. This practically means that if an actor with organizational characteristics of the Swedish federation of forest was active in these particular networks of Bavaria, it would have an extremely good potential to develop power.

11 private associations have the organizational characteristics (namely overcome appropriately the average limits) of the "lawful" type. The irony is however, none of them appear in the German networks so as to achieve the highest possible power effect in combination with the favorable conditions there. They appear in other networks which are not so favorable for this type (Finland, Greece, UK, Sweden, and the certification of sustainability in Spain). From these 11 "unlucky" actors, 3 are market-oriented and 8 are non-profit associations. 


\subsubsection{The "trustworthy" type}

A trustworthy actor with multidisciplinary team has its optimal chance in a ,non crowded"network with intensive state contacts and low importance of state.

Table 12. The 'trustworthy" type

\begin{tabular}{|c|c|c|c|}
\hline & Not standardized coefficients & Standardized coefficients & $\mathrm{P}$ \\
\hline (Constant) & 2,127 & & ,301 \\
\hline \multicolumn{4}{|l|}{$\begin{array}{l}\text { Organizational } \\
\text { factors }\end{array}$} \\
\hline TRUSTWOR & 3,105 & ,281 & 000 \\
\hline MULTIDIS & ,343 & ,199 & ,007 \\
\hline \multicolumn{4}{|c|}{ Network factors } \\
\hline ACTORS &,- 247 & $\begin{array}{ll}-, 566 \\
\end{array}$ &, 000 \\
\hline POTLOBB & $9,200 \mathrm{E}-02$ & ,322 & 000 \\
\hline RELIMPST &,- 621 &,- 184 & 015 \\
\hline
\end{tabular}

Dependent Variable: POWER

- Relevance of each factor to the composition of accumulated power:

Table 13. Power anatomy in the 'trustwo rthy" type

\begin{tabular}{|c|c|c|c|c|c|c|}
\hline & \multicolumn{6}{|c|}{ Dependent variables: } \\
\hline & \multicolumn{2}{|l|}{ Trust status } & \multicolumn{2}{|c|}{ Incentive status } & \multicolumn{2}{|l|}{ Irreplaceability } \\
\hline & $\begin{array}{l}\text { Standardized } \\
\text { Coefficients }\end{array}$ & $\mathrm{P}$ & $\begin{array}{l}\text { Standardized } \\
\text { Coefficients }\end{array}$ & $\mathrm{P}$ & $\begin{array}{l}\text { Standardized } \\
\text { Coefficients }\end{array}$ & $\mathrm{P}$ \\
\hline (constant) & & ,121 & & ,327 & & ,861 \\
\hline TRUSTWO & 244 & ,003 &,- 006 & ,959 & ,227 &, 016 \\
\hline MULTIDIS & 249 & ,001 & 237 &, 026 & 015 & 861 \\
\hline POTLOBB & ,261 & ,001 &,- 058 & ,596 & ,304 & ,001 \\
\hline RELIMPST &,- 143 &, 068 &,- 070 & ,516 &,- 269 &, 004 \\
\hline ACTORS &,- 576 & ,000 &,- 155 &, 170 &,- 372 &, 000 \\
\hline
\end{tabular}

- Examination of autocorrelations: 3 out of 10 (33\%) overlappings

Table 14. Autocorrelations in the ,trustworthy“

type

\begin{tabular}{|c|c|c|c|c|}
\hline \multirow{2}{*}{ MULTIDIS } & MULTIDIS & \multicolumn{3}{|c|}{$\begin{array}{l}\text { POTLOBB } \\
\text { RELIMPST|ACTORS }\end{array}$} \\
\hline & 1 & & & \\
\hline POTLOBB & $\begin{array}{r}-, 067 \\
.532\end{array}$ & 1 & & \\
\hline RELIMPST & $\begin{array}{l}, 015 \\
887\end{array}$ & $\begin{array}{r}-, 005 \\
945\end{array}$ & 1 & \\
\hline ACTORS & $\begin{array}{r}-, 011 \\
, 915 \\
\end{array}$ & $\begin{array}{r}-, 319 \\
, 000 \\
\end{array}$ & $\begin{array}{r}, 279 \\
, 000 \\
\end{array}$ & 1 \\
\hline TRUSTWO & $\begin{array}{l}, 010 \\
, 922\end{array}$ & $\begin{array}{r}-, 040 \\
, 544\end{array}$ & $\begin{array}{l}090 \\
, 172 \\
\end{array}$ & $\begin{array}{l}\mathbf{3 3 3} \\
, \mathbf{, 0 0 0}\end{array}$ \\
\hline
\end{tabular}

As discussed, proliferating actors decrease the lobbying possibilities and the relative importance of the state. The new relation that appears is that the average trustworthiness of each organization increases with the number of the actors. This could be explained as follows: the more the participants in a network, the better 
chance an actor has to select partners to which it can develop a harmonious and positive relation. And they will probably maintain a positive superficial impression (trustworthiness) about this organization.

\subsection{Analysis of organizational factors}

- The relevance of trustworthiness

Trustworthiness strengthens trust status and to certain extent irreplaceability. Trustworthiness has been described by BUSKENS (1999) as a property honoured by trust. In other words, Buskens has already distinguished trust from trustworthiness regarding the latter as a potential for trust rather than as an identical concept. In this analysis we have already shown that trustworthiness is not even necessary for developing trust status (for example, in other types, trustworthiness does not appear as a relevant organizational factor at all).

The substantive difference is that trustworthiness is only a subjective impression (or feeling), while trust status is an objective action: a form of leadership. Power and hierarchy (status) that come about through this action and thereby the satisfaction of interests are an unambiguous political reality and not subjective at all.

In order to understand the nature of the trustworthiness, we are going to present the strong relation between trustworthiness and system conformity (-radicalism):

Table 15. Trustworthiness and radicalism

\begin{tabular}{|r|rr|c|}
\cline { 2 - 4 } \multicolumn{1}{c|}{} & Unstandardized coefficient & Standardized coefficient & P \\
\hline (Constant) & 2,770 & &, 000 \\
\hline RADICALI &,- 324 &,- 274 &, 000 \\
\hline
\end{tabular}

Dependent variable: TRUSTWOR

This also explains the similarities between the "lawful" and the "trustworthy" type. An organization can hardly use subversive means in the political arena maintaining its trustworthiness. The implementation of such a means is - as explained above - the action power. Trustworthiness can only exist as a potential of instrumental power (trustworthy promises or threatens that later or never are implemented).

Trustworthiness can be honored with trust only under specific conditions. As in the case of lawfulness, it would not be an unreasonable argument that trustworthiness seems to be especially important in a network with few actors, because then, the untrustworthiness becomes known much more rapidly and emphasized as 
"unsociable" behavior. The numerous lobbying possibilities can also play a positive role in the utilization and wider advertising of a trustworthy image.

- The relevance of multidisciplinarity

The role of the multidisciplinarity and its specific meaning under conditions of good lobbying possibilities, few actors and low state importance have been analyzed. Multidisciplinarity can also achieve a power synergy with the trustworthiness as it can easier become plausible.

\subsection{Analysis of network factors}

- The relevance of actor number

'Crowdedness' is the most important of the network factors. Although in the case of the "lawful type" crowdedness only makes a negative impact on the development of trust status, in the case of the "tru stworthy" type crowdedness also impedes the irreplaceability. This second negative impact can be explained as follows: the more participants in a network, the sharper the competition is between them for the power monopoly and simultaneously the more alternative lobbying paths that they construct with and toward each other. Thus, crowdedness makes more difficult for someone to become irreplaceable.

As discussed, crowdedness seems to mitigate the negative impact of untrustworthiness. Or in other words a non-crowded network makes trustworthiness more indispensable to the survivability of an organization. For the same reasons as in the 5.1.1, crowdedness also seems to impede the effective use of multidisciplinarity.

\section{- The relevance of potential lobbying}

Potential lobbying plays the same role as the "lawful" type. It contributes to both the development of trust status and irreplaceability, and it can foster the virtuous of multidisciplinarity. Simultaneously, we have discussed above that it makes a trustworthy image more effective in the political arena. 
- The relevance of relative importance of the state

Like in the case of the "lawful" type, the relative importance of the state can also make a negative impact on the role of private multidisciplinarity.

The qualitative relations of a network to organizational factors can be summarized using the following table:

Table 16. Qualitatively analyzed relations between network and organizational factors

\begin{tabular}{|l|l|l|}
\hline \multicolumn{1}{|c|}{ Organizational factors } & TRUSTWOR & MULTIDIS \\
Network factors & & \\
\hline ACTORS & + & - \\
\hline POTLOBB & + & + \\
\hline RELIMPST & 0 & - \\
\hline
\end{tabular}

(-): impeding positive or aggravate negative impact

(+): favoring positive or mitigating negative impact

\subsection{Empirical case of 'trustworthy" type}

The nearest case of an actor that developed power as a "trustwor thy" type was the Association of Bavarian Agrarians (Germany) in the biotope inventory network. The issue of biotope inventory has been characterized by intensive conflicts between conservation and market-oriented interest groups, because the basic question concerned which areas should be classified as conservation areas. The Association of Agrarians belonged to the market-oriented side of the conflict. It developed a considerable power status in this network $(10,2)$, while its opponents (nature conservation groups and state actors related to nature conservation) had very weak power status $(5,3,5$, and 2,7$)$.

The high power of the Bavarian Agrarians can be attributed to the fact that the Association is regarded as a very trustworthy $(2,6)$ by a large group of partners (forest owners, land and estate owners, Bavarian Ministry of Agriculture, University of Munich, Council of Communities, and politicians). In this way, the Agrarians have gained in plausibility, institutional support and pressure potential. Its argumentation is further strengthened by their multidisciplinarity. They employ four disciplines: forest science, agricultural science, law, and economics. This is a considerable amount of multidisciplinarity for a market-oriented group. In other words, the Agrarians can effectively combine promises and demands related to market 
development with multifaceted arguments. Simultaneously, it participates in a network with only 16 participants (low competition) and many lobbying chances $(29,3)$. The relative importance of state to the private sector is very low $(0,35)$. Under these conditions, the Agrarians have a good chance to activate their potentials, to act flexibly and implement their power.

The two German networks prove also the most favorable ones. If an organization has trustworthiness higher than 2,34 and multidisciplinarity higher than 3 , then it has very good chances in these German networks. In total, 14 private associations were found to fulfil the organizational factors of the "trustworthy" type. 5 are $\mathrm{m}$ arket-oriented and while 9 non-profit associations. Only one of them is active in a favorable German network (discussed above). The other 13 associations are dispersed in other networks that are not as favorable for the "trustworthy” type (Denmark, Greece, UK, Spain).

\subsubsection{The 'little brother" type}

An actor with powerful partners and various financing resources has its optimal chance in a mono-sectoral network with ,equal chances“ where many possible contacts are still unexplored.

Table 17. The ' 1 ittle brother' type

\begin{tabular}{|l|r|r|r|r|}
\cline { 2 - 5 } \multicolumn{1}{c|}{} & Not standardized coefficients & Standardized coefficients & P \\
\hline $\begin{array}{l}\text { Constant) } \\
\text { Organizational } \\
\text { factors }\end{array}$ & 13,837 & &, 000 \\
\hline PARTNSTR &, 663 &, 424 &, 000 \\
\hline FINRESOU &, 341 &, 227 &, 005 \\
\hline Network factors & $-3,180$ &,- 484 &, 000 \\
\hline POWERINE &,- 476 &,- 323 &, 011 \\
\hline INTERSEC &,- 154 &,- 312 &, 000 \\
\hline DENSITY & & & \\
\hline
\end{tabular}

Dependent Variable: POWER

- Relevance of each factor to the composition of accumulated power

Table 18. Power anatomy in the 'little brother"type

\begin{tabular}{|c|c|c|c|c|c|c|}
\hline & \multicolumn{6}{|c|}{ Dependent variables: } \\
\hline & \multicolumn{2}{|l|}{ Trust status } & \multicolumn{2}{|c|}{ Incentive status } & \multicolumn{2}{|l|}{ Irreplaceability } \\
\hline & \begin{tabular}{l|} 
Standardized \\
Coefficients
\end{tabular} & $\mathrm{P}$ & $\begin{array}{l}\text { Standardized } \\
\text { Coefficients }\end{array}$ & $P$ & $\begin{array}{l}\text { Standardized } \\
\text { Coefficients }\end{array}$ & $\mathrm{P}$ \\
\hline (Constant) & &, 001 & & ,875 & &, 000 \\
\hline FINRESOU & ,250 & ,002 &, 057 & ,619 & ,078 & ,419 \\
\hline PARTNST &, 448 &, 000 &, 113 & ,464 & ,164 & ,209 \\
\hline INTERSEC &,- 291 &, 025 & ,014 & ,939 &,- 418 & ,009 \\
\hline POWERIN &,- 407 &, 000 &,- 097 & ,535 &,- 520 &, 000 \\
\hline DENSITY &,- 251 & ,003 &, 052 & ,658 &,- 329 &, 001 \\
\hline
\end{tabular}


- Examination of autocorrelations: 5 out of $10(50 \%)$ overlappings

Table 19. Autocorrelations in the ,little brother“6 type

\begin{tabular}{|r|r|r|r|r|}
\hline & PARTNST & FINRESOU & POWERIN & INTERSEC \\
\hline PARTNST & 1 & & & \\
&, & & & \\
\hline FINRESOU &, 147 & 1 & & \\
&, 175 & & & \\
\hline POWERIN & $\mathbf{- , 1 7 7}$ &,- 146 & 1 & \\
& $\mathbf{, 0 3 1}$ &, 166 &, & \\
\hline INTERSEC & $\mathbf{, , 5 8 0}$ &,- 004 & $\mathbf{- , 4 0 6}$ & 1 \\
& $\mathbf{, 0 0 0}$ &, 971 & $\mathbf{, 0 0 0}$ & \\
\hline DENSITY & $\mathbf{, 3 9 6}$ &, 201 & $\mathbf{- , 3 2 0}$ &,- 068 \\
& $\mathbf{, 0 0 0}$ &, 056 & $\mathbf{, 0 0 0}$ &, 302 \\
\hline
\end{tabular}

Power inequality appears to lesson the chances of an organization making powerful ,friends“. This can be explained by the fact that in a network where a purely liberal and individualistic game takes place, everyone wants to concentrate power for him/herself. Under these conditions, powerful actors merely want to become more powerful and strengthen their oligarchy, without sharing this power with any "little brother". They rather want to keep the "little" that much weaker so as to preserve their own dominance in the future.

Intersectorality also seems to impede making powerful partners because it makes contacts to foreign sectors more difficult. However, intersectorality appears to impede power concentration for a few leading actors. A possible explanation for this would be that an intersectoral network is equally unfamiliar to every actor and everyone has difficulties finding and using optimal chances (orientation difficulties). Increasing density improves the probability of making powerful partners, since each actor has the chance to make more contacts and discover among them more powerful partners they can cooperate with. Nevertheless, it is also clear that through further exploration of a network, new resources and advantageous contact points are disclosed and more freely used by every actor. For this reason, power inequality seems to decrease with density. 


\subsection{Analysis of organizational factors}

- The relevance of partner strength

The development of positive relations and cooperation with powerful partners with compatible interests that lead up to building of official or unofficial coalitions have been considered to be of decisive importance to the power status of an actor (SCHUBERT 1989). "Friends" that already possess considerable power improve the trust status of an organization. However, the powerful partners 'share' their power more willingly with "little brothers" in networks with low oligarchy. Under high oligarchy, every actor would try to only concentrate power to improve its own position and is not so willing to make coalitions with other powerless organizations. Another network condition that impedes an organization from making powerful "friends" is high intersectorality. The more heterogeneous and foreign sectors are involved, the less familiar an organization is to other actors. Under these conditions, more powerful actors have the luxury to search and choose a more advantageous actor for their purposes from a wide range of sectors (industry, financing etc) than a "little brother" from the domestic sector (e.g. agro -forestry). A strong landowners association, for example, has the opportunity to find more powerful partners for itself from the sectors of industry or financing (banks) than a weak forest owners association can find from the agro-forestry sector.

- The relevance of financing resources

In the Theory of Organized Interests, one finds many arguments for the great importance of financial resources. These have been operationalized in our analysis as the number of alternative financing resources and it is relevant to trust status development ${ }^{62}$. Financing resources are decisive for the existence of an organization and its influence on other actors. A wealthy organization can support policies or other

\footnotetext{
${ }^{62}$ Other finance-relevant indicators like human resources and public relation costs have also been measured and compared but they have not proved power-relevant here.
} 
actors using financial help and so acquire new powerful partners ${ }^{63}$ too (KROTT 2001, p.74-75).

Although financing resources are considered to be very meaningful for ascertaining the power of an organization, they do not appear as a power-relevant factor in every type. They need to be combined with certain conditions, in order to achieve a power synergy. The first condition is to use financing in order to attract new strong partners. The second one is low density (many unexplored contact points); In a network with many unexplored contact points, a rich organization can more easily gain the power monopoly over others more easily by promising financial support.

\subsection{Analysis of network factors}

- The relevance of power inequality (oligarchy)

Oligarchy appears to be the most important network condition (-484) that impedes both the trust status and the irreplaceability of an organization. Oligarchy signifies an official or unofficial hierarchy in a network, where most participants depend on a power-holding elite that further determines the roles of the functionaries in a network (decision-makers, executors etc.) (RIDDER 1979, p.35). Thus, the more oligarchy has been developed, the more difficult it becomes for an inferior actor to develop its own status of trust and irreplaceability and thus perpetuate itself.

- The relevance of intersectorality

The negative role of intersectorality has already been analyzed in the case of the 'lawful" type. There, it was an impeding factor to the development of trust. Here, it impedes the development of irreplaceability. This difference can be explained as follows: in the case of a "lawful" actor that uses multidisciplinarity in order to persuade others, being unfamiliar with heterogeneous policy sectors is obviously an obstacle to this goal. In the case of a "little brother" that tries to use the power of others, more powerful actors may prefer to find a more advantageous partner for

\footnotetext{
${ }^{63}$ However, the power function (new friends) seems rather to work like a means of instrumental power namely promises and threatens that rarely take place. Otherwise the financing resources should also be significant for the incentive that an organization gains from the others.
} 
themselves from another sector. This makes the "little brother" less irreplaceable for them.

- The relevance of density

Density appears only in this type as a significant factor. It makes a negative impact both on trust and irreplaceability. From the above discussion it seems to impede the monopoly of financing promises and chances. This makes an actor less irreplaceable to others. The negative impact of high density on the trust status (cf. FLACHE 1996, p.216) of an actor can be explained as similar to impact of the 'crowdedness' in the case of the "lawful" type: the more actors contact a potential partner, the more difficult it becomes for each actor to persuade the desired partner that it is the most suitable one to cooperate.

The qualitative relations of a network to organizational factors can be summarized on the following table:

Table 20. Qualitatively analyzed relations between network and organizational factors

\begin{tabular}{|l|l|l|}
\hline \multicolumn{1}{|c|}{ Organizational factors } & PARTNST & FINRESOU \\
Network factors & & \\
\hline POWERINE & - & 0 \\
\hline INTERSEC & - & 0 \\
\hline DENSITY & 0 & - \\
\hline
\end{tabular}

(-): impeding positive or aggravate negative impact

$(+)$ : favoring positive or mitigating negative impact

\subsection{Empirical case of 'little brother" type}

The nearest case of an actor that developed power as a "little brother" type is the WWF of Sweden in the network of Swedish forest policy. Its aim is to establish effective environmental control regulations (like certification procedures) in forest strategy. This contradicts to the interests of market-oriented groups (like forest owners) and the public services that are their best partners (like forest service). The WWF' s power status was 7. This was comparable with its opponent, the Federation of Forest Industries (power $=7,7$ ). In contrast to the industry federation, the power of the WWF is not based on system conformity. It is actually characterized as radical by the other actors in the network (radicalism $=1,5$ ). Its power is based on its average 
partner strength $(7,55)$ and its alternative financing resources $(7)$. Both are in this case higher than the average values (approx. 6 and 4 respectively).

One the most powerful "friends" of the WWF is the Ministry of Environment (power=10,8). This partner can offer considerable support to WWF when WWF disagrees with the initiatives of the forest service (which is subordinated to the Ministry of Agriculture) or with the tactics of the forest industry or forest owners. The next most powerful partner for the WWF is the Swedish Association for Nature Conservation (power=9,8). Third is the Swedish Environmental Protection Agency (power=8,7).

The WWF also has a wide range of alternative financing resources at its disposal: national financing projects, international state sources like the EU, its own members, stable sponsors, occasional donors, and symbolic contributions by extraordinary sponsors, and finally capital investments. All these resources assure economic stability, continuity and the capacity to reliably finance its own projects or projects of other actors.

At the same time, the WWF is participating in a network with relatively low inequality (oligarchy $=1,68$ ). Thus, it has no sharp competition to deal with and can easily create high power status using its favorable partnerships. Intersectorality is also low (5 sectors involved: forestry, nature conservation, trade, research policy and industrial policy). So, there are not many opportunities to find partners from foreign sectors, and there is a higher possibility for the less powerful actors to develop partnerships with strong actors of the same sector (like WWF in this network). Finally, the low density $(26,92)$ provides for few contact points and support chances and makes the WWF's financing resources more irreplaceable to other actors.

Networks which are favorable for actors that want to develop power as a "little brother" type are the Swedish forestry strategy and the two German networks. 15 private associations fulfil the organizational characteristics for developing power by adopting the "little brother" type. 4 of them are market -oriented and the 11 nonprofit-oriented. 1 market-oriented appears in Germany (both networks), and 1 nonprofit-oriented in Swedish forestry strategy (discussed above). 6 appear in Denmark, 4 in Greece, 1 in Ireland, 1 in the UK (Scottish forestry strategy), and 1 in Spain (castanea research project). 


\subsubsection{The two types of power activation factors (or communication-related types)}

The arguments from the Theory of Organized Interests we drawn on here include that are used here two Influence potentials: a. influence on general communication and b. expertise (particularly in the two types understood as scientific information and not as multidisciplinarity like previously). A communication strategy is regarded by (almost) all organizations today as a critical to survival in a network. The use of general information as means of influence has two forms: 1 . imposition of an "important" information image (CCGI) and 2. control of general information distribution (CBGI).

The use of scientific information for strengthening political argumentation has also proven significant enough to power implementation under specific conditions, particularly for imposing an "important" scientific image (CCSI).

Based on SIMON's hypotheses, we are going to argue that although information "importance" and control show a strong quantitative relation to power, they do not generate power at all. Their strong quantitative relation to the power can only be understood if they are considered as a means to activate (implement) existent power potential.

\subsubsection{The 'omniscient”'type}

A powerful actor can implement its power by imposing general or scientific information as "important" and controlling general communication in a network w ith little material needs.

Table 21. The 'omniscient" type

\begin{tabular}{|c|c|c|c|}
\hline & Not standardized coefficients & Standardized coefficients & Significance \\
\hline (Constant) & 4,211 & & , 000 \\
\hline \multicolumn{4}{|c|}{ Organizational factors } \\
\hline CCGI & ,387 & ,457 & ,000 \\
\hline CCSI & $7,867 \mathrm{E}-02$ & ,203 &, 000 \\
\hline CBGI & $4,225 \mathrm{E}-02$ & ,133 &, 004 \\
\hline \multicolumn{4}{|l|}{ Network factors } \\
\hline RELDENINCE &,- 114 &,- 220 & 000 \\
\hline
\end{tabular}


- Relevance of each factor to the composition of activated power

Table 22. Power anatomy in the "omniscient" type

\begin{tabular}{|c|c|c|c|c|c|c|}
\hline & \multicolumn{6}{|c|}{ Dependent variables: } \\
\hline & \multicolumn{2}{|c|}{ Trust status } & \multicolumn{2}{|c|}{ Incentive status } & \multicolumn{2}{|l|}{ Irreplaceability } \\
\hline & $\begin{array}{l}\text { Standardized } \\
\text { Coefficients }\end{array}$ & $\mathrm{P}$ & $\begin{array}{l}\text { Standardized } \\
\text { Coefficients }\end{array}$ & $\mathrm{P}$ & $\begin{array}{l}\text { Standardized } \\
\text { Coefficients }\end{array}$ & $\mathrm{P}$ \\
\hline (Constant) & & ,000 & & ,556 & & ,006 \\
\hline CCGI &, 505 & ,000 & ,243 & ,003 & ,371 &, 000 \\
\hline CCSI & ,159 &, 003 & 020 & ,794 & 077 & ,284 \\
\hline CBGI &, 074 &, 103 & ,249 &, 000 & ,132 &, 029 \\
\hline RELDEINCE &,- 256 &, 000 &,- 030 & ,640 &,- 111 & ,069 \\
\hline
\end{tabular}

- Examination of autocorrelations: 6 out of $6(100 \%)$ overlappings

Table 23. Autocorrelations in the „omniscient" type

\begin{tabular}{|c|c|c|c|}
\hline \multirow[b]{2}{*}{ 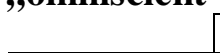 } & \\
\hline & CCGI & CCSI & CBGI \\
\hline \multicolumn{4}{|l|}{ CCGI } \\
\hline \multirow[t]{2}{*}{ CCSI } & ,603 & 1 & \\
\hline &, 000 & & \\
\hline \multirow[t]{2}{*}{ CBGI } & ,321 & ,343 & 1 \\
\hline & ,000 &, 000 & \\
\hline \multirow[t]{2}{*}{ RELDEINCE } &,- 380 &,- 189 &,- 146 \\
\hline & ,000 & ,004 &, 026 \\
\hline
\end{tabular}

The importance of scientific information, CCSI, shows a strong positive relation to the importance of general (public) information, CCGI. This is understandable, since scientific information is a part of general information. Of course, these two variables are not identical and thus it is not self-evident that an actor that distributes 'important" general information will automatically maintain a good reputation as a "scientist" (cf. DUKE 2002).

The control of general information (CBGI), namely the number of information channels that an actor intervenes in and that are dependent on the actor shows a strong positive relation both to CCGI and to CCSI. This may be understood as follows: if an actor is powerful enough and thereby able to impose its own information (opinions, norms or facts) as "important" to others, then this actor can simultaneously consolidate the attention of others and also their hope for "useful communication" in itself. The powerful actor can thereby direct and control the flow of information. At the same time, the control of information channels by the most powerful actor at a given moment helps this actor prevent the development of other decision centers within a network by other actors with similar power levels. As long as other actors, even those with similar power status, are communicatively isolated, they can hardly reach ('implement') their power potential (cf. SIMON 1981, p.187). 
The RELDEINCE signifies the relevance of material needs in a network and seems to have a negative impact on persuasiveness (information importance) and communication control based on trust status. As defined, the trust status means the growth of a cohesive network of trust relationships. Thus, if material needs can be satisfied directly for a concrete return service (balanced exchange), then there are no suitable conditions for developing generalized exchanges (trust-based promises). Namely, the incentive is a means of direct control $^{64}$, which overpowers a long-term trust relation (VOGT 1997, cf. EISENSTADT 1995).

Under these conditions, it is expected that in a network where the material support is of great relevance, then reputation plays a secondary role; in everyday language, this could be formulated: 'food is more important than the soul'.

\subsection{Analysis of organizational factors}

- The relevance of "important" general information

"...in empirical science we aspire only to approximate truths; ...when we find discrepancies between theory and data, our first impulse is to patch rather than to rebuild from the foundations"(SIMON 1978)

These words from Simon are grounded on the realization that 'important" information is constructed and imposed and does not constitute an objective entity that produces power and specific hierarchies in which everyone holds a clear position. This insight applies to both general information and more specialized "scientific" information. In this work, when we have measured the "importance" of information (CCGI or CCSI), we have actually measured the image of the importance of information. According to our results, the more powerful an actor is, the more "important" information it distributes. However, this powerful actor has not acquired power due to its "important" information re sources, but rather imposed its information as "important" to others due to its power status (especially the status of

\footnotetext{
${ }^{64}$ E.g. an environmental organization can help an industry persuade the inhabitants of a region that the clear-cutting of this area is beneficial for them, if it receives a sufficient sponsorship by this industry.
} 
trust and irreplaceability). SIMON (1981, p.187) has already distinguished power resources from information use. He has already argued that the importance of information and thus the attention paid to it by the recipients (less powerful actors) should actually be attributed to the importance (power) of information sources (more powerful actors); An actor with higher trust status gains higher resonance. In other words, it is first the power that appears and afterwards the information "importance". Two empirical arguments have been derived from our analysis that support this hypothesis:

a. The relative density of general information plays at any rate a relatively restricted role in a network ( RELDENGI $^{65}=47,20 \%$ ). Thus, a variable with such a restricted role could not generate much power.

b. The term "Important" information is only a subjective characterization of a certain number of actors (not necessarily all) that receive this information, while the status of trust and irreplaceability constitutes an objective hierarchy through which an actor of a high status imposes its own will regardless of the subjective estimations, feelings or interests of the others. So, a subjective view ('importance") cannot produce an objective one (hierarchy) but rather inversely; the hierarchy can produce public opinion building.

We will additionally try to illustrate the function of information importance with some examples:

First, let's discuss the generation of information importance in the academic arena; many students combine data from their own experience, values and concepts or facts of their disciplines and build new concepts that can prove to have much more effective predictive properties and the capacity to solve practical problems in the future $^{66}$. A student can (almost) completely impose his/her innovative ideas on other students only when (and if) he/she becomes a professor. A professor gains first of all

${ }^{65}$ Analogous to RELDEINCE

${ }^{66}$ There has already appeared the case of the STUDENT-distribution in statistics that has been named like this, because it had been presented anonymously at conference by a student and afterwards it proved very useful in statistical analysis. 
irreplaceability towards the students (for example the latter expect a letters of recommendation from him) and he can also gain trust status. Afterwards, the most effective way for a scientist to effectively impose his/ her ideas on other scientists worldwide is to be awarded a Nobel price ${ }^{67}$ (trust status) and not so much through supporting his findings with "strong" empirical evidence (to every piece of empirical evidence, there can be opposed another piece of empirical evidence derived from another part of reality, depending on the differing experiential range of each researcher $)^{68}$. Much more manipulation of empiricism appears in applied subdisciplines of biology like molecular biology that represent a current fashion and strongly depend on the medical and bio-chemical industry; if a professor-reviewer expects grants from the industry to develop - or merely maintain - his bio-chemical laboratory, will he really dare accept a submitted paper for publication that impedes the interests of his grant-givers?

As a second example we can consider a situation of power relations between NGOs in the network of Natura $2000^{69}$ ("shadow" lists of environmentalists in Brussels, 1999); The WWF, the federation of European forest owners (French abbreviation CEPF), the umbrella organization of agricultural producers in Europe (French abbreviation COPA) and the federation of the European hunters (French abbreviation FACE) were involved. In 1999, the DG (general direction) for the Environment at the

\footnotetext{
${ }^{67}$ The Nobel price is also strongly related to personal and political relations. Let's mention the case of Einstein: he had become famous to the public due to the theory of relativity, but he was awarded the Nobel price for the analysis of the photoelectric phenomenon. Why for the restricted elite of the Nobel foundation the photoelectric phenomenon was more "important" than the theory of relativity, can only be answered through analysis of personal or political criteria.
}

${ }^{68}$ For example, even if a political survey includes a statistical analysis of 3000 organizations in Germany, this can still be considered to be an "inadequate" sample in comparison to the approximately 10000 organizations that one can find in Europe or to the 100000 that perhaps can exist in the world with different properties etc.

${ }^{69}$ The Natura 2000 was a directive of the EU since 1992, which was aiming to protect natural areas with particular characteristics. The exploitation groups saw this as a threat against the free management and market-effectiveness of agriculture and forestry. The conservation groups managed to pass their own "shadow" lists of suggested protected areas without any co -action or substantial negotiation with the exploitation groups. 
European Commission was dominated by nature conservation lobbyists (WWF etc), sicne the nature exploitation lobbyists (agriculture and forestry) had underestimated and neglected this field for many years (they only focused on the DG Agriculture and Industry) (HASANAGAS 2001). The WWF was for Commission officials a "trustworthy" organization, which was serving the public interest without making any market profit. Simultaneously, the WWF had a well-organized multidisciplinary team and when it discovered a network with few actors and good opportunities for lobbying a state actor like DG Environment (which had little in-house expertise ${ }^{70}$ ), the WWF immediately jumped at the chance.

Following the principles of the "trustworthy" type, the WWF established both trust status and irreplaceability; Trust status towards the commission officials and irreplaceability towards other actors, after its incorporation in the corporate decisionmaking system of the DG Environment concerning Natura 2000. Thus, when it submitted its unofficial "Shadow" lists suggesting biotopes to be protected by Natura 2000 , these were much more acceptable and 'important" than the official suggestions of the exploitation interest groups.

As we have remarked, an actor is considered by others to provide "important" information when it has previously acquired trust or irreplaceability status. The new power dimension that appears for the first time here is financial incentive (gaining dependence of others on the basis of favorable material resources or in other words "legal" or "illegal" bribery). The incentive is strongly related to information 'Importance". Let's present a hypothetical example from corruption theory:

A union of agro-forestry consultants that has already gained enough trust can suggest only one advantageous technique for combating a virus, as long as it profits by this and it never 'discloses' another technique. As long as these consultants are the only 'experts' in an environmental-rural network, they can monopolize the dependence of their clients (e.g. agricultural unions), selling 'unique' consulting. The clients may also consider these 'unique' solutions as 'favorable' under these monopoly conditions. And these monopoly conditions are ultimately maintained by the communicative isolation induced by the CCGI (and the CCSI) of the consultants. This example helps us understand better why the control of information channels,

\footnotetext{
${ }^{70}$ The lack of autonomous state expertise is as discussed usual in the EU institutions.
} 
CBGI, so visibly increases along with the importance of the provided information (CCGI and CCSI). Blind trust and the consequent failure to search for other alternatives leads to an over-concentration of competencies and power on the persuasive actor (e.g. consultants). This fosters the possibility to control others by offering financial incentives (cf. HEIDENHEIMER/ JOHNSTON 2002).

In the case of the "o mniscient" type, first the status of trust or irreplaceability is generated. These power dimensions can be effectively practiced by providing information (norms and factors) that are considered by other actors to be "important", due to an established institutional infrastructure of trust- or irreplaceability-based hierarchy. So, information plays the role of a driving means. Afterwards, using this means, the actor can further strengthen the power status he already has by inducing monopoly conditions (communicative isolation) and offering 'attractive' or 'unique' incentives (external accumulation of power ${ }^{71}$ ).

- The relevance of "Important" scientific information

A similar explanatory discourse also applies to the so-called "importance of scientific information". However, a strong scientific image (namely an image of "objectivity") is based on trust status rather than irreplaceability. As we observe in the coefficients of the "omniscient" type, a scientific image does not produce any additional opportunities to give incentives and only remains a driving force within restricted sub-networks. Examples of such sub-networks are the so-called "policy core beliefs" (SABATIER 1998, p. 99-100, 121). These are essentially different interpretations of a relatively abstract and (thereby) generally acceptable ideology. As mentioned above, for the ideology of "sustainability certification" there are, using an example, two main interpretations: the criteria of the "forest stewardship council" and those of "pan -European forest certification".

The first interpretation has been adopted by conservation groups and the second one by market-oriented groups. They have thus built two different policy-subsystems (coalitions) based on two different criteria systems which of course were derived

\footnotetext{
${ }^{71}$ This external accumulation should cause any confusion about the "omniscient" type. The factors of this type are still related to implementation and not to generation of power. The incentive is originally generated through the trust and not by the organizational or network factors.
} 
through selection and emphasis of different scientific facts according to respective political values (cf. ELLIOT 1999). For example, in their political argumentation exploitation groups accent to the impact of natural-economic factors (such as rural and forest working and production systems), while conservation groups accent impacts of wood industry development on cultural values etc.

- The relevance of controlling general communication

In our examination of autocorrelation we have already discussed why controlling general information channels is so strongly related to general information "Importance". Practically, the powerful actor achieves coordination through the CBGI. If we accept the coordination definition suggested by SIMON (1981, p.166) that coordination consists of the acceptance of the same decision by all actors in a network- then through the control of general communication, the powerful actor is able to gain the attention of the others to only hear its own argumentation, thus withdrawing other possibly antagonistic alternatives that are suggested by other actors. In this way, the powerful actor drastically improves its chances of being accepted by the others.

It is observable that the CBGI is only related to the incentive and no other power dimension. This is an argument for the hypothesis that the control of general communication is only generated by the information "importance" as discussed above and not directly by trust status or irreplaceability like the CCGI. Afterwards, through the control of general communication, powerful actors create the "untransparency" necessary to continue to practice its own gift giving and gain the control, undisturbed by any potential competitors. Such communication is a very critical function, especially in liberal networks, because there are none of the traditional obstacles to maintaining unsurpassable boarders between classes and thereby maintaining a stable hierarchy (no holy values or "mysterious" authoritative powers) (KECK 1991, p.324, JORDAN/ MALONEY, 1997). The only obstacle is the lack of an overview; the inaccessibility to critical data about where the chances are and where the traps are located. We could in other words say the communication control further "assures" the monopoly of informat ion (persuasion) and helps an actor establish itself as a legitimate and "irreplaceable" provider of financial incentives, with which it controls the behavior of receivers (s. following figure). 


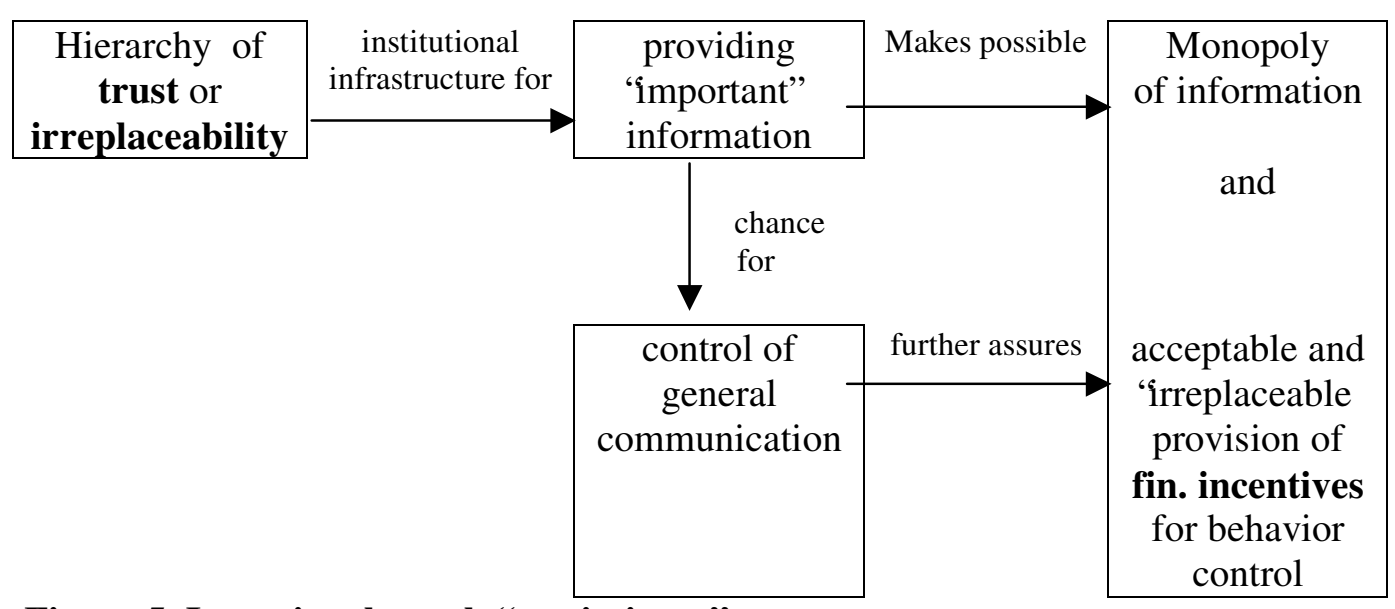

Figure 5. Incentive through 'omniscience"

\subsection{Analysis of network factors}

- The relevance of relative density of incentive

The role of RELDEINCE has already been discussed in the examination of autocorrelations. As we observe in the power anatomy of the omniscient type, the RELDEINCE makes a negative impact on the trust status development (affecting the disposition for generalized exchange relations). Therefore, RELDEINCE can be considered to directly impede on the positive impact of the CCGI and the CCSI as both of them are directly dependent on trust status, and thus the positive impact of the CBGI, which is produced by the CCGI, is also indirectly dependent.

Table 24. Qualitatively analyzed relations between network and organizational factors

\begin{tabular}{|l|l|l|l|}
\hline \multicolumn{1}{|c|}{ Organizational factors } & CCGI & CCSI & CBGI \\
Network factors & & & \\
\hline RELDEINCE & - & - & - \\
\hline
\end{tabular}

(-): impeding positive or aggravating negative impact

$(+)$ : favoring positive or mitigating negative impact 


\subsection{Empirical case of 'omniscient" type}

The nearest case to an actor that implemented its power as an "omniscient" type was the Swedish Association for Nature Conservation in the Swedish network of key biotopes. This issue concerned the characterization of certain areas as "conservation areas". The us ual conflicts between environmental and market-oriented groups appeared.

This association had an eminent power status $(14,34)$ in the network, while its main opponent (a state forest service) had only 3,71. This eminent power status enabled the association to impose its own general arguments and scientific facts as quite important (CCGI=12,13 and CCSI=12,38). Its scientific and general arguments were considered and taken seriously not only by regional agencies of environmental protection, but also by regional forestry agencies and big forest companies (like StoraEnso and Holmen). Due to its long involvement in environmental policy issues, this association managed to develop and maintain multiple contacts. Thus, it could play the role of the go-between for this issue $(\mathrm{CBGI}=17,28)$. This role was strengthened by its "importance" image in general and scientific argumentation, which attracted the attention of other actors and kept possible competitors away. Under these conditions, this association is also preferable as an incentive giver, who supports legitimate projects. The relative density of commitment in this network was relatively low $(12,07)$. Hence, as economic needs are not so decisive, the legitimization (plausible argumentation) maintains its eminent importance for decision-making.

Several networks had a lower relative density of incentives than the average $(15,69)$ and thus offered good chances to actors that want to implement their power as omniscient types. These were the Greek network, the two Swedish ones, the two Scottish ones, and the two German ones. In total, there were 27 actors which fulfilled the organizational characteristics for the omniscient type. 18 of them are active in the above favorable networks (1 in Greece, 6 in Sweden, 4 in UK, and 7 in Germany). From these 27 actors, 12 are public and 15 private actors. 14 deal with exploitation of natural resources, 10 with conservation, 1 is a single enterprise, and 2 are scientific institutions. 


\subsubsection{The 're -distributor"'type}

The powerful actor does not need to 'learn' but rather reconstructs. A powerful actor receives occasional general information and reconstructs it in order to provide "Important" general and scientific information. It has its optimal chances in a network with no scientific links.

Table 25. The 're -distributor' type

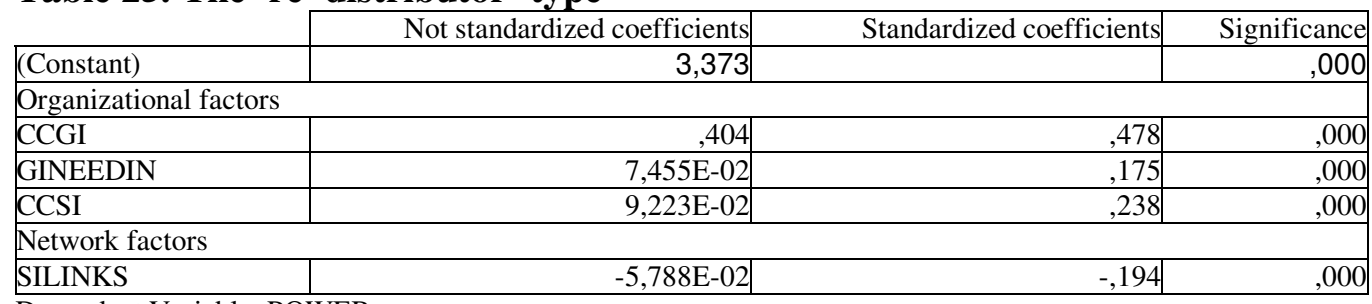

Dependent Variable: POWER

- Relevance of each factor to the composition of activated power

Table 26. Power anatomy in the 're -distributor" type

\begin{tabular}{|c|c|c|c|c|c|c|}
\hline & \multicolumn{6}{|c|}{ Dependent variables: } \\
\hline & \multicolumn{2}{|l|}{ Trust status } & \multicolumn{2}{|c|}{ Incentive status } & \multicolumn{2}{|l|}{ Irreplaceability } \\
\hline & $\begin{array}{l}\text { Standardized } \\
\text { Coefficients }\end{array}$ & $\mathrm{P}$ & $\begin{array}{l}\text { Standardized } \\
\text { Coefficients }\end{array}$ & $\mathrm{P}$ & \begin{tabular}{l|} 
Standardized \\
Coefficients
\end{tabular} & $\mathrm{P}$ \\
\hline (Constant) & & 000 & & ,916 & & ,084 \\
\hline CCGI &, 510 & ,000 & ,294 & ,001 & ,402 &, 000 \\
\hline CCSI & ,181 &, 000 & 078 & ,311 & ,109 & ,121 \\
\hline GINEEDIN & ,145 & ,001 & ,107 & 091 & ,162 &, 005 \\
\hline SILINKS &,- 239 & ,000 &,- 009 & ,895 &,- 075 & ,235 \\
\hline
\end{tabular}

- Examination of autocorrelations: 4 out of $6(67 \%)$ overlappings

Table 27. Autocorrelations in the 're -distributor" type

\begin{tabular}{|r|r|r|r|}
\cline { 2 - 4 } \multicolumn{1}{c|}{} & CCGI & CCSI & GINEEDIN \\
\hline CCGI & 1 & & \\
&, & & \\
\hline CCSI & $\mathbf{, 6 0 3}$ & 1 & \\
& $\mathbf{, 0 0 0}$ &, & \\
\hline GINEEDIN &, 015 &, 003 & 1 \\
&, 820 &, 961 & $\mathbf{- , 2 1 1}$ \\
\hline SILINKS & $\mathbf{- , 4 2 2}$ & $\mathbf{- , 2 0 1}$ & $\mathbf{, 2 1}$ \\
& $\mathbf{, 0 0 0}$ & $\mathbf{, 0 0 2}$ & $\mathbf{0 0 1}$ \\
\hline
\end{tabular}

The positive relation between CCGI and CCSI has already been analyzed in the "omniscient" type. Two new factors come up in the re -distributor type: the occasional reception of information (GINEEDIN) and the absolute number of the scientific information links within a network (SILINKS). The occasional reception of information does not contain many autocorrelations. On the contrary, scientific links 
prove to be an impeding factor to all three organizational factors. To look deeper into this function of scientific links, we have to consider them an indicator of intensity (frequent and extensive discussions) and freedom of expression within scientific communication. Thus, as the absolute number of scientific links increases within the network, the more difficult it becomes for each actor to gain the "blind" trust of others. Or in other words, it looks as if everybody has access to a certain expertise and thereby control.

\subsection{Analysis of organizational factors}

- The relevance of the "importance" of general information

The role of the CCGI has already been discussed in the relevant paragraph on the "omniscient" type. Both in the "omniscient" and in the "re -distributor" type, the CCGI is generated by the presence of trust or irreplaceability and can consequently set the stage for incentive giving as well. The only difference in the "re-distributor" type is that the network factor impeding the positive impact of the CCGI is not RELDEINCE but intensive scientific communication (SILINKS). As we have discussed, it impedes the development of trust-based general information image.

- The relevance of the "importance" of scientific information

The role and the generation of the CCSI has been analyzed in the "omnis cient" type. In the case of the "re-distributor" type, we can additionally remark that the CCSI of each individual actor is impeded by the science intensity of the network. Numerous scientific links and contacts automatically means larger accessibility for actors to alternative scientific sources. In this way, it is much more difficult for an actor to develop a high CCSI and gain the monopoly of the scientific communication in the network.

- The relevance of occasional reception of general information

This is the characteristic organizational factor of the "re-distributor" type. The "re distributor" receives current information from other actors in a network (monitoring, OSTROM 1999). This information is, probably, to a large extent directly relevant to a 
specific issue and is expected to illuminate the current strengths, weaknesses and interests of others. This occasional information also has the advantage of flexibility as it is only directly captured by the first contact partners (it is measured like the indegree and not for example as a status which would mean a chain of successive dependence).

We observe that GINEEDIN relates only to irreplaceability and trust status; an actor that possesses an irreplaceable position or has gained enough trust can also have a closer access to actual information. An explanation of this function could be that powerful actors that do not control the general communication have at least the potential to receive actual information from others and thereby strengthen the construction of "important" information that is (and should be) relevant to the specific issue and interesting to other participants. In this way, it tries to persuade them. Simultaneously, powerful receivers defend themselves against being persuaded and misled by other relatively powerful actors. Namely, they evaluate ${ }^{72}$ received information (meaning they extract more or different conclusions from information than what merely the senders expect). In other words, GINEEDIN plays a double role; an offensive one (strengthening of persuasion) and a defensive one (evaluation) (GILL 1994, p.173).

Thus, GINEEDIN is not derived from the CCGI like the CBGI in the case of the "omniscient" type, but inversely, the CCGI is strengthened through actual GINEEDIN. Simultaneously, the CCGI may also be strongly based on trust status and irreplaceability exactly as in the case of the "omniscient"type. As a next step, the CCGI is powerful enough to create a chance for monopoly and gaining incentive even without the subsidiarity of the CBGI, like in the "omniscient" type (s. figure 6 achieving similar results through different means).

\footnotetext{
${ }^{72}$ At this point, we also should clarify that the information reception does not break the proverb and the Simons hypothesis- that "the powerful does not need to learn"; The powerful may here receive information not passively as a "good apprentice" but rather selects and reconstructs it critically so as to manipulate the communication to its own advantages.
} 


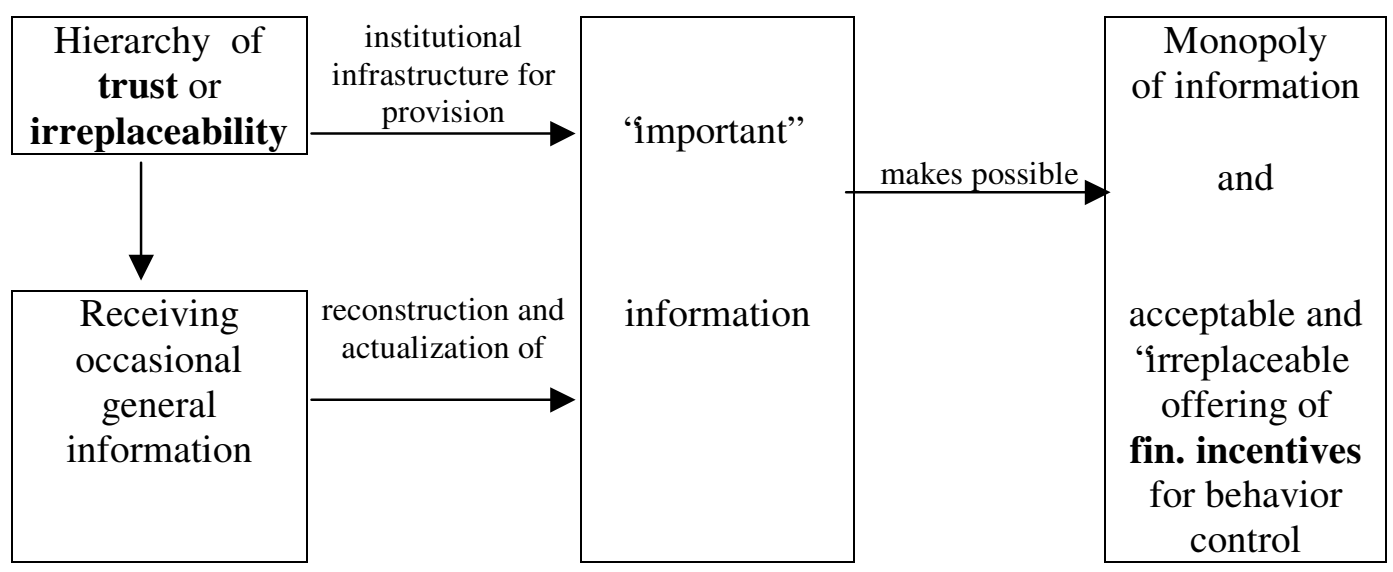

Figure 6. Incentive through 're -distribution"

Within a network with strong scientific pluralism (high SILINKS) it becomes much more difficult for an actor to access 'exclusive' relevant information about a particular issue - information that can be used for constructing valuable "Important" information able to monopolize the attention of the others.

A characteristic example of a "re -distributor" was a union of agricultural producers that had its own environmental lawyers. In the network of the directive Natura 2000 in Brussels (1999), the exploitation groups were rather inexperienced with this issue, as they had not dealt with the policy-making procedures of the DG Environment for a long time. This union easily implemented its trust status as it was able to receive, understand and reconstruct the strengths and weaknesses of the directive and to provide the concerned exploitation groups with 'important" advise and arguments.

\subsection{Analysis of network factors}

- The relevance of scientific links

The negative impact of scientific links (scientific pluralism) has already been discussed. We can conclude that with the proliferation of the scientific information links, the critical attitude (control) of each actor toward others increases and the development of trust status becomes more difficult for everyone. Obviously, an actor which is going to 'sell' information based on its trust status does not have such optimal chances in a network where science is accessed by everyone. We can summarize the impact of the SILINKS on other organizational factors as follows: 
Table 28. Qualitatively analyzed relations between network and organizational factors

\begin{tabular}{|l|l|l|l|}
\hline \multicolumn{1}{|c|}{ Organizational factors } & CCGI & CCSI & GINEEDIN \\
Network factors & & & \\
\hline SILINKS & - & - & - \\
\hline
\end{tabular}

(-): impeding positive or aggravating negative impact

$(+)$ : favoring positive or mitigating negative impact

\subsection{Empirical case of 're -distributor" type}

Two organizations are quite close to implementing their power as "re -distributors": the WWF and Nependesh in the network of Denmark. This network is concerned with the certification of sustainability. Both organizations are oriented towards nature conservation. They have a power status equalling 11,11 and 10,7 respectively. CCGI $=11,02$ and 11,94. GINEEDIN= 9,25 and 7,5. CCSI $=28,09$ and 26,97. The network where they participate has SILINKS $=10$, which is markedly lower than the average $(21,97)$. They trust each other. Despite their conflicts with market-oriented actors (certain forest agencies and forest owners), their general and scientific arguments seem to find great resonance with most actors of both parts. They also receive information from many actors, even those they have conflicts with or mistrust, because this information helps them understand more or different things than the information givers want to understand. They evaluate their information. Thus, they are able to assess the strengths and weaknesses of other actors, and so thus offer them the arguments that they will accept. Actors that employ scientific tools can evaluate such arguments more critically. But in this network, science seems to play a rather minor role (the scientific information links are only 10\%). Thus, scientific information provided by the WWF and Nependesh is easily accepted. These two organizations also play the role of a legitimate incentive giver to conservationoriented groups and also to syndicates of industry and forest workers.

Several networks proved to have a low number of scientific information links and thus to be favorable to actors that want to implement their power as "re-distributors". These were the two Swedish networks, the research project castanea in Spain, the Greek one, the two German ones, the Danish one and the Irish one. All in all, 22 actors fulfil the organizational characteristics for the re-distributor type. 17 of them appear in favourable networks listed above: 5 in Sweden (key biotopes), 3 in Spain (castanea research project), 1 in Greece, 5 in Germany, and 3 in Denmark. None of these "good" re -distributors appear in the Swedish network of the forestry strategy or 
in Ireland. Thus, we can practically say that these two networks are not used as effectively by actors who seek to implement their power by adopting the redistributor type. These 22 actors include 10 public and 12 private ones. 11 are exploitation-oriented, 9 are conservation-oriented, 1 is a single enterprise, and 1 is a scientific institution.

\section{Summary:}

In general, trust makes up $82 \%$ of the power composition, while the incentive is only $8 \%$ and the irreplaceability only $10 \%$.

Not all the network characteristics and organized interest models proposed until now have proven relevant to our 3-dimension power definition, rather only some of them in certain combinations. Of these combinations are the five types:

The "lawful" type: An actor with a multidisciplinary team that is lawful but not state controlled has optimal chances in ,non-crowded“and mono-sectoral networks with intensive state contacts, where the state does not play any important role.

The "trustworthy" type: A trustworthy actor with a multidisciplinary team has optimal chances in a ,non-crowded" network with intensive state contacts and low importance of state.

The "little brother" type: An actor with powerful partners and various financing resources has optimal chances in a mono-sectoral network with 'equal chances', where many possible contacts remain unexplored.

The "omniscient" type: An actor can implement its power by imposing general or scientific information as "Important" on a network with little material needs.

The "re-distributor" type: The powerful actor does not need to 'learn' but rather "reconstruct". A powerful actor receives occasional general information and reconstructs it in order to provide "Important" general and scientific information. It has optimal chances in a network with no scientific links.

The first three types include organization-related factors that are used for accumulating power, while the last two include communication-related factors (information) that are used for implementing accumulated power.

Phenomena of external power accumulation (like incentive through trust) have been analyzed. In general, the five types were qualitatively discussed and the role of information was analyzed. With these arguments, we bolster SIMON's theory that there is no objectively "important" information that produces power, b ut powerful actors can impose their information as "important".

Also, not all of the above mentioned power-relevant factors are equally relevant to all three power dimensions. In the first three types, only trust and irreplaceability are accumulated. In the last two, incentive is also generated on the basis of trust and irreplaceability, using information as a driving force. 


\section{Discussion: What is expected to be 'original"'on this work}

\subsection{Integration of the new results into the existent theory}

Theoretically, our findings do not contradict any previous theories but rather specify and support them. We have formulated five types that combine organizational $(\mathrm{O})$ and network $(\mathrm{N})$ factors, producing maximal power $(\mathrm{P})$ synergy $[\mathrm{P}=f(\mathrm{O}, \mathrm{N})]$. Our findings also support and specify New Institutionalist theory, particularly actorcentered institutionalism (SCHARPF 1997), since we show that the power of an actor depends on both actor- and network-related factors. These five types connect theoretical models corresponding to organizational factors with descriptive network dimensions (combination of deductive and inductive process). This research may also serve as a possible example for typology methods in future research. Additionally, we have tried to clarify processes of power generation, implementation and accumulation (external, internal, s. POPITZ 1992).

Moreover, we have also seen that the distinction between the general and scientific information is a power-relevant distinction and we have argued that the distribution of "important" information (and information control) is an effect and not a potential of power. Information becomes a driving force that is applicable only when the power already exists. In this work, Simon's hypothesis has been empirically supported and further specified. While Simon had already distinguished information "Importance" from power, he had not clarified that not only is information "importance" an effect of power and thus a means to implement it as a driving force, but information control is also directly produced by the information "importance". And this information control is exactly what he has called "coordination" (namely making all other participants follow the same decision). Finally, a general finding that completes Simon's theory is that Simon's arguments regarding the behavior of individuals (physical persons) within an interest group is also comparable and applicable to the study of communicative behavior of interest groups within a network. This strengthens the approach of many new institutionalist studies, which regard organizations as entities analogous to physical persons, who are active in wider systems (networks) and thus should be examined using a combination of rational economic and sociological approaches (PAPPENHEIM 2000). 
Empirically, an operational power definition for policy networks (namely beyond the dyads) has been suggested and tested. Our findings regarding the anatomy of power ( $82 \%$ trust, $12 \%$ irreplaceability and $8 \%$ financial incentives) may be regarded as a quite important result, because trust seems to be the most relevant power dimension in the political arena (rather than for example money or institutional pressure). Through a combination of deductive and inductive processes, the five types of power factors (lawful, trustworthy, little brother, omniscient, and re-distributor) connect network variables which have until now been used in descriptive network models with organizational variables that relate to organizational theory (mainly contingency theory, resource-dependence and transaction-cost model and decision-making theory).

The variables of our typology are measured by operational indicators which specify organizational potentials and network dimensions suggested by several authors in qualitative and descriptive form. These have been discussed in section 2. This specification may be regarded as an empirical support for the qualitative potentials and dimensions suggested until now, which discloses their immanent properties (relation to power and to each other) and makes them more operational for policy consulting $^{73}$. Here, we will concisely present them using the following two tables:

\footnotetext{
${ }^{73}$ Certainly, as already said, these types are not the only which can emerge and serve here rather as an example of typology and illustration of theories. A larger number of more "secure" types can emerge in future research by a greater empirical sample.
} 
Table 29. Completion and specification of previous models of Theory of Organized Interests

\begin{tabular}{|c|c|c|c|c|c|}
\hline \multirow[t]{2}{*}{$\begin{array}{l}\text { Our operational } \\
\text { organizational factors }\end{array}$} & \multirow{2}{*}{$\begin{array}{lr}\text { Previously suggested } \\
\text { qualitative } \\
\text { organizational } \\
\text { (structures } & \text { factors } \\
\text { potentials) } & \text { and } \\
& \end{array}$} & \multirow[t]{2}{*}{ Author } & \multicolumn{3}{|c|}{$\begin{array}{c}\text { Impact on power dimensions } \\
\text { (during their accumulation or } \\
\text { implementation) }\end{array}$} \\
\hline & & & Trust & Incentive & $\begin{array}{l}\text { Irreplaceab } \\
\text { ility }\end{array}$ \\
\hline \multicolumn{6}{|l|}{$\begin{array}{l}\text { Structure-related } \\
\text { factors } \\
\text { (relevant to power } \\
\text { accumulation) }\end{array}$} \\
\hline $\begin{array}{l}\text { Multidisciplinarity } \\
\text { MULTIDIS }\end{array}$ & Expertise & $\begin{array}{l}\text { BURKOLTER- } \\
\text { TRACHTEL (1981) } \\
\text { KROTT (2001) } \\
\text { ALEMANN (1996) } \\
\text { NOLLERT (1997) } \\
\text { SIMON (1981) } \\
\text { MAJONE (1989) } \\
\end{array}$ & + & $\mathbf{0}$ & $\mathbf{0}$ \\
\hline $\begin{array}{l}\text { Radicalism } \\
\text { RADICALI }\end{array}$ & $\begin{array}{l}\text { (opposite formulation: } \\
\text { cooperation with the } \\
\text { state) }\end{array}$ & $\begin{array}{l}\text { KROTT (2001) } \\
\text { ALEMANN (1996) }\end{array}$ & - & $\mathbf{0}$ & - \\
\hline $\begin{array}{l}\text { State character } \\
\text { STATECH }\end{array}$ & $\begin{array}{l}\text { Incorporation in public } \\
\text { organizations }\end{array}$ & KROTT (2001) & - & $\mathbf{0}$ & $\mathbf{0}$ \\
\hline $\begin{array}{l}\text { Trustworthiness } \\
\text { TRUSTWOR }\end{array}$ & Reputation & \begin{tabular}{|l|} 
BUSKENS (1999) \\
BURKOLTER- \\
TRACHTEL (1981) \\
\end{tabular} & + & $\mathbf{0}$ & + \\
\hline $\begin{array}{l}\text { Number of alternative } \\
\text { financing } \\
\text { resources } \\
\text { FINRESOU }\end{array}$ & Financial resources & KROTT (2001) & + & $\mathbf{0}$ & $\mathbf{0}$ \\
\hline \multirow[t]{2}{*}{$\begin{array}{l}\text { Partners strength } \\
\text { PARTNSTR }\end{array}$} & Political support & $\begin{array}{l}\text { HENNING/ WALD } \\
(2000)\end{array}$ & \multirow[t]{2}{*}{+} & \multirow[t]{2}{*}{$\mathbf{0}$} & \multirow[t]{2}{*}{$\mathbf{0}$} \\
\hline & Coalitions & KROTT (2001) & & & \\
\hline \multicolumn{6}{|l|}{$\begin{array}{l}\text { Communication- } \\
\text { related factors } \\
\text { (relevant to power } \\
\text { implementation) }\end{array}$} \\
\hline $\begin{array}{l}\text { Importance of general } \\
\text { information CCGI }\end{array}$ & $\begin{array}{l}\text { Attention given to } \\
\text { information }\end{array}$ & SIMON (1981) & + & + & + \\
\hline \multirow{2}{*}{$\begin{array}{ll}\text { Importance } & \text { of } \\
\text { scientific } & \\
\text { information CCSI }\end{array}$} & $\begin{array}{l}\text { Attention given to } \\
\text { scientific information }\end{array}$ & SIMON (1981) & \multirow[t]{2}{*}{+} & \multirow[b]{2}{*}{$\mathbf{0}$} & \multirow[b]{2}{*}{$\mathbf{0}$} \\
\hline & $\begin{array}{l}\text { Exchange of expert } \\
\text { information }\end{array}$ & $\begin{array}{l}\text { HENNING/ WALD } \\
(2000)\end{array}$ & & & \\
\hline $\begin{array}{l}\text { Control of general } \\
\text { information CBGI }\end{array}$ & Coordination & SIMON (1981) & $\mathbf{0}$ & + & $\mathbf{0}$ \\
\hline $\begin{array}{l}\text { Occasional } \\
\text { information } \\
\text { reception } \\
\text { GINEEDIN } \\
\end{array}$ & Monitoring & $\begin{array}{l}\text { OSTROM (1999), GILL } \\
(1994)\end{array}$ & + & $\mathbf{0}$ & + \\
\hline
\end{tabular}


Table 30. Specification of previous network dimensions

\begin{tabular}{|c|c|c|c|c|c|}
\hline \multirow{2}{*}{$\begin{array}{l}\text { Our operational } \\
\text { network factors }\end{array}$} & \multirow{2}{*}{$\begin{array}{c}\text { Similar suggested } \\
\text { qualitative network } \\
\text { dimensions }\end{array}$} & \multirow[t]{2}{*}{ Author } & \multicolumn{3}{|c|}{ Impact on power dimensions } \\
\hline & & & Trust & Incentive & Irreplaceability \\
\hline $\begin{array}{l}\text { Actor number } \\
\text { ACTORS }\end{array}$ & Actors & $\begin{array}{l}\text { WAARDEN (1992) } \\
\text { BLOM-HANSEN (1997) } \\
\text { MARSH/ RHODES } \\
(1992) \\
\text { HENNING/ WALD } \\
(2000) \\
\text { JORDAN/ SCHUBERT } \\
(1992)\end{array}$ & - & $\mathbf{0}$ & - \\
\hline $\begin{array}{l}\text { Intersectorality } \\
\text { INTERSEC }\end{array}$ & $\begin{array}{l}\text { Scope of policy- } \\
\text { making, uncertainty, } \\
\text { social entropy }\end{array}$ & $\begin{array}{l}\text { OSTROM (1999) } \\
\text { O' TOOLE/ MEIER } \\
(1999,2001), \text { JORDAN/ } \\
\text { SCHUBERT }(1992)\end{array}$ & - & $\mathbf{0}$ & $\mathbf{0}$ \\
\hline $\begin{array}{l}\text { Potential lobbying } \\
\text { POTLOBB }\end{array}$ & Segmentation & $\begin{array}{l}\text { HENNING/ WALD } \\
(2000)\end{array}$ & + & $\mathbf{0}$ & + \\
\hline $\begin{array}{l}\text { Relative importance of } \\
\text { the state } \\
\text { RELIMPST }\end{array}$ & $\begin{array}{l}\text { Power distribution } \\
\text { (State dominance), } \\
\text { autonomy of private } \\
\text { actors }\end{array}$ & $\begin{array}{l}\text { WAARDEN (1992) } \\
\text { OSTROM (1999) }\end{array}$ & - & $\mathbf{0}$ & - \\
\hline $\begin{array}{l}\text { Power equality } \\
\text { POWERINE }\end{array}$ & $\begin{array}{l}\text { Structure, uncertainty, } \\
\text { social entropy } \\
\text { (Linking pattern) }\end{array}$ & $\begin{array}{l}\text { O' TOOLE/ MEIER } \\
(1999,2001), \text { WAARDEN } \\
(1992)\end{array}$ & - & $\mathbf{0}$ & - \\
\hline $\begin{array}{l}\text { Density } \\
\text { DENSITY }\end{array}$ & $\begin{array}{l}\text { Structure, uncertainty, } \\
\text { social entropy } \\
\text { (Density) }\end{array}$ & $\begin{array}{l}\text { O' TOOLE/ MEIER } \\
(1999,2001), \text { WAARDEN } \\
(1992)\end{array}$ & - & $\mathbf{0}$ & - \\
\hline $\begin{array}{l}\text { Relative density of } \\
\text { incentive } \\
\text { RELDEINCE }\end{array}$ & $\begin{array}{l}\text { Structure } \\
\text { (Multiplexity) }\end{array}$ & WAARDEN (1992) & - & $\mathbf{0}$ & $\mathbf{0}$ \\
\hline $\begin{array}{l}\text { Scientific information } \\
\text { links } \\
\text { SILINKS }\end{array}$ & Expert information & $\begin{array}{l}\text { HENNING/ WALD } \\
(2000)\end{array}$ & - & $\mathbf{0}$ & $\mathbf{0}$ \\
\hline
\end{tabular}

A new formula that has also been applied here and has proven to have quantitative properties for further research is the oligarchy (power inequality):

Oligarchy $=\frac{\text { Status } \max -\text { Status } \min }{\text { AverageStatus }}$ 


\subsection{Methodological aspects: strengths and weaknesses of this work}

We have already discussed the advantages and disadvantages of the complete network analysis in section 3. Here, we can present these more systematically and concisely (table 31):

Table 31: Evaluation of complete network analysis

\begin{tabular}{|c|c|}
\hline \multicolumn{2}{|c|}{ Complete network analysis } \\
\hline Advantages & Disadvantages \\
\hline - Disclosure of latent structures (oligarchy) & - Self-selection \\
\hline $\begin{array}{l}\text { - Operationalization of power and measurement of } \\
\text { relative positions (e.g. status or in-degree) and } \\
\text { policy impact of subjective factors (cross- } \\
\text { assessment variables like radicalism, } \\
\text { trustworthiness) }\end{array}$ & $\begin{array}{l}\text { - Small size } \\
\text { - Weakness of telephone interviews }\end{array}$ \\
\hline - ‘Objective” bounding (by the participants) & $\begin{array}{l}\text { - Many autocorrelations of independent variables } \\
\text { are possible }\end{array}$ \\
\hline
\end{tabular}

Because of the relatively "small" size of our sampling, the results (five types) could be confronted with criticism by empirical researchers or practitioners. These comments would also not be definitive and complete because they would be based on restricted parts of reality (normative bounding according to the observation capacity or interests of each commentator) or on norms (feelings, prejudices or political tasks and values) that practitioners often call "experience". The complete bounding of our network analysis would be confronted with this "experience" and the discussion would remain endless. Telephone interviews are not the most reliable technique for data capture which exists. More reliable for future research would be employing additional methods like document analysis, (participant) observation, and group discussion through conferences and workshops which should be designed and planed for this purpose through a research project of several years (e.g. 3-6 years). In these, not only researchers but also stakeholders of networks would play an active role. Thus, a diachronic observation of network interactions and developments and a comparison between different conditions would be possible and the results would become more reliable for further generalizations.

The following compromise might be acceptable at this point: the advantages of the complete network analysis are obvious, but the disadvantage of the "small" size makes the results open to empirical criticism. Thus, future policy research should be carried out using the advantages of complete network analysis but employing considerably more scientific forces in order to open up much more cases (e.g. not only 12 networks incl. 234, but 100 networks incl. 2000 actors). Apart from that, the disadvantage of self-selection characterizing snowball sampling and thus making 
statistical properties ambiguous might present a future locus of research for Heckmann's models (s. above and below too).

\subsubsection{Heckman's contribution to the self-selection weakness}

The self-selection problem discussed in section 3 can be viewed as a problem of lacking observations. Wages and hours cannot be observed among non-working individuals. Likewise power status cannot be observed among non-participating actors, had they chosen to participate. To obtain unbiased estimates of basic structural parameters, the estimation procedure has to recognize that a sample of participating actors is not the result of random selection, but the result of the self-selection of individual actors implied by success maximization (with the consequent risks). This could be a future project that would have additional importance because networks are systems and not additive samples (like working individuals in a labor market) (s. section 6). This problem has already been discussed by LEENDERS (1995, p.208) as well. He has suggested that statistical models that can test theories of social networks are nonexistent due to the interdependence that characterizes social networks. Therefore, networks can only be studied through complete analysis, meaning selfselection. And we suggest that Heckman's methods could be a solution.

\section{Summary:}

The 3-dimensional power model proved to have properties for political practice and research and in this view the conception of power as a structural effect (relative position of an actor in an official or unofficial hierarchy) makes sense. There are external accumulation effects and the dimensions have significant relations to certain organizational and network characteristics. These characteristics make older models more concrete and complete, make New Institutionalism more operational for policy consulting and give further initiative to concrete research in future. The abstract mathematic instruments of quantitative network analysis and the general systemic approach have also become more operational. Combined with New Institutionalism, these instruments can make policy and organizational consulting more precise and competitive in the knowledge market. The conclusions of this work could give initiatives for applying network analysis to other areas (such as corruption that resembles incentive). The work of Heckman on self-selection seems to be applicable to network analysis (snowball sampling). 


\section{Conclusions}

\subsection{Theoretical conclusions}

The main theoretical result of this work is that not every actor is powerful in every network because power depends on both organizational and network factors, as the recent New Institutionalist hypotheses have claimed.

While many models until now have dealt with the question of how a network emerges or changes and how an actor reacts, we have dealt with the question of who holds power in a network and have suggested a specific approach for assessing power. We have also tried to derive specific power types from abstract theoretical models. We have operationalized dimensions suggested for describing networks as well as organizational factors that have been suggested in the Theory of Organized Interests. According to our results, not all of them were relevant to our power definition, only ten organizational factors (multidisciplinarity, system conformity, administrative autonomy from the state, trustworthiness, alternative financing resources, partners strength, "importance" of general and scientific information, control of general information, receiving of occasional information).

From these organizational factors the first six are organization-related (dependent on the internal structure or the external behavior of an actor) and through the qualitative analysis we have argued that they generate power. The last four are communicationrelated (information exchange) and we have argued that they do not generate but activate existing power (they are used as means of implementation means, or in other words, driving forces).

From the network factors we have extracted only eight (number of actors, intersectorality, potential lobbying, relative importance of the state, power inequality, density, relative density of incentive, number of scientific information links). Once again the first six make an impact on power generation and the last two on power implementation.

From these organizational and network factors we have extracted five power-relevant combinations (patterns), which constitute our quantitative typology (the main aim of this work). We can conclude that the old descriptive typologies of political networks have been a foundation upon which we have built our power factors typology in this work, but to a large extent they were not power-relevant (low explanatory value) and 
one could not assess the power development using them. The same also applies to the organizational factors.

Our distinction between power generation and power implementation factors was based on the SIMON's theory and on our own empirical results. SIMON's theory has also been supported by our empirical results, in that it argued that information (exchange) is not a power resource but a power effect. More concretely, an actor does not become powerful because it possesses "important" information but it imposes its information as "important" due to already possessing a strong power position.

It is also remarkable that each organizational and network factor does not make the same impact on all power dimensions (trust, incentive and irreplaceability). These three dimensions generate each other: specifically incentive is generated by trust through communication mechanisms (information "importance" and control) or irreplaceability. Irreplaceability may be also based on trust. This is a characteristic example of external power generation (instrumental power from authoritative power). It illustrates the hypothesis of POPITZ about the external power generation.

Trust plays the most important role in the power composition (82\%), though it is an unofficial dimension. The other two dimensions, incentive and irreplaceability, can be said to have an official character. For example, when incentive occurs on the basis of favorable support that is officially provided in the political program for participants who help achieve its realization; or when an actor is irreplaceable because it possesses an official position in the network (e.g. program coordinator). Looking back on the power pyramid (oligarchy) we can visualize a network as a certain hierarchy (sharp or flat, official or unofficial). Thus, the hypothesis of network and system theory that power is a structural phenomenon is verified (even if this structure is unofficial and latent). New Institutionalist theory is proven accurate once again at this point because the examination of the unofficial structures pertains to its assumptions and targets.

\subsection{Suggestions for the political practice}

What we can accent here is the need for replacing certain prejudices that can dominate political practice with viable generalizations of wide acceptability and practical relevance. This is possible by using quantitative results that illustrate and specify existent qualitative theories. In this way, abstract theories become more concrete and plausible, while the risk of deceptive ad hoc hypotheses is minimized. 
Based on the five quantitative patterns, one can make concrete suggestions to an actor about its policy-making and organizational structure, in order to help it become successful in its network. The combination of quantitative and qualitative approaches and the need for competent assessment improves the chances for social scientists to be competitive on the market.

In the course of analysing the "lawful" type, we have seen that the state character of an organization (to include state representatives in its organs) is more of a negative factor for the power development exactly as to be subversive to the state. With this, rather the state can control the organization than the organization maintains "good" and advantageous relations to the state. System conformity is just as practically important as independence from the state.

In course of analysing the "trustworthy" type, we have seen that trustworthiness is not identical with trust. As BUSKENS (1999) has implied, trustworthiness is a subjective impression (feeling) of each actor to another one. Trust is an objective power, which can lead trustors to success or catastrophe. Only under concrete conditions - that we have discussed - can trustworthiness be transformed into trust status or irreplaceability.

The "little brother" is the only type where certain financial factors play a role in. Obviously, financing resources do not mean everything. They can only help an actor attract more powerful actors for cooperation.

In the "omniscient" type and "re -distributor" types, we have argued that the role of information is decisive but as driving means for power implementation and not as a resource for power generation. We have also demonstrated that a powerful actor not only imposes "important" information on the less powerful actors but also receives information from the others within the network. We have also illustrated phenomena of external power accumulation (irreplaceability or incentive from trust) that could be useful for more accurate and strategic policy consulting and coordination. This apparently takes place because powerful actors need to reconstruct and re-sell actual "important" information that should look interesting to everybody.

As a final practical comment we can also point out that each power dimension is generated or activated by different factors. This should also be considered in planning policy-making or in organizational consulting. 


\subsection{Open questions for future research}

The first question would be how we could improve the use of issue-oriented networks as a statistical sample, as long as they can be relatively small and not "random" according to the conventional definition. The main corrective strategy that we have followed in our work was to weigh the disadvantage of few cases with the advantage of many variables and open up networks with successive contacts previously unknown to the researchers. In the future it would be useful to know what an optimal balance between cases and variables would be, in order to grasp the highest number of acceptable regressions in a given number of networks. One could perhaps try to optimize the ratio of significance and autocorrelations (formula 11).

A second question could be the application of Heckman's methods to network sampling. Heckman's insight is that observations are often lacking due to conscious (self-selection) choices made by the actors (ROYAL SWEDISH ACADEMY 2000, p.2). The relation between the reasons for lacking observations and the nature of nonlacking observations thus takes on an intriguing theoretical shape. This presents a challenge for further research. He has suggested the following correction (also known as the two-stage method) (formula 12 and 13 respectively):

$$
\begin{gathered}
P_{i}=x_{1 i} b_{1}+E_{1 i} \\
e_{i}^{*}=x_{2 i} b_{2}+E_{2 i}
\end{gathered}
$$

Formula 12 determines the power status of an actor, whereas formula 13 is a "participation equation" describing individual propensity to participa te. Thus, $P_{i}$ is the observed power status for an actor $\mathrm{i}$ if it participates and $e_{i}^{*}$ a latent variable that signifies the propensity to participate; $x_{1 i} b_{1}$ and $x_{2 i} b_{2}$ are vectors of observed explanatory variables, such as internal features like chairperson age or member number etc. Finally, $E_{1 i}$ and $E_{2 i}$ are stochastic errors representing the influence of unobserved variables affecting $P_{i}$ and $e_{i}^{*}$. The parameters of participation interest are $b_{1}$ and $b_{2}$.

Based on these two equations, Heckman has developed a method for the estimation of the influence of unobserved variables on a sample. In a network sampling we could also estimate the non-networked actors, if one had previously found out these vectors in the case of policy networks. 
A third research point might be a deeper qualitative analysis of the role of the information and other possible organizational and network factors in the generation of incentive. It is already remarkable that no financial factors appear to be directly relevant to incentive. Further research on incentive could also be useful for corruption research.

Finally, a fourth question would be how we could distinguish "scientific" from "general" information without being dependent on the cross -assessment between actors. To this end a clear definition of science would be necessary (for example maximally acceptable number of norms that are mixed in objective facts). Through the kind of cross-assessment we have practiced in this survey, one can actually measure the "scientific image" of each actor better than science as an objective entity.

\section{Summary:}

Theoretically, New Institutionalism and the 3-dimensional power model have proved rich in properties and seem to set a sound basis for future research. Methodologically, quantitative network analysis can be useful because it is the only method for precisely measuring structural phenomena like power, information variables etc. as well as latent (unofficial) hierarchies (as our pyramids can often be) and other structures like perceived "importance", control and occasional reception of information. The formula for oligarchy was a new suggestion that may enrich network analysis instruments. The status and indegree can be used to distinguish hierarchical (and more stable) from occasional (and less stable) structures.

The "punctuated equilibrium" between the advantages and disadvantages of the method of complete network analysis has motivated thoughts about future research questions regarding the quality of regression (high significance for dependent variables and low autocorrelations) and the insights of Heckman on the weakness of self-selection. Further research on a sharper separation between "scientific" and "hon-scientific" information could also be useful. A combined research strategy of qualitative and quantitative research (qualitative hypotheses-quantitative examination and precise explanatory models- qualitative understanding) is necessary in order to make policy consulting applicable to politics and the further theorizing more accurate. 


\section{Appendices}

\section{Operationalization of variables}

\begin{tabular}{|c|c|c|}
\hline Variable & Question & Formula \\
\hline Issue & $\begin{array}{l}\text { 1. Please mention an environmental-forest } \\
\text { policy affaire (issue) of the last } 2 \text { years, in } \\
\text { which your association was successful }\end{array}$ & $\begin{array}{|cl|}\text { Categorised as follows: } \\
- & \text { natural resource management } \\
- & \text { critical natural areas } \\
- & \text { growth management and infrastructure } \\
- & \text { air quality control } \\
- & \text { water quality control } \\
- & \text { water allocation } \\
- & \text { waste management } \\
- & \text { green technologies } \\
- & \text { energy production and distribution } \\
- & \text { historic, cultural and aesthetic resources } \\
\end{array}$ \\
\hline $\begin{array}{l}1 . \\
\text { Power (power) \% }\end{array}$ & 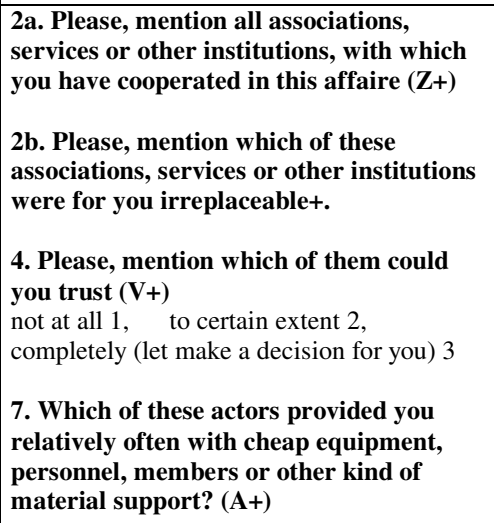 & $\begin{array}{c}\text { power }= \\
\text { trust } \\
+ \\
\text { irreplaceability } \\
+ \\
\text { incentive }\end{array}$ \\
\hline $\begin{array}{l}2 . \\
\text { Perceived } \\
\text { Power (perpower) }\end{array}$ & $\begin{array}{l}\text { 6. How successfully could you impose your } \\
\text { plan against each other of these } \\
\text { associations, services or other institutions, } \\
\text { if you wanted? (G+) } \\
\text { Not at all } 1, \quad \text { to certain extent } 2 \text {, } \\
\quad \text { completely } 3\end{array}$ & perpower $_{i}=\frac{\sum_{j}^{N} G_{i j}}{N}$ \\
\hline $\begin{array}{l}3 . \\
\text { Closeness centrality } \\
\text { of general } \\
\text { information (ccgi) \% }\end{array}$ & $\begin{array}{l}\text { 5a. Which of them provided your } \\
\text { organization with enough information (I+) }\end{array}$ & $C c_{(i)}=\left\lfloor\sum_{j} d(j, i)\right\rfloor^{-1}$ \\
\hline $\begin{array}{l}4 . \\
\text { Betweenness } \\
\text { centrality of general } \\
\text { information } \\
\text { (cbgi) } \%\end{array}$ & $\begin{array}{l}\text { 5a. Which of them provided your } \\
\text { organization with enough information (I+) }\end{array}$ & $C b_{(i)}=\sum \frac{\left|P_{i}(i, j)\right|}{|P(i, j)|}$ \\
\hline $\begin{array}{l}5 . \\
\text { Closeness centrality } \\
\text { of scientific } \\
\text { information } \\
(\text { ccsi }) \%\end{array}$ & $\begin{array}{l}5 \mathrm{~b} \text {. Please, mention } 3 \text { of them which } \\
\text { provided the scientifically most important } \\
\text { information }\end{array}$ & $C c_{(i)}=\left\lfloor\sum_{j} d(j, i)\right\rfloor^{-1}$ \\
\hline $\begin{array}{l}\text { 6. Betweenness } \\
\text { centrality } \\
\text { of scientific } \\
\text { information (cbsi)\% }\end{array}$ & $\begin{array}{l}\text { 5b. Please, mention } 3 \text { of them which } \\
\text { provided the scientifically most important } \\
\text { information }\end{array}$ & $C b_{(i)}=\sum \frac{\left|P_{i}(i, j)\right|}{|P(i, j)|}$ \\
\hline
\end{tabular}




\begin{tabular}{|c|c|c|}
\hline $\begin{array}{l}7 . \\
\text { State character } \\
\text { (statech) }\end{array}$ & $\begin{array}{l}10 . \\
\text { a. are there also state representatives in } \\
\text { the decision organs of your association } 3 \\
\text { b. your association exists because there is } \\
\text { a specific state law which demands its } \\
\text { existence } 2 \\
\text { c. or it exists only due to the initiative of its } \\
\text { members } 1\end{array}$ & $\begin{array}{l}\text { Stach }= \\
1(\mathbf{c}) \\
2(\mathbf{b}) \\
4(\mathbf{a}+\mathbf{c}) \\
5(\mathbf{a}+\mathbf{b})\end{array}$ \\
\hline $\begin{array}{l}8 . \\
\text { Legal status } \\
\text { (legalsta) }\end{array}$ & $\begin{array}{l}\text { 11a. Are the members of your association } \\
\text { - only individuals } 1 \\
\text { - only other associations } 3 \\
\text { - both of them } 2\end{array}$ & $\begin{array}{l}\text { Legalsta= } \\
1 \\
2 \\
3\end{array}$ \\
\hline $\begin{array}{l}9 . \\
\text { Organization type } \\
\text { (orgtyp) }\end{array}$ & $\begin{array}{l}\text { 11b. Is your association } \\
\text { - a local one (at the level of community or } \\
\text { city) } 1 \\
\text { - a regional one (at the level of prefecture, } \\
\text { geographical department or federal state) } 2 \\
\text { - a national one } 3 \\
\text { - an international one } 4\end{array}$ & $\begin{array}{l}\text { Orgatyp= } \\
1 \\
2 \\
3 \\
4\end{array}$ \\
\hline $\begin{array}{l}\text { 10. Non profit } \\
\text { orientation } \\
\text { (nonprofi) }\end{array}$ & $\begin{array}{l}\text { 12. How could you describe the goals of } \\
\text { your associations according to its } \\
\text { constitution in no more than } 5 \text { key words? } \\
\text {....... }\end{array}$ & $\begin{array}{l}\text { Nonprofi }= \\
1 \text { (only individual market interests) } \\
2 \text { (balanced) } \\
3 \text { (non profit) }\end{array}$ \\
\hline $\begin{array}{l}11 . \\
\text { Heterogeneity } \\
\text { (heteroge) }\end{array}$ & $\begin{array}{l}\text { 13a. (Only for exploitation groups) What } \\
\text { are the members of your association? } \\
\text { - forest owners } \\
\text { - forest enterprise owners } \\
\text { - land owners } \\
\text { - stock farmers } \\
\text { - cork producers } \\
\text { - other... } \\
\text { 13b. (Only for conservation groups) } \\
\text { Which activity sectors are you dealing } \\
\text { with? } \\
\text { - Forest protection } \\
\text { - Wildlife } \\
\text { - Atmosphere pollution } \\
\text { - Climate change } \\
\text { - Marine and coastal ecosystems } \\
\text { - other... }\end{array}$ & $\begin{array}{l}\text { Heteroge }= \\
\text { Sum of interest sectors } \\
1 \\
2 \\
3 \\
4 \\
. \\
. \\
\text {. }\end{array}$ \\
\hline $\begin{array}{l}12 . \\
\text { Involvement } \\
\text { (involvem) }\end{array}$ & $\begin{array}{l}\text { 14a. In how many state committees did } \\
\text { your association have its own } \\
\text { representatives? }\end{array}$ & $\begin{array}{l}\text { Involvem }= \\
\text { Sum of state committees } \\
0 \\
1 \\
2 \\
3 \\
4 \\
. \\
. \\
.\end{array}$ \\
\hline $\begin{array}{l}13 . \\
\text { Institutional state } \\
\text { support } \\
\text { (instasup) }\end{array}$ & $\begin{array}{l}\text { 14b. Did your association find acceptance } \\
\text { in these committees? } \\
\text { Not at all } 1 \text {, } \\
\quad \text { very much } 3\end{array}$ & $\begin{array}{l}\text { Instasup= } \\
1 \\
2 \\
3\end{array}$ \\
\hline $\begin{array}{l}14 . \\
\text { Veto right (veto) }\end{array}$ & $\begin{array}{l}\text { 14c. In how many decision-making } \\
\text { procedures did your association have veto- } \\
\text { right? }\end{array}$ & $\begin{array}{l}\text { Veto= } \\
0 \\
1 \\
2 \\
. \\
.\end{array}$ \\
\hline $\begin{array}{l}15 . \\
\text { Authorization to } \\
\text { negotiate (authoneg) }\end{array}$ & $\begin{array}{l}\text { 14d. Does your association have an } \\
\text { authorization to make binding decisions } \\
\text { for the whole sector that it represents? } \\
\text { Yes No }\end{array}$ & $\begin{array}{l}\text { Authoneg= } \\
1 / 0\end{array}$ \\
\hline
\end{tabular}




\begin{tabular}{|c|c|c|}
\hline $\begin{array}{l}16 . \\
\text { Coalition potential } \\
\text { (coalpote) }\end{array}$ & $\begin{array}{l}\text { 15a. In how many other umbrella } \\
\text { associations is your association a member? } \\
\text { (a) } \\
\text { 15b. In how many of them was your } \\
\text { association a founding member? (b) }\end{array}$ & Coalpote $=a+b$ \\
\hline $\begin{array}{l}17 . \\
\text { Number of Members } \\
\text { (memnum) }\end{array}$ & $\begin{array}{l}\text { 16a. How many members are organized in } \\
\text { your association? And if they are also } \\
\text { other associations, } \\
\text { how many are these associations } \\
\text { and } \\
\text { how many are the individuals altogether (a) }\end{array}$ & Memnum= a \\
\hline $\begin{array}{l}18 . \\
\text { Organization degree } \\
\text { (orgagrad) \% }\end{array}$ & $\begin{array}{l}\text { 16b. How many percent of the potential } \\
\text { members have been already organized in } \\
\text { your association? (a) }\end{array}$ & Orgagrad $=\mathbf{a}$ \\
\hline $\begin{array}{l}19 . \\
\text { Member strength } \\
\text { (memstren) }\end{array}$ & $\begin{array}{l}\text { 17. How many percent of your members } \\
\text { exert a relatively strong political, social or } \\
\text { economic influence? } \\
\text { 1. } 0-20 \% \\
\text { 2. } 20-40 \% \\
\text { 3. } 40-60 \% \\
\text { 4. } 60-80 \% \\
\text { 5. } 80-100 \% \\
\end{array}$ & \begin{tabular}{|l} 
Memstren= \\
1 \\
2 \\
3 \\
4 \\
5
\end{tabular} \\
\hline $\begin{array}{l}20 . \\
\text { Member } \\
\text { qualification } \\
\text { (memqual) }\end{array}$ & $\begin{array}{l}\text { 18a. How many percent of your members } \\
\text { have finished the university? } \\
\text { 1. } 0-20 \% \\
\text { 2. } 20-40 \% \\
\text { 3. } 40-60 \% \\
\text { 4. } 60-80 \% \\
\text { 5. } 80-100 \% \\
\end{array}$ & $\begin{array}{l}\text { Memqual= } \\
1 \\
2 \\
3 \\
4 \\
5\end{array}$ \\
\hline $\begin{array}{l}21 . \\
\text { Multidisciplinarity } \\
\text { (multidis) }\end{array}$ & $\begin{array}{ll}\text { 18c. } & \text { What kind of experts deal with the } \\
\text { management of your organization? } \\
- & \text { Forest scientists } \\
- & \text { Biologists } \\
- & \text { Lawyers } \\
- & \text { Economists } \\
- & \text { Political scientists } \\
- & \text { Other... }\end{array}$ & $\begin{array}{l}\text { Multidis }= \\
\text { Sum of expert sectors } \\
0 \\
1 \\
2 \\
3 \\
.\end{array}$ \\
\hline $\begin{array}{l}22 . \\
\text { Training (training) }\end{array}$ & $\begin{array}{l}\text { 18d. How many times per year does your } \\
\text { association organize seminars or other } \\
\text { meetings for the further education or } \\
\text { training of its members? (a) }\end{array}$ & Training $=\mathbf{a}$ \\
\hline $\begin{array}{l}23 . \\
\text { Financial resources } \\
\text { (finresou) }\end{array}$ & 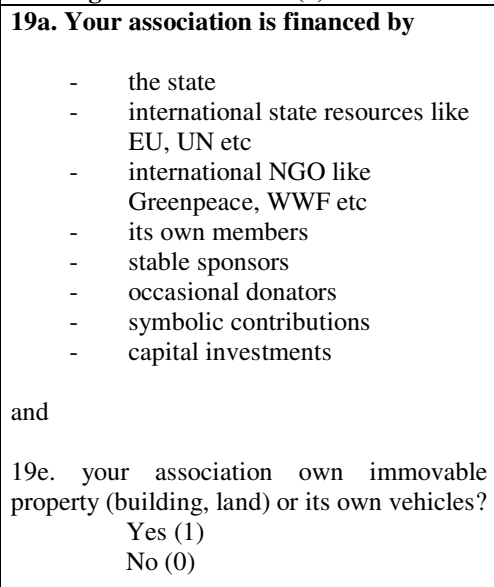 & $\begin{array}{l}\text { Finresou= } \\
19 \mathrm{a} \text { (number of sources) }+19 \mathrm{e}(0 \text { or } 1)\end{array}$ \\
\hline $\begin{array}{l}24 . \\
\text { Human resources } \\
\text { (humanres) }\end{array}$ & 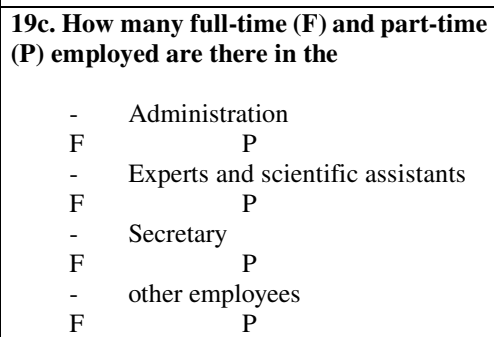 & $\begin{array}{l}\text { Humanres }= \\
4 *(\operatorname{admF}+\operatorname{admP} / 2) \\
+ \\
3 *(\operatorname{expF}+\operatorname{expP} / 2) \\
+ \\
2 *(\operatorname{secF}+\operatorname{secP} / 2) \\
+ \\
\text { otherF+otherP/2 }\end{array}$ \\
\hline
\end{tabular}




\begin{tabular}{|c|c|c|}
\hline $\begin{array}{l}25 . \\
\text { Volunteers } \\
\text { (voluntee) }\end{array}$ & $\begin{array}{l}\text { 19b. How many volunteers do you have at } \\
\text { an average in each activity? (a) }\end{array}$ & Voluntee $=\mathbf{a}$ \\
\hline $\begin{array}{l}26 . \\
\text { External consulting } \\
\text { (extcons) }\end{array}$ & $\begin{array}{l}\text { 19d. How many times per year do you } \\
\text { have external professional consulting? (a) }\end{array}$ & Extcons=a \\
\hline $\begin{array}{l}27 . \\
\text { Public relations } \\
\text { (publrela) }\end{array}$ & $\begin{array}{l}\text { 19f. How much is approx. the percent of } \\
\text { expenses for public relations (press, } \\
\text { brochures, receptions etc)? } \\
\text { 1. } 0-20 \% \\
\text { 2. } 20-40 \% \\
\text { 3. } 40-60 \% \\
\text { 4. } 60-80 \% \\
\text { 5. } 80-100 \%\end{array}$ & $\begin{array}{l}\text { Publrela= } \\
1 \\
2 \\
3 \\
4 \\
5\end{array}$ \\
\hline $\begin{array}{l}28 . \\
\text { Member renewal } \\
\text { (memrenew) }\end{array}$ & $\begin{array}{l}\text { 20. How many new members do you } \\
\text { recruit per year? } \\
\text { 1.0-20\% } \\
\text { 2. } 20-40 \% \\
\text { 3. } 40-60 \% \\
\text { 4. } 60-80 \% \\
\text { 5. } 80-100 \%\end{array}$ & $\begin{array}{l}\text { Memrenew= } \\
1 \\
2 \\
3 \\
4 \\
5\end{array}$ \\
\hline $\begin{array}{l}29 . \\
\text { Dogmatism } \\
\text { (dogmatis) }\end{array}$ & $\begin{array}{l}\text { 9. How dogmatic or flexible do you find } \\
\text { each other association? (D+) } \\
\text { - completely dogmatic (3) } \\
\text { - not so dogmatic, it has only certain reserves } \\
\text { (2) } \\
\text { - flexible enough (1) }\end{array}$ & $\operatorname{dogmatis}_{i}=\frac{\sum_{j}^{N} D_{j i}}{N}$ \\
\hline $\begin{array}{l}30 . \\
\text { Radicalism } \\
\text { (radicali) }\end{array}$ & $\begin{array}{l}\text { 8. How radical-activist do you find each of } \\
\text { the other associations? (Ex+) } \\
\text { - As radical-activist as Greenpeace or more } 3 \\
\text { - only exceptionally } 2 \\
\text { - not at all (1) }\end{array}$ & radicali $_{i}=\frac{\sum_{j}^{N} E x_{j i}}{N}$ \\
\hline $\begin{array}{l}31 . \\
\text { Internal competence } \\
\text { concentration } \\
\text { (intcomco) }\end{array}$ & $\begin{array}{l}\text { 16a. How many members are organized in } \\
\text { your association? And if they are also } \\
\text { other associations, } \\
\text { how many are these associations } \\
\text { and } \\
\text { how many are the individuals altogether } \\
\text { (a=memnum) } \\
\text { 22a. How many members constitute the } \\
\text { Board of your association? (BM) } \\
\text { 22b. How often do you call an election } \\
\text { according to the constitution? (1 board } \\
\text { election/ } X \text { year) } \\
\text { 22d. How many times per year holds the } \\
\text { General Assembly a meeting, if there is } \\
\text { one at all? (Y times per year) } \\
\text { 22e. How many members come to the } \\
\text { General Assembly at an average? (GAM) }\end{array}$ & int comco $=X * \frac{\text { memnum }}{B M}+\frac{\text { memnum }}{G A M * Y}$ \\
\hline $\begin{array}{l}32 . \\
\text { Chair person } \\
\text { replacement } \\
\text { (chairrep) }\end{array}$ & $\begin{array}{l}\text { 22c. How many times is the chairperson } \\
\text { replaced in the last } 3 \text { elections? }\end{array}$ & $\begin{array}{l}\text { Chairrep= } \\
\mathbf{0} \\
1 \\
2 \\
3\end{array}$ \\
\hline $\begin{array}{l}\text { 33. Agenda setting } \\
\text { (agendase) }\end{array}$ & $\begin{array}{l}\text { 22f. Who formulates the agenda of the } \\
\text { General Assembly? } \\
-\quad \text { Board or employees (2) } \\
-\quad \text { the members (1) }\end{array}$ & $\begin{array}{l}\text { Agendase }= \\
1 \\
2\end{array}$ \\
\hline
\end{tabular}




\begin{tabular}{|c|c|c|}
\hline $\begin{array}{l}34 . \\
\text { Partner strength } \\
\text { (partnstr) }\end{array}$ & $\begin{array}{l}\text { 2a. Please, mention all associations, } \\
\text { services or other institutions, with which } \\
\text { you have cooperated in this affaire }(\mathbf{Z}+) \text {. } \\
\text { 3. Please, mention which of them you had } \\
\text { a conflict with (K+). } \\
\text { 2b. Please, mention which of these } \\
\text { associations, services or other institutions } \\
\text { were for you irreplaceablet. } \\
\text { 4. Please, mention which of them could } \\
\text { you trust (V+) } \\
\text { not at all } 1, \text { to certain extent } 2, \\
\text { completely (let make a decision for you) } 3 \\
\text { 7. Which of these actors provided you } \\
\text { relatively often with cheap equipment, } \\
\text { personnel, members or other kind of } \\
\text { material support? (A+) }\end{array}$ & $\begin{array}{l}\text { partnstr }_{i}=\frac{\sum_{j}^{N} \text { power }_{j}}{\sum_{j}^{N} Z_{i j}-K_{i j}} \\
\begin{array}{l}\text { where j: all actors to which i had a contact without } \\
\text { conflict }\end{array}\end{array}$ \\
\hline $\begin{array}{l}35 . \\
\text { Perceived internal } \\
\text { friction (perinfri) }\end{array}$ & $\begin{array}{l}\text { 13c. Are there conflicts in priority setting? } \\
\text { Not all } 1, \text { little } 2, \quad \text { many } 3\end{array}$ & $\begin{array}{l}\text { Perinfri= } \\
1 \\
2 \\
3\end{array}$ \\
\hline $\begin{array}{l}36 . \\
\text { Expertise (expertis) }\end{array}$ & $\begin{aligned} & \text { 18c. What kind of experts deal with the } \\
& \text { management of your organization? } \\
&- \text { Forest scientists } \\
&- \text { Biologists } \\
&- \text { Lawyers } \\
&- \text { Economists } \\
&- \text { Political scientists } \\
&- \text { Other... } \\
&\end{aligned}$ & $\begin{array}{l}\text { Expertis : } \\
\text { Archit } \\
\text { Biolog } \\
\text { Econom } \\
\text { ect... }\end{array}$ \\
\hline $\begin{array}{l}37 . \\
\text { Privatization } \\
\text { (privatis)\% }\end{array}$ & $\begin{array}{l}\text { 2a. Please, mention all associations, } \\
\text { services or other institutions, with which } \\
\text { you have cooperated in this affaire }(\mathrm{Z}+) \text {. }\end{array}$ & privatis $=\frac{\sum \text { privateActors }}{N} * 100$ \\
\hline $\begin{array}{l}38 . \\
\text { Conflict } \\
\text { (conflict)\% }\end{array}$ & $\begin{array}{l}\text { 3. Please, mention which of them you had } \\
\text { a conflict with }(\mathrm{K}+) \text {. }\end{array}$ & conflict $=\frac{\sum_{i}^{N} \sum_{j}^{N} K_{i j}}{N-N} * 100$ \\
\hline $\begin{array}{l}39 . \\
\text { Segmentation } \\
\text { (segmenta)\% } \\
\end{array}$ & $\begin{array}{l}\text { 2a. Please, mention all associations, } \\
\text { services or other institutions, with which } \\
\text { you have cooperated in this affaire }(\mathrm{Z}+) \text {. }\end{array}$ & segmenta $=\frac{\sum Z_{\text {privateactors } \rightarrow \text { stateactors }}}{\sum \text { privateActors }}$ \\
\hline $\begin{array}{l}40 . \\
\text { Intersectorality } \\
\text { (intersec) }\end{array}$ & $\begin{array}{l}\text { 2a. Please, mention all associations, } \\
\text { services or other institutions, with which } \\
\text { you have cooperated in this affaire }(\mathrm{Z}+) \text {. }\end{array}$ & $\begin{array}{ll}\text { Intersec= } \\
\text { Sum of policy areas represented either by public or } \\
\text { private units: } \\
-\quad \text { nature conservation } \\
- & \text { forestry } \\
- & \text { general agriculture } \\
- & \text { industry } \\
- & \text { consulting } \\
- & \text { general enterprizing (except for industry or } \\
- & \text { consulting) } \\
- & \text { tater management } \\
- & \text { hunism/ recreationg/ fishing } \\
- & \text { science (units producing knowledge as first } \\
- & \text { priority) } \\
- & \text { energy } \\
- & \text { empral culture and education } \\
- & \text { regional/ rurt } \\
\text { pul development }\end{array}$ \\
\hline $\begin{array}{l}41 . \\
\text { Potential lobbying } \\
\text { (potlob) }\end{array}$ & $\begin{array}{l}\text { 2a. Please, mention all associations, } \\
\text { services or other institutions, with which } \\
\text { you have cooperated in this affaire }(\mathrm{Z}+) \text {. }\end{array}$ & potlob $=\frac{\sum Z_{\text {privateActors } \rightarrow \text { stateActors }}}{\sum^{N} \sum^{N} Z_{i j}} * 100$ \\
\hline
\end{tabular}




\begin{tabular}{|c|c|c|}
\hline $\begin{array}{l}42 . \\
\text { Formal action fields } \\
\text { (actionfi) }\end{array}$ & 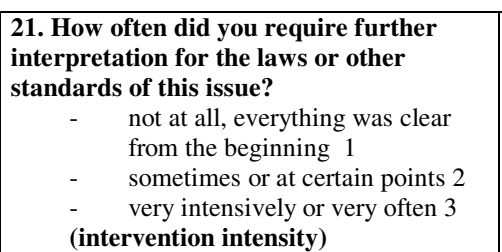 & Actionfi $=(\text { intervention intensity })^{-1}$ \\
\hline $\begin{array}{l}43 . \\
\text { Possibility of state } \\
\text { monopoly (pos.st.m) }\end{array}$ & $\begin{array}{l}\text { 2a. Please, mention all associations, } \\
\text { services or other institutions, with which } \\
\text { you have cooperated in this affaire }(\mathrm{Z}+) \text {. } \\
\text { 2b. Please, mention which of these } \\
\text { associations, services or other institutions } \\
\text { were for you irreplaceable+. }\end{array}$ & pos.st.m $=\frac{\sum_{i}^{N} \text { irreplacable }_{i \rightarrow \text { stateActors }}}{\sum \text { stateActors }}$ \\
\hline $\begin{array}{l}44 . \\
\text { Possibility of private } \\
\text { monopoly } \\
\text { (pos.pr.m) }\end{array}$ & $\begin{array}{l}\text { 2a. Please, mention all associations, } \\
\text { services or other institutions, with which } \\
\text { you have cooperated in this affaire }(\mathrm{Z}+) \text {. } \\
\text { 2b. Please, mention which of these } \\
\text { associations, services or other institutions } \\
\text { were for you irreplaceable+. }\end{array}$ & pos.pr.m $=\frac{\sum_{i}^{N} \text { irreplacable }_{i \rightarrow \text { privateActors }}}{\sum \text { privateActors }}$ \\
\hline $\begin{array}{l}45 . \\
\text { Chair person age } \\
\text { (chairage) }\end{array}$ & $\begin{array}{l}\text { 22.g How old were the chair persons in the } \\
\text { last } 3 \text { elections (average)? }\end{array}$ & Chairage $=$ Average \\
\hline $\begin{array}{l}46 . \\
\text { Repertoire } \\
\text { (repertoi) }\end{array}$ & $\begin{array}{l}\text { 23. How many new objects (themes, } \\
\text { activities area etc) have you dealt with in } \\
\text { the framework of your projects in the last } \\
2 \text { years? (a) }\end{array}$ & Repertoi $=\mathbf{a}$ \\
\hline $\begin{array}{l}47 . \\
\text { Organization age } \\
\text { (orgage) }\end{array}$ & $\begin{array}{l}\text { 24. When was your Association founded? } \\
\text { (a) }\end{array}$ & Orgage $=2002-\mathrm{a}$ \\
\hline
\end{tabular}

\section{Network matrix}

\section{Legends:}

Z: contact, K: conflict, V: trust, I: information (general or scientific),

G: self-assessed power, A: incentive, Ex: radicalism, D: dogmatism

\begin{tabular}{|c|c|c|c|c|c|c|c|c|c|c|c|c|c|c|c|c|c|c|c|}
\hline $\begin{array}{c}\text { Actors } \\
-\end{array}$ & 1 & 2 & 3 & 4 & 5 & 6 & 7 & 8 & 9 & 10 & 11 & 12 & 13 & 14 & 15 & 16 & .. & .. & .. \\
\hline 1. & $\begin{array}{l}\mathrm{Z} \\
\mathrm{K} \\
\mathrm{V} \\
\mathrm{I} \\
\mathrm{G} \\
\mathrm{A} \\
\mathrm{Ex} \\
\mathrm{D} \\
\end{array}$ & \begin{tabular}{|l|}
$\mathrm{Z}$ \\
$\mathrm{K}$ \\
$\mathrm{V}$ \\
$\mathrm{I}$ \\
$\mathrm{G}$ \\
$\mathrm{A}$ \\
$\mathrm{Ex}$ \\
$\mathrm{D}$ \\
\end{tabular} & $\begin{array}{l}\mathrm{Z} \\
\mathrm{K} \\
\mathrm{V} \\
\mathrm{I} \\
\mathrm{G} \\
\mathrm{A} \\
\mathrm{Ex} \\
\mathrm{D}\end{array}$ & $\begin{array}{l}\mathrm{Z} \\
\mathrm{K} \\
\mathrm{V} \\
\mathrm{I} \\
\mathrm{G} \\
\mathrm{A} \\
\mathrm{Ex} \\
\mathrm{D}\end{array}$ & \begin{tabular}{|l|}
$\mathrm{Z}$ \\
$\mathrm{K}$ \\
$\mathrm{V}$ \\
$\mathrm{I}$ \\
$\mathrm{G}$ \\
$\mathrm{A}$ \\
$\mathrm{Ex}$ \\
$\mathrm{D}$ \\
\end{tabular} & $\begin{array}{l}\mathrm{Z} \\
\mathrm{K} \\
\mathrm{V} \\
\mathrm{I} \\
\mathrm{G} \\
\mathrm{A} \\
\mathrm{Ex} \\
\mathrm{D} \\
\end{array}$ & $\begin{array}{l}\mathrm{Z} \\
\mathrm{K} \\
\mathrm{V} \\
\mathrm{I} \\
\mathrm{G} \\
\mathrm{A} \\
\mathrm{Ex} \\
\mathrm{D} \\
\end{array}$ & \begin{tabular}{|l}
$\mathrm{Z}$ \\
$\mathrm{K}$ \\
$\mathrm{V}$ \\
$\mathrm{I}$ \\
$\mathrm{G}$ \\
$\mathrm{A}$ \\
$\mathrm{Ex}$ \\
$\mathrm{D}$ \\
\end{tabular} & $\begin{array}{l}\mathrm{Z} \\
\mathrm{K} \\
\mathrm{V} \\
\mathrm{I} \\
\mathrm{G} \\
\mathrm{A} \\
\mathrm{Ex} \\
\mathrm{D} \\
\end{array}$ & $\begin{array}{l}\mathrm{Z} \\
\mathrm{K} \\
\mathrm{V} \\
\mathrm{I} \\
\mathrm{G} \\
\mathrm{A} \\
\mathrm{Ex} \\
\mathrm{D}\end{array}$ & $\begin{array}{l}\mathrm{Z} \\
\mathrm{K} \\
\mathrm{V} \\
\mathrm{I} \\
\mathrm{G} \\
\mathrm{A} \\
\mathrm{Ex} \\
\mathrm{D}\end{array}$ & $\begin{array}{l}\mathrm{Z} \\
\mathrm{K} \\
\mathrm{V} \\
\mathrm{I} \\
\mathrm{G} \\
\mathrm{A} \\
\mathrm{Ex} \\
\mathrm{D}\end{array}$ & \begin{tabular}{|l}
$\mathrm{Z}$ \\
$\mathrm{K}$ \\
$\mathrm{V}$ \\
$\mathrm{I}$ \\
$\mathrm{G}$ \\
$\mathrm{A}$ \\
$\mathrm{Ex}$ \\
$\mathrm{D}$ \\
\end{tabular} & $\begin{array}{l}\mathrm{Z} \\
\mathrm{K} \\
\mathrm{V} \\
\mathrm{I} \\
\mathrm{G} \\
\mathrm{A} \\
\mathrm{Ex} \\
\mathrm{D}\end{array}$ & $\begin{array}{l}\mathrm{Z} \\
\mathrm{K} \\
\mathrm{V} \\
\mathrm{I} \\
\mathrm{G} \\
\mathrm{A} \\
\mathrm{Ex} \\
\mathrm{D}\end{array}$ & $\begin{array}{l}\mathrm{Z} \\
\mathrm{K} \\
\mathrm{V} \\
\mathrm{I} \\
\mathrm{G} \\
\mathrm{A} \\
\mathrm{Ex} \\
\mathrm{D}\end{array}$ & $\begin{array}{l}\mathrm{Z} \\
\mathrm{K} \\
\mathrm{V} \\
\mathrm{I} \\
\mathrm{G} \\
\mathrm{A} \\
\mathrm{Ex} \\
\mathrm{D}\end{array}$ & $\begin{array}{l}\mathrm{Z} \\
\mathrm{K} \\
\mathrm{V} \\
\mathrm{I} \\
\mathrm{G} \\
\mathrm{A} \\
\mathrm{Ex} \\
\mathrm{D}\end{array}$ & \begin{tabular}{|l}
$\mathrm{Z}$ \\
$\mathrm{K}$ \\
$\mathrm{V}$ \\
$\mathrm{I}$ \\
$\mathrm{G}$ \\
$\mathrm{A}$ \\
$\mathrm{Ex}$ \\
$\mathrm{D}$
\end{tabular} \\
\hline 2. & $\begin{array}{l}\mathrm{Z} \\
\mathrm{K} \\
\mathrm{V} \\
\mathrm{I} \\
\mathrm{G} \\
\mathrm{A} \\
\mathrm{Ex} \\
\mathrm{D}\end{array}$ & \begin{tabular}{|l}
$\mathrm{Z}$ \\
$\mathrm{K}$ \\
$\mathrm{V}$ \\
$\mathrm{I}$ \\
$\mathrm{G}$ \\
$\mathrm{A}$ \\
$\mathrm{Ex}$ \\
$\mathrm{D}$ \\
\end{tabular} & \begin{tabular}{|l}
$\mathrm{Z}$ \\
$\mathrm{K}$ \\
$\mathrm{V}$ \\
$\mathrm{I}$ \\
$\mathrm{G}$ \\
$\mathrm{A}$ \\
$\mathrm{Ex}$ \\
$\mathrm{D}$ \\
\end{tabular} & $\begin{array}{l}\mathrm{Z} \\
\mathrm{K} \\
\mathrm{V} \\
\mathrm{I} \\
\mathrm{G} \\
\mathrm{A} \\
\mathrm{Ex} \\
\mathrm{D} \\
\end{array}$ & \begin{tabular}{|l}
$\mathrm{Z}$ \\
$\mathrm{K}$ \\
$\mathrm{V}$ \\
$\mathrm{I}$ \\
$\mathrm{G}$ \\
$\mathrm{A}$ \\
$\mathrm{Ex}$ \\
$\mathrm{D}$ \\
\end{tabular} & $\begin{array}{l}\mathrm{Z} \\
\mathrm{K} \\
\mathrm{V} \\
\mathrm{I} \\
\mathrm{G} \\
\mathrm{A} \\
\mathrm{Ex} \\
\mathrm{D} \\
\end{array}$ & $\begin{array}{l}\mathrm{Z} \\
\mathrm{K} \\
\mathrm{V} \\
\mathrm{I} \\
\mathrm{G} \\
\mathrm{A} \\
\mathrm{Ex} \\
\mathrm{D} \\
\end{array}$ & \begin{tabular}{|l}
$\mathrm{Z}$ \\
$\mathrm{K}$ \\
$\mathrm{V}$ \\
$\mathrm{I}$ \\
$\mathrm{G}$ \\
$\mathrm{A}$ \\
$\mathrm{Ex}$ \\
$\mathrm{D}$ \\
\end{tabular} & $\begin{array}{ll}\mathrm{Z} \\
\mathrm{K} \\
\mathrm{V} \\
\mathrm{I} \\
\mathrm{G} \\
\mathrm{A} \\
\mathrm{Ex} \\
\mathrm{D} \\
\end{array}$ & $\begin{array}{l}\mathrm{Z} \\
\mathrm{K} \\
\mathrm{V} \\
\mathrm{I} \\
\mathrm{G} \\
\mathrm{A} \\
\mathrm{Ex} \\
\mathrm{D} \\
\end{array}$ & $\begin{array}{l}\mathrm{Z} \\
\mathrm{K} \\
\mathrm{V} \\
\mathrm{I} \\
\mathrm{G} \\
\mathrm{A} \\
\mathrm{Ex} \\
\mathrm{D} \\
\end{array}$ & $\begin{array}{l}\mathrm{Z} \\
\mathrm{K} \\
\mathrm{V} \\
\mathrm{I} \\
\mathrm{G} \\
\mathrm{A} \\
\mathrm{Ex} \\
\mathrm{D} \\
\end{array}$ & $\begin{array}{l}\mathrm{Z} \\
\mathrm{K} \\
\mathrm{V} \\
\mathrm{I} \\
\mathrm{G} \\
\mathrm{A} \\
\mathrm{Ex} \\
\mathrm{D} \\
\end{array}$ & $\begin{array}{ll}\mathrm{Z} \\
\mathrm{K} \\
\mathrm{V} \\
\mathrm{I} \\
\mathrm{G} \\
\mathrm{A} \\
\mathrm{Ex} \\
\mathrm{D} \\
\end{array}$ & $\begin{array}{l}\mathrm{Z} \\
\mathrm{K} \\
\mathrm{V} \\
\mathrm{I} \\
\mathrm{G} \\
\mathrm{A} \\
\mathrm{Ex} \\
\mathrm{D} \\
\end{array}$ & $\begin{array}{l}\mathrm{Z} \\
\mathrm{K} \\
\mathrm{V} \\
\mathrm{I} \\
\mathrm{G} \\
\mathrm{A} \\
\mathrm{Ex} \\
\mathrm{D} \\
\end{array}$ & $\begin{array}{l}\mathrm{Z} \\
\mathrm{K} \\
\mathrm{V} \\
\mathrm{I} \\
\mathrm{G} \\
\mathrm{A} \\
\mathrm{Ex} \\
\mathrm{D} \\
\end{array}$ & $\begin{array}{l}\mathrm{Z} \\
\mathrm{K} \\
\mathrm{V} \\
\mathrm{I} \\
\mathrm{G} \\
\mathrm{A} \\
\mathrm{Ex} \\
\mathrm{D} \\
\end{array}$ & \begin{tabular}{|l}
$\mathrm{Z}$ \\
$\mathrm{K}$ \\
$\mathrm{V}$ \\
$\mathrm{I}$ \\
$\mathrm{G}$ \\
$\mathrm{A}$ \\
$\mathrm{Ex}$ \\
$\mathrm{D}$ \\
\end{tabular} \\
\hline - & & & & & & & & & & & & & & & & & & & \\
\hline - & & & & & & & & & & & & & & & & & & & \\
\hline - & & & & & & & & & & & & & & & & & & & \\
\hline - & & & & & & & & & & & & & & & & & & & \\
\hline & & & & & & & & & & & & & & & & & & & \\
\hline
\end{tabular}


III. Example of stepwise regression (the extraction of the 'lawful" type) Dependent Variable: Power

\begin{tabular}{|r|r|r|r|r|r|}
\hline & & $\begin{array}{c}\text { Not standardized } \\
\text { coefficients }\end{array}$ & & $\begin{array}{c}\text { Standardized } \\
\text { coefficients }\end{array}$ & Significance \\
\hline Modell & & \multicolumn{1}{c|}{ B } & Standard error & Beta & \\
\hline 1 & (Constant) & 10,762 &, 965 & &, 000 \\
\hline & ACTORS &,- 230 &, 040 &,- 527 &, 000 \\
\hline 2 & (Constant) & 7,969 & 1,064 & &, 000 \\
\hline & ACTORS &,- 200 &, 036 &,- 457 &, 000 \\
\hline & POTLOBB &, 109 &, 024 &, 381 &, 000 \\
\hline 3 & (Constant) & 6,647 & 1,151 & &, 000 \\
\hline & ACTORS &,- 198 &, 035 &,- 452 &, 000 \\
\hline & POTLOBB &, 113 &, 023 &, 395 &, 000 \\
\hline & MULTIDIS &, 354 &, 137 &, 206 &, 011 \\
\hline 4 & (Constant) & 8,311 & 1,279 & &, 000 \\
\hline & ACTORS &,- 219 &, 035 &,- 502 &, 000 \\
\hline & POTLOBB &, 111 &, 022 &, 387 &, 000 \\
\hline & MULTIDIS &, 357 &, 132 &, 208 &, 008 \\
\hline & RELIMPST &,- 704 &, 267 &,- 208 &, 010 \\
\hline 5 & (Constant) & 11,702 & 1,727 & &, 000 \\
\hline & ACTORS &,- 237 &, 034 &,- 542 &, 000 \\
\hline & POTLOBB & $9,780 E-02$ &, 022 &, 342 &, 000 \\
\hline & MULTIDIS &, 401 &, 128 &, 233 &, 002 \\
\hline & RELIMPST &,- 799 &, 259 &,- 236 &, 003 \\
\hline & RADICALI & $-1,979$ &, 707 &,- 216 &, 006 \\
\hline 6 & (Constant) & 13,390 & 1,757 & &, 000 \\
\hline & ACTORS &,- 241 &, 033 &,- 552 &, 000 \\
\hline & POTLOBB &, 103 &, 021 &, 362 &, 000 \\
\hline & MULTIDIS &, 410 &, 123 &, 238 &, 001 \\
\hline & RELIMPST &,- 764 &, 249 &,- 226 &, 003 \\
\hline & RADICALI & $-2,574$ &, 709 &,- 281 &, 000 \\
\hline & STATECH &,- 627 & -218 &,- 216 &, 005 \\
\hline
\end{tabular}




\section{Practical meaning of power values}

\begin{tabular}{|c|c|c|c|c|c|}
\hline $\begin{array}{l}\text { Trust } \\
(1,2,3)\end{array}$ & $\begin{array}{c}\text { Incentives } \\
(0,1)\end{array}$ & $\begin{array}{l}\text { Irreplace } \\
\text { ability } \\
(0,1)\end{array}$ & $\begin{array}{l}\text { Power } \\
\text { value }\end{array}$ & Meaning & Aggregation \\
\hline 1 & 0 & 0 & 1 & $\begin{array}{l}\text { Lowest authoritative and } \\
\text { instrumental power- mere } \\
\text { existence in the network }\end{array}$ & $1=$ Only exists \\
\hline 1 & 1 & 0 & 2 & $\begin{array}{l}\text { Only part of instrumental } \\
\text { power }\end{array}$ & \multirow{3}{*}{$\begin{array}{l}\text { Only part of one (1) power } \\
\text { form } \\
2=\mathbf{1}^{*} \text { part }\end{array}$} \\
\hline 1 & 0 & 1 & 2 & $\begin{array}{l}\text { Only part of instrumental } \\
\text { power }\end{array}$ & \\
\hline 2 & 0 & 0 & 2 & $\begin{array}{l}\text { Only part of authoritative } \\
\text { power }\end{array}$ & \\
\hline 1 & 1 & 1 & 3 & $\begin{array}{l}\text { Only total instrumental } \\
\text { power }\end{array}$ & \multirow{4}{*}{$\begin{array}{l}\text { One total power form or } 2 \\
\text { parts } \\
3=\mathbf{1} * \text { total } \\
\text { or } \\
3=\mathbf{2} * \text { parts }\end{array}$} \\
\hline 2 & 1 & 0 & 3 & $\begin{array}{l}\text { Part of authoritative power } \\
\text { and part of instrumental } \\
\text { power }\end{array}$ & \\
\hline 2 & 0 & 1 & 3 & $\begin{array}{l}\text { Part of authoritative power } \\
\text { and part of instrumental } \\
\text { power }\end{array}$ & \\
\hline 3 & 0 & 0 & 3 & $\begin{array}{l}\text { Only total authoritative } \\
\text { power }\end{array}$ & \\
\hline 2 & 1 & 1 & 4 & $\begin{array}{l}\text { Part of authoritative power } \\
\text { and total instrumental } \\
\text { power }\end{array}$ & \multirow{3}{*}{$\begin{array}{l}\text { One total power form and } \\
\text { one part } \\
4=\mathbf{1} * \text { total+1*part }\end{array}$} \\
\hline 3 & 1 & 0 & 4 & $\begin{array}{l}\text { Total authoritative power } \\
\text { and part of instrumental } \\
\text { power }\end{array}$ & \\
\hline 3 & 0 & 1 & 4 & $\begin{array}{l}\text { Total authoritative power } \\
\text { and part of instrumental } \\
\text { power }\end{array}$ & \\
\hline 3 & 1 & 1 & 5 & $\begin{array}{l}\text { Total authoritative power } \\
\text { and total instrumental } \\
\text { power }\end{array}$ & $\begin{array}{l}\text { Both total power forms } \\
5=2 * \text { total }\end{array}$ \\
\hline
\end{tabular}


V. Application of bivariate and multivariate regression of the 18 variables considering power as a dependent variable

\begin{tabular}{|c|c|c|c|c|}
\hline & \multicolumn{2}{|c|}{ Bivariate regression } & \multicolumn{2}{|c|}{$\begin{array}{c}\text { Multivariate regression } \\
\text { including all } 18 \text { variables }\end{array}$} \\
\hline & $\begin{array}{l}\text { Standardized } \\
\text { coefficients }\end{array}$ & Significance & $\begin{array}{l}\text { Standardized } \\
\text { coefficients }\end{array}$ & Significance \\
\hline STATECH &,- 075 &, 482 &,- 095 &, 070 \\
\hline MULTIDIS &, 184 &, 082 &, 014 &, 830 \\
\hline FINRESOU & ,258 & ,013 & ,121 & ,038 \\
\hline RADICALI &,- 151 & ,021 &, 004 &, 953 \\
\hline PARTNSTR & ,586 & ,000 &, 160 &, 159 \\
\hline INTERSEC &,- 299 & ,000 &, 169 &, 221 \\
\hline POTLOBB & ,292 & ,000 &,- 184 &, 168 \\
\hline RELIMPST &, 039 &, 555 &,- 024 &, 834 \\
\hline POWERINE &,- 241 & ,000 &,- 028 &, 850 \\
\hline DENSITY & ,271 & ,000 &,- 392 & ,001 \\
\hline TRUSTWOR &,- 012 &, 850 &, 116 &, 074 \\
\hline ACTORS &,- 503 & ,000 &,- 401 & ,098 \\
\hline CCGI &, 706 &, 000 &, 409 & ,000 \\
\hline CBGI & ,381 & ,000 & ,181 & ,017 \\
\hline CCSI & ,566 & ,000 & ,206 & ,007 \\
\hline GINEEDIN & ,224 & ,001 &, 044 &, 621 \\
\hline SILINKS &,- 481 & ,000 &, 067 & ,648 \\
\hline RELDENCO &,- 452 & ,000 &,- 153 &, 326 \\
\hline
\end{tabular}




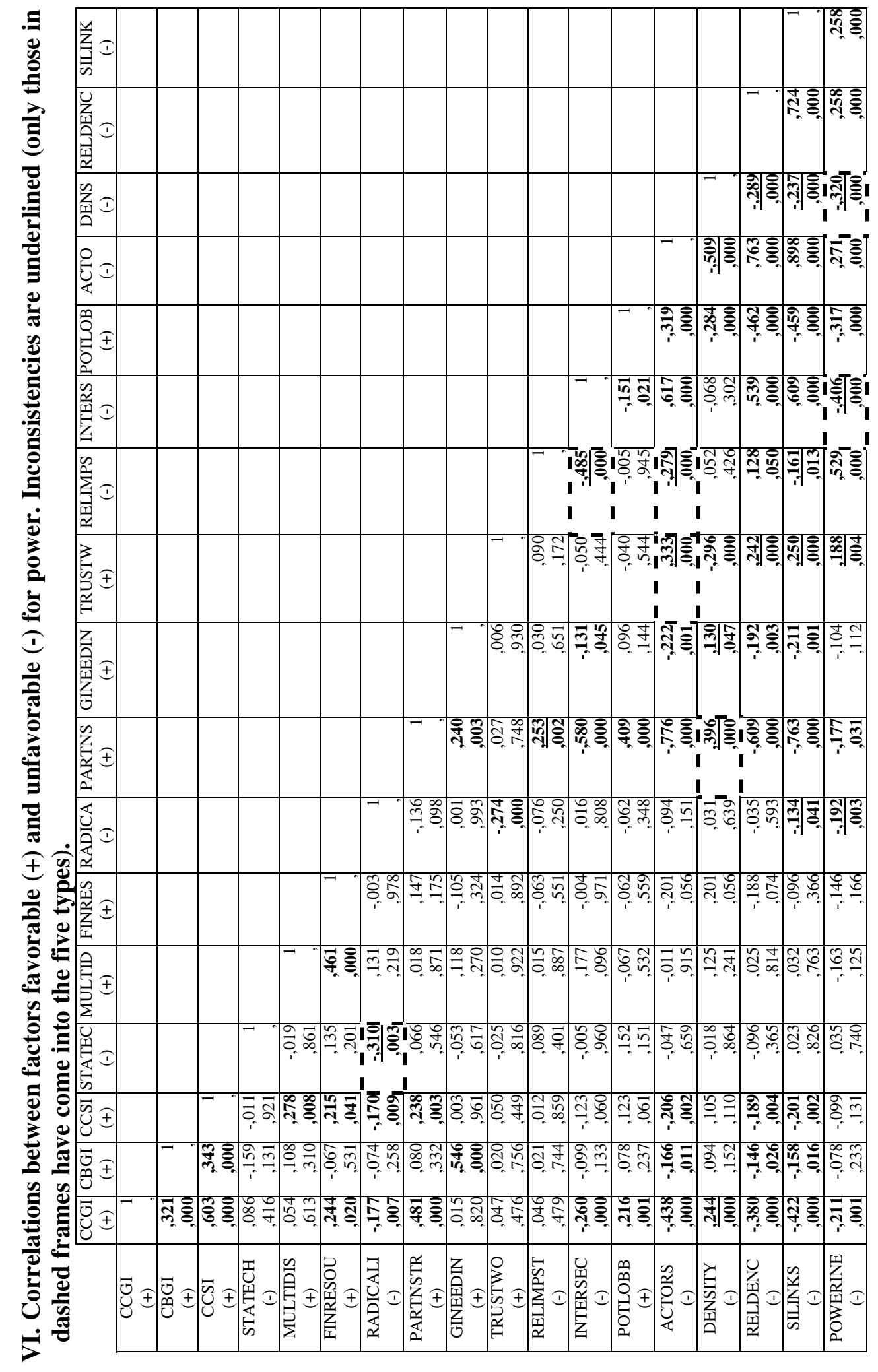




\section{Visualization of the 12 networks}

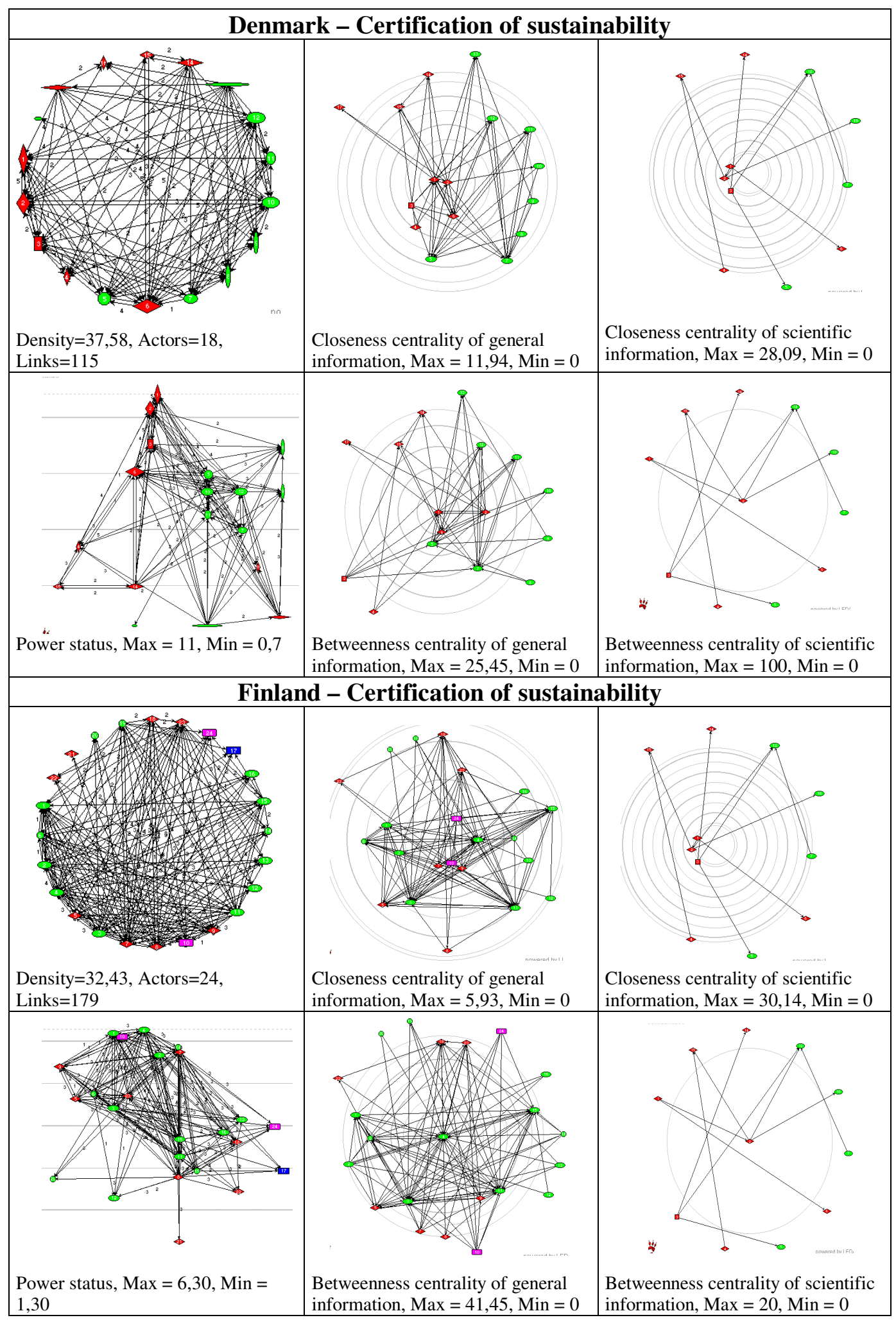




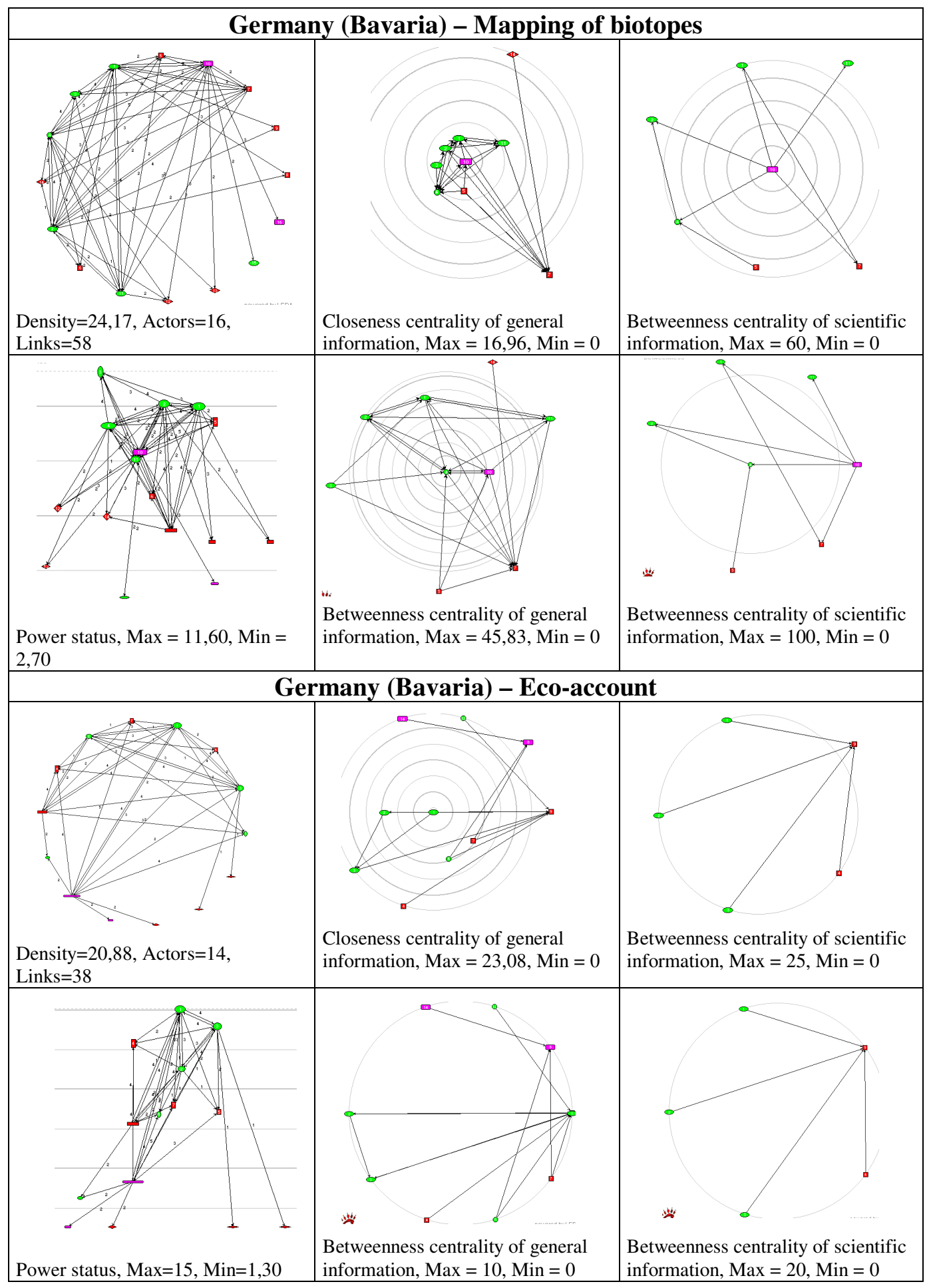




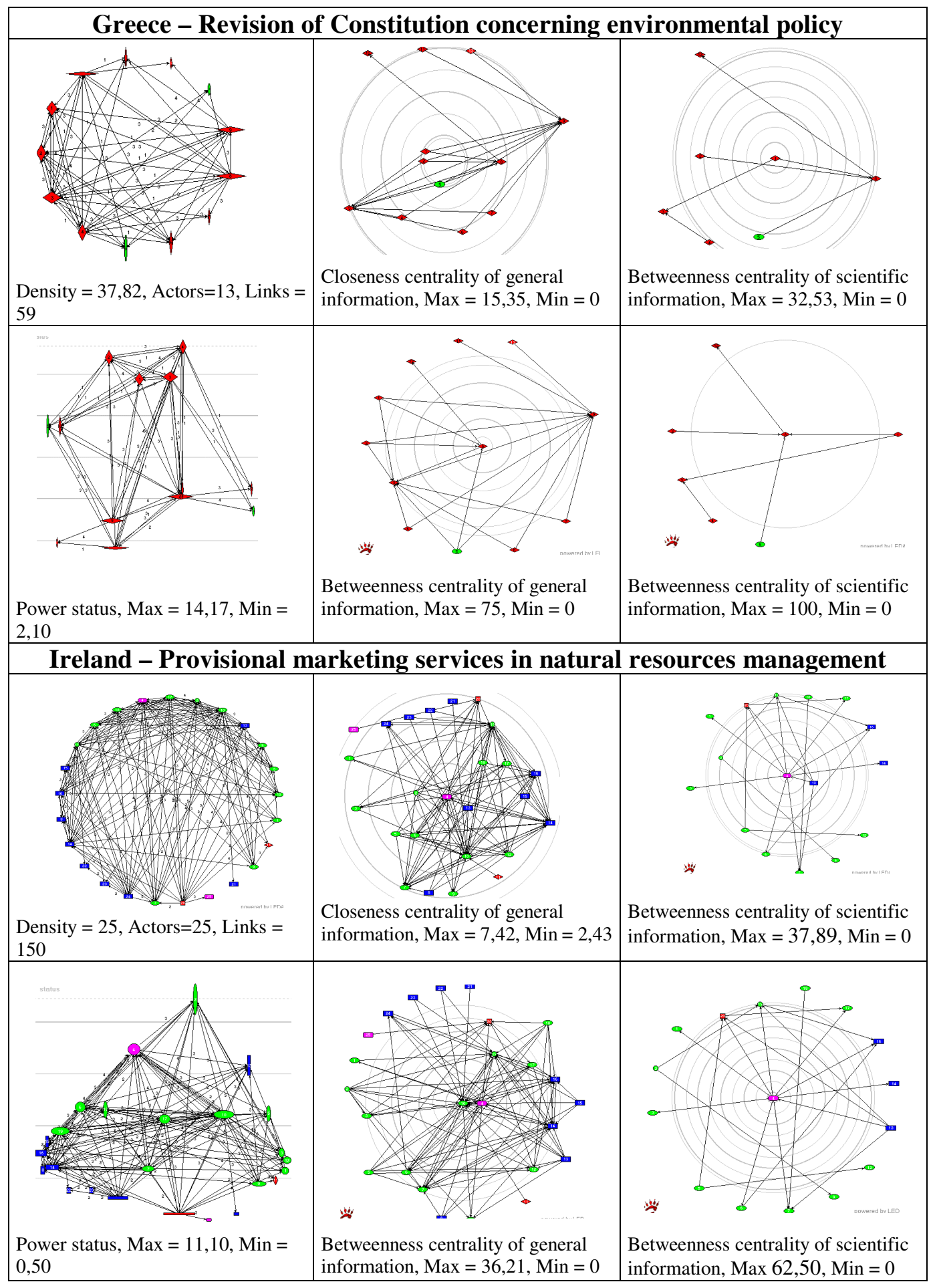




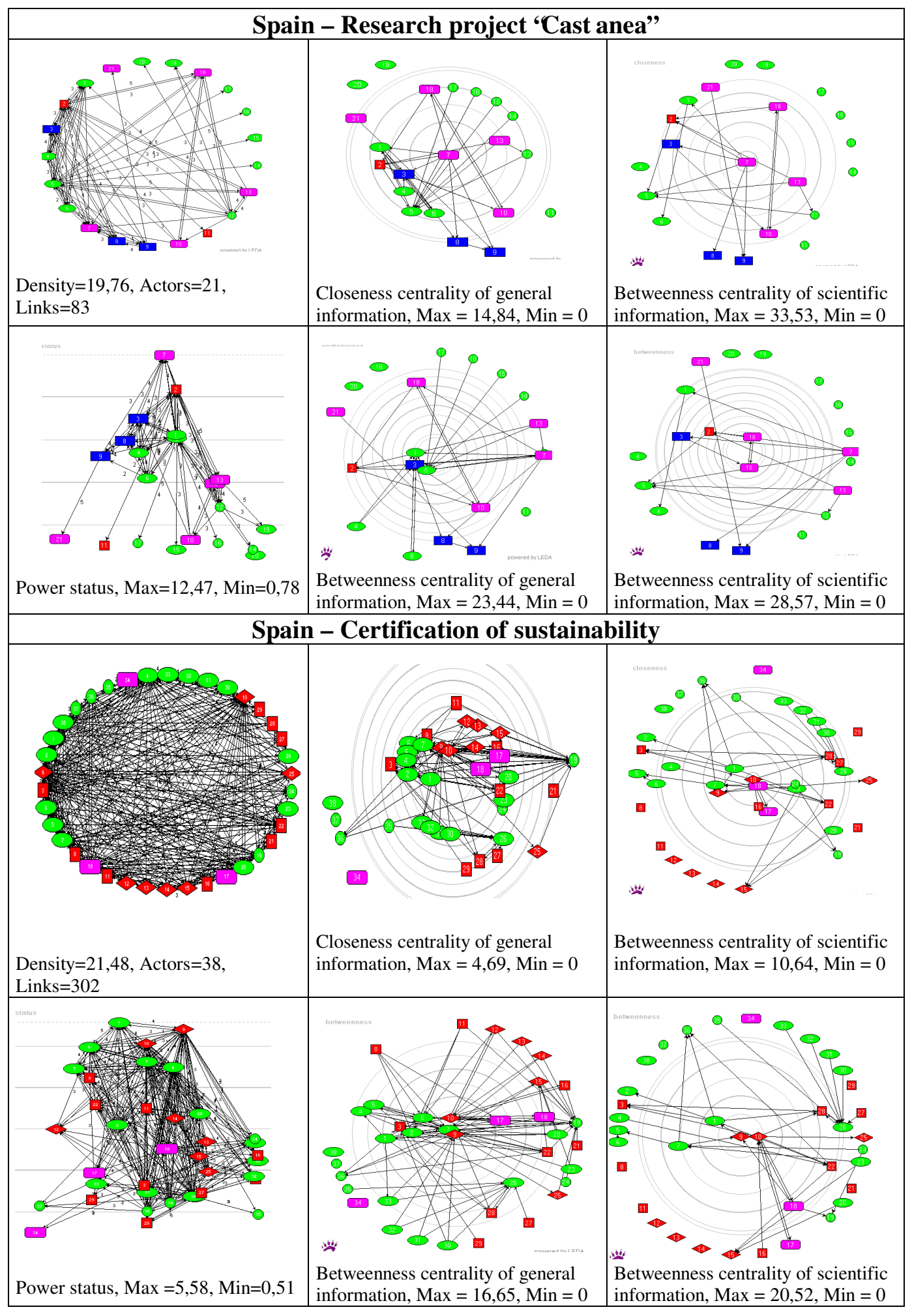




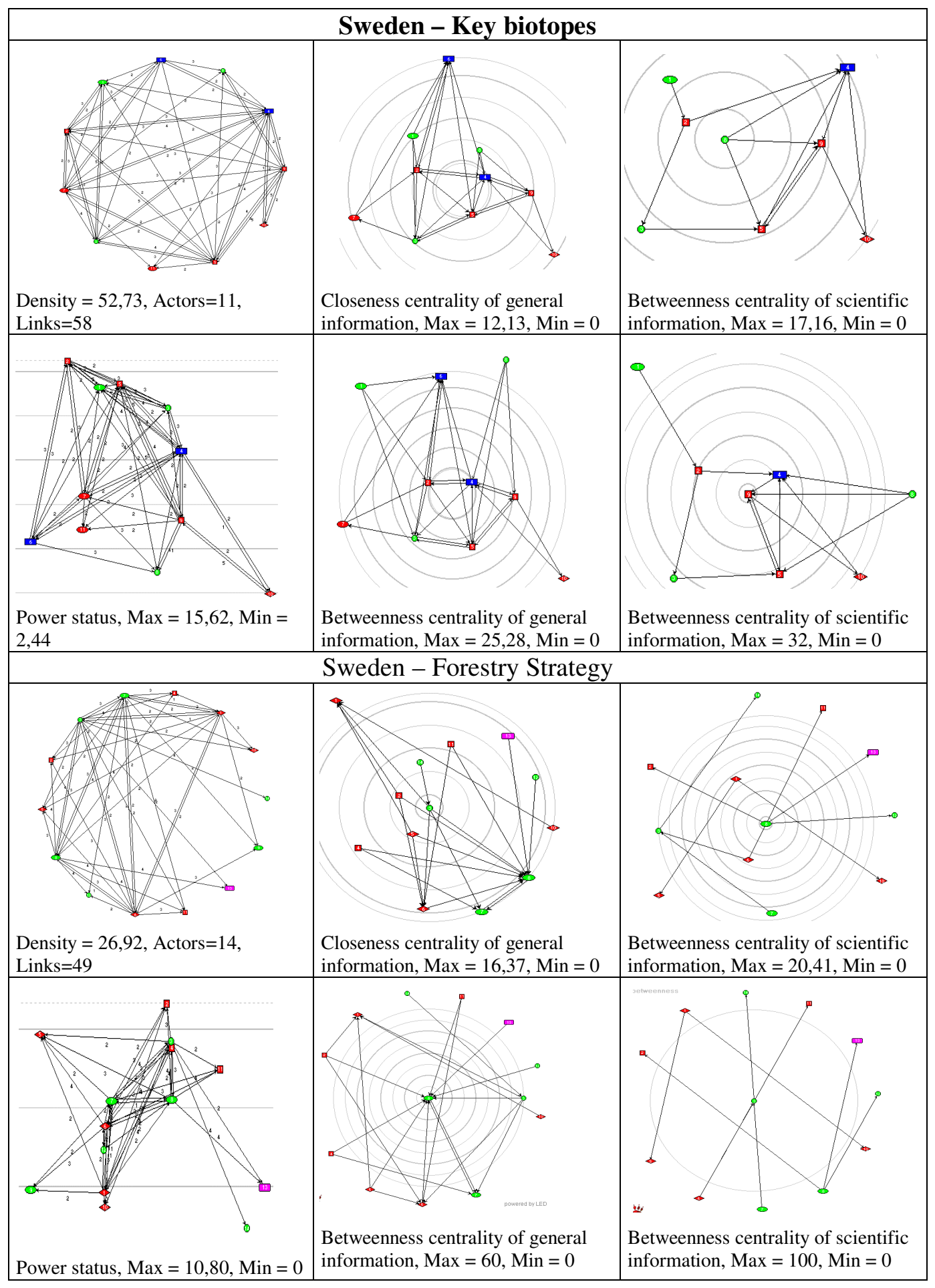




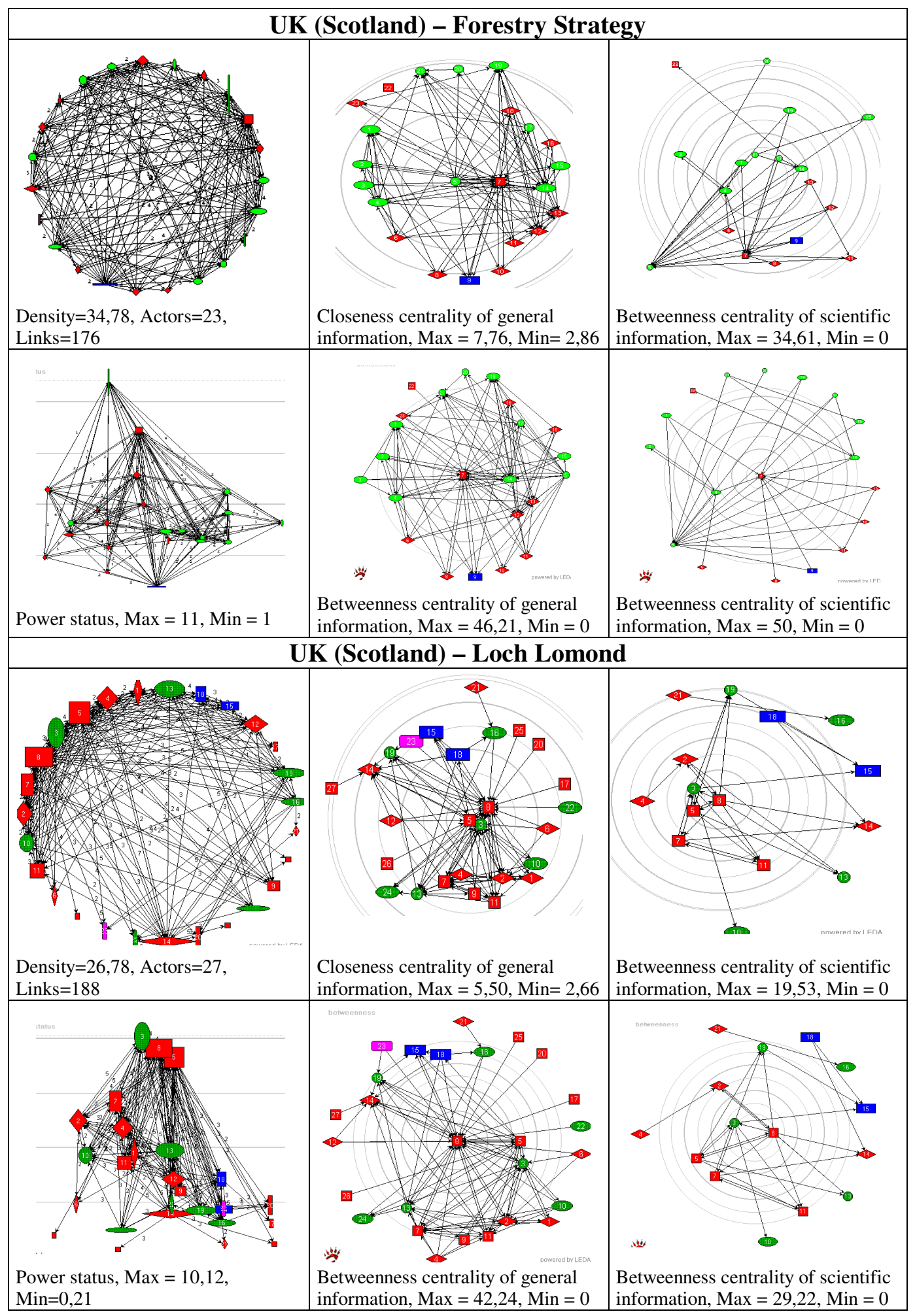




\section{References}

ALDRICH, H.E./ PFEFFER, J. 1976: Environments of Organizations. In: Annual Review of Sociology, Vol. 2. Palo Alto, CA: Annual Reviews, Inc.

ALEMANN, U. von 1996: Interessenverbände. Informationen zur politischen Bildung (Interest associations. Information on political education). 4. Quartal 1996, 253.

ARENDT, H. 1967: Vita activa. Piper. München

ARENDT, H. 1970: Macht und Gewalt (On Violence). Piper. München

ARNDT, H. 1974: Wirtschaftliche Macht. Tatsache und Theorien. (Economic power. Facts and theories). C.H. Muenchen. Muenchen

ARISTOTLE 1996: The politics and the constitution of Athens. (Ed.) S. Everson. Cambridge University Press

ATKINSON, M..M/ COLEMANN, W.D. 1989: Strong states and weak states: Sectoral policy networks in advanced capitalist economies. In: British journal of political science 19, 47-67

ATTESLANDER, P. 1995: Methoden der empirischen Sozialforschung (Methods of emprical sociel research). Verlag Walter de Gruyter, Berlin/ New York

BACHRACH, P./ BARATZ, M. S., 1962: Two Faces of Power. In: American Political Science Review 56. 947-52

BACHRACH, P./ BARATZ, M. S., 1963: Decisions and Non-Decisions: An Analytical Framework. In: American Political Science Review 57. $632-42$

BAUR, M./ BENKERT, M./ BRANDES, U./ CORNELSEN, S./ GAERTLER, M./ KOEPF, B./ LERNER, J./ WAGNER, D. 2002: Visone - Software for Visual Social Network Analysis. Porc. 9th Intl. Symp. Graph Drawing, Lecture Notes in Computer Science 2265, 463-464, Springer 2002 
BLOM-HANSEN, J. 1997. A ,new institu tional“" perspective on policy networks. In: Public administration 75, Winter 1997, 669-693

BOEHRET, G/ JANN, W./ KRONEWETT, E. 1988: Innenpolitik and politische Theorie (Internal policy and political theory). Westdeutscher Verlag. Opladen

BORZEL,T.,A. 1997: What's so special about networks?- An exploration of the concept and usefulness in studying European Governance. European Integration Online Papers (EioP).1,No 16.

BORZEL,T.A. 1998: Organizing Babylon- on the different conceptions of policy networks. In: Public Administration 76 (2), 253-273

BRANDES, U./ KENIS, P./ WAGNER, D. 1999: Communicating centrality in policy network drawings. IEEE transactions on visualization and computer graphics, 9 (2): 241-253 (2003)

BRANDES, U./ RAAB, J./ WAGNER, D. 2001: Exploratory network visualization: Simultaneous display of actor status and connections. In: Journal of Social Structure 2 (4) (October 19, 2001)

BRYMAN, A. 2001: Social Research Methods. Oxford Press

BURKOLTER-TRACHTEL, V. 1981: Zur Theorie sozialer Macht: Konzeptionen, Grundlagen und Legitimierung, Theorien, Messung, Tiefenstruktur und Modele (On the theory of social power: Conceptions, fundamentals and legitimation, theories, measurement, deep structure and models). Switzerland

BUESCHGES, G./ ABRAHAM, M. 1997: Einführung in die Organisationssoziologie (Introduction into the Organizational Sociology). Teubner

BUSKENS, V. 1999: Social Networks and Trust. Netherlands

CHANDLER, A.D. 1962: Strategy and structure. Cambridge, MA: MIT Press

CHILD, J. 1972: Organizational structure, environment, and performance. The role of strategic choice. Sociology, 6, 1-22 
COLEMANN, J. 1986: Individual interests and collective action. Cambridge

COOK, K. S./ EMERSON, R. M. 1978: Power, Equity and Incentive in Exchange Networks. In: American Sociological Review. 1978, 43, 721739

CUBBAGE, F./ O'LAUGHLIN, J./ BULLOCK, C. 1993: Forest resource policy. John Wiley \& Sons, INC.

DIMAGGIO, P./ POWER, W. 1983: The iron cage revisited: Institutional isomorphism and collective rationality in organizational fields. In: American Sociological Review, 48, 147-60

DOLATA, U. 2000: Risse im Netz - Konkurrenz und Kooperation in der Technikentwicklung und -regulierung (Flaws in network - competition and cooperation in the technical development and regulation). In: Politische Verteljahresschrift 41. Jg. (2000), Sonderheft 31/2000

DOWDING,K., 1994: Roundable The Theory of Policy Communities and Policy Networks. In: Contemporary Political Studies, V.I,59-78

DUDLEY, G./ RICHARDSON, J. 1997: Competing policy frames in the EU policy making: The rise of free market ideas in EU Steel Policy 19851996. In: European Integration online Papers, V.1 (1997), No 013

DUKE, K. 2002: Getting beyond the "official line": Reflections on dilemmas of access, knowledge and power in researching policy networks. In: Journal of Social Policy 31(2002): 39-59

EASTHOPE, G. 1974: A history of social research methods. Longman. London

EISENSTADT, S.N. 1995: Power, Trust, and Meaning. Essays in Sociological Theory and Analysis. Chicago, London

ELLIOT, C., 1999: Forest Certification: Analysis from a Policy Network Perspective. Lausanne, EPFL 
ENGLISH, M.R./ DALE, H.V./ RIPER-GEIBIG, C./ RAMSEY, W.H. 1998. Overview. Tools to aid Environmental Decision-Making. English, M.R./ Dale, H.V. (Ed.) 1-32. Springer

EVANS, M. 2001. Understanding dialectics in policy network analysis. In: Political studies 2001, 49, 542-550

ETZIONI, A. 1969: Readings on modern organizations. Englewood Cliffs, N.J.: Prentice-Hall

ETZIONI, A, 1975: Die aktive Gesellschaft. Eine Theorie gesellschaftlicher und politischer Prozesse (The active society. A theory of social and political processes). Westdeutscher Verlag. Opladen

FALKNER, G./ MUELLER, W./ EDER, M./ HILLER, K./ STEINER, G./ TRATTNIGG, R. 1999. The impact of EU membership in policy networks in Austria: creeping change beneath the surface. In: Journal of the European public policy 6:3 September 1999, 496-516

FLACHE, A. 1996: The double edge of networks. An analysis of the effect of informal networks on cooperation in social dilemmas. Groningen University

FOUCAULT, M. 1980: Power/Knowledge. Selected Interviews and Other Writings 1972-1977. Brighton. Harvester Press.

FOUCAULT, M. 1982: The Subject and Power. Afterword to Hubert L. Dreyfus / Paul Rabinow: Michel Foucault: Beyond Structuralism and Hermeneutics. London. Harvester Weatsheaf.

GIDDENS, A. 1997: Sociology. Polity Press. Cambridge

GILL, P. 1994: The intelligence services. In: Contemporary Political Science. 170-180, 1

GRANOVETTER, M. 1985: Economic action and social structure: The problem of embededness. In: American Journal of Sociology 91: 481-510

HALL, R.H. 1996: Organizations. Structures, processes, and outcomes. Simon and Schuster. New Jersey 
HASANAGAS, N.D. 2001: Implications of the Europeanization in Transectoral Environmental Policy Areas. In: Interdisciplinary Environmental Review V.3,\#2,2001,118-133

HASANAGAS, N.D. 2003: Lobbying management: Principles and methods of a more effective practice in the environmental labyrinth of the European Union. In: Scottish Forestry. The journal of the Royal Scottish Forestry Society. V.57, \#1, 2003, 28-32

HAVILAND, W. 1999. Cultural anthropology. Harcourt Brace \& Co. Florida

HEIDENHEIMER, A.J. 1970: Political corruption: Readings in comparative analysis, 18-28

HEIDENHEIMER, A.J./ JOHNSTON, M. 2002: Political Corruption: concepts and contexts. (Ed.) by A. J. Heidenheimer and M. Johnston. Transaction Publishers. New Brunswick and London.

HENNING, Ch./ WALD, A. 2000: Zur Theorie der Interessenvermittlung: Ein Netzwerkansatz dargestellt am Beispiel der Gemeinsamen Europäischen Agrarpolitik (On the theory of interest intermediation: A network-analysis principle illustrated by the case-study of the Common European Agricultural Policy). In: Politische Vierteljahreszeitschrift, 41.Jg. (2000), Heft 4, 647-676

HOBERG, G. 2001. In Search of Sustainability. British Columbia Forest Policy in the 1990s. British Columbia University

HOMER-DIXON, T.F. 1999. Environment, Scarcity, and Violence. Princeton University Press

HORSTER, N. 1997: Principles of Exchange and Power. Integrating the Theory of Social Institutions and the Theory of Value. Munich

IMMERGUT, E. 1992: Health Care Politics: Ideas and Institutions in Western Europe. Cambridge University Press

JORDAN, G./ MALONEY, W. 1997. The protest business? Mobilizing campaign groups. Manchester University Press 
JORDAN, G./ SCHUBERT, K. 1992: A preliminary ordering of policy network labels. In: European Journal of Political Research 21, 7-27

KAPPELHOFF, P. 1993: Soziale Tauschsysteme. Strukturelle und dynamische Erweiterungen des Marktmodels (Social exchange systems. Structural and dynamical enlargements of the market model). Oldenburg Verlag. Muenchen

KATZ, L. 1953: A new Status index derived from sociometric analysis. In: Psychometrika, V.18,\#1, March, 1953

KECK, O. 1991: Macht und Information bei Max Weber: Eine spieltheoretische Rekonstruktion (Power and information in Max Weber: A game-theoretical reconstruction). In: Macht in der Demokratie. Denkanstösse zur Wiederbelebung einer klassischen Frage in der zeitgenössischen politischen Theorie 63-85 (Hrsg.) M.T. Greven. Nomos. Baden-Baden

KIESSLER, K./ SCHOLL, W. 1976: Partizipation und Macht in aufgabenorientierten Gruppen. Ein Feldexperiment zur Theorie der organizatorischen Bedingtheit von Gruppenprozessen (Participation and power in task-oriented groups. A field experiment on the theory of the organizational conditioning of group processes). Haag und Herchen. Köln

KNOKE, D./ KUKLINSKI, J. 1982: Network Analysis. Sage Publications. Beverly Hills, London, New Delhi

KRASNER, S. 1984: Approaches to the state: alternative conceptions and historical dynamics. In: Comparative politics 16: 223-46

KROTT, M. 1990: Öffentliche Verwaltung im Umweltschutz. Ergebnisse einer behördenorientierten Policy-Analyze am Beispiel Waldschutz (Public administration in environmental conservation. Results of serviceoriented policy-analysis in case study forest conservation). A. Pelinka, C. Haerpfer (Hg.). Wien

KROTT, M./ SUDA, M. 2001: Von der Selbsttäuschung zu der Erkenntnis. Einführung in die methodischen Probleme der Befragung. (From the self-deception to knowledge. Introduction in the methodical problems of inquiry). In: Befragung als Methode der Sozialforschung in 
der Forstwissenschaft. (Hrsg.) M. Krott, M. Suda. Sauelaender. Frankfurt.

KROTT, M./ TRAXLER, F. 1992: Verbändeorganization im Umweltschutz. Strategische Entwicklungsalternativen (Organizing of associations in environmental conservation. Strategic development alternatives). Wien.

KROTT, M. 2001: Politikfeldanalyze Forstwirtschaft. Eine Einführung für Studium und Praxis (Forest policy-analysis. An introduction for study and implementation). Wien

KUEHNEL, S.-M./ KREBS, D. 2001: Statistik für die Sozialwissenschaften. Grundlagen, Methoden, Anwendungen. (Statistics for the Social Sciences. Basis, methods, applications). Rowohlt. Hamburg

LAUMANN, E.O./ PAPPI, F.U. 1973: New directions in the study of community elites. In: American Sociological Review, V.38, N.2, April 1973, 212-30

LAWRENCE, P. R./ LORSCH, J.W. 1967: Organization and Environment. Cambridge. MA: Harvard University Press

LEENDERS, R.T.A.J. 1995: Structure and influence. Statistical models for the dynamics of actor attributes, network structure and their interdependence. Groningen University

LUHMANN, N. 1975: Macht (Power). 2. Aufl. Stuttgart: Enke, 1988.

LUHMANN, N. 1987: Soziale Systeme. Grundriss einer allgemeinen Theorie (Social systems. Outline of a general theory). Suhrkamp. Frankfurt a.M.

MAJONE, G. 1989: Evidence, Argument und Persuasion in the Policy Process. Yale University, New Haven und London

MARCH, J.G./ OLSEN, J.P. 1996: Institutional perspectives on political institutions. In: Governance 9: 247-64 
MARSH, D./ RHODES, R.A.W. 1992: Policy Communities and Issue Networks. Beyond Typology. In: Policy networks in British government. (Ed.) Marsh, D. and Rhodes, R.A.W. Oxford. 249-268

MARSH, D./ SMITH, M. 2001. There is more than one way to do political science: on different ways to study policy networks. In: Political studies, 2001, 49, 528-541

MAYNTZ, R., 1991: Modernization and the Logic of Interorganizational Networks. Working Paper. Max-Planck für Gesellschaftsforschung

MAYNTZ, R./ SCHARPF, F. 1995: Der Ansatz des akteurzentrierten Institutionalismus (The approach of actor-centered Institutionalism). In: Gesellschaftliche Selbstregelung und politische Steuerung. (Hrsg.) R. Mayntz, F. Scgarpf. 39-72. Campus, Frankfurt a.M.

MEIER, K. /O' TOOLE, L. 2001: Managerial strategies and behavior in networks: A model with evidence from US Public Education. In: Journal of Public Administration Research and Theory 11, 3, July 2001, 271-93

MILLS, M./ SAWARD, M., 1994: Policy Communities: Theoretical Issues. All very well in practice, but what about the theory? A critique of the British idea of policy networks. In: Contemporary Political Science. 79-92,1

NEE, V. 1998: Norms and networks in economic and organizational performance. In: The American Economic Review V.88, NO 2, 5/1998, 85-89

NIESSLEIN, E. 1995: Um die Zukunft der deutschen Forstwirtschaft (About the future of the German forestry). Holzzentralblatt 121 (1995) $181-186$

NOLLERT, M. 1997: Verbändelobbying in der Europäischen UnionEuropäische Dachverbände im Vergleich (Association lobbying in the European Union- European umbrella associations in comparison). In: Verbände in vergleichender Perspektive. Beiträge zu einem vernachlässigten Feld. 107-136. U. v. Alemann, B. Wessels (Hg.). Berlin. 
OSTROM, E./ GARDNER, R./ WALKER, J.M. 1994: Rules, games and common-pool resources. University of Michigan Press, Ann Arbor, MI

OSTROM, E. 1999: Self-Governance and Forest Resources. Occasional Paper No.20.Center for International Forestry Research

O' TOOLE, L./ MEIER, K. 1999: Modeling the impact of Public Management: Implications of structural context. In: Journal of Public Administration Research and Theory 9, 4, October 1999, 505-526

PAPPENHEIM, R. 2000: Neue Institutionenökonomik und politische Institutionen (New institutional economics and political institutions). Faculty of economics. University of Jena

PARSONS, T. 1963: On the Concept of Political Power. Proceedings of the American Philosophical Society, June 1963. In: Steven Lukes (ed.): Power. New York: New York University Press, 1986. 94-143.

PETERS, G. 1996. Political institutions, Old and New. A new handbook of political science. (Ed.) R.E. Goodin, H.-D. Klingemann, Oxford University Press

PETERS, G. 1999. Institutional Theory in Political Science. The 'New Institutionalism”. Pinter. New York

PETERSON, J. 1994: The European Community and Policy Networks. In: Contemporary Political Studies 1994, I, 151-169

PFEFFER, J./ SALANCIK, G. 1978: The external control of organizations: A resource dependence perspective. New York: Harper and Row

POPITZ, H. 1992: Phänomene der Macht (Phenomena of power). J.C.B. Mohr Tuebingen

RAAB, Ch.D. 2001: Understanding policy networks: a comment on Marsh and Smith. In: Political studies: 2001 Vol 49, 551-556

RAAB, J. 2002. Where do policy networks come from? In: Journal of public administration research and theory 12 (2002):4:581-622 
RAGIN, C.C. 1989: The comparative method. Moving beyond qualitative and quantitative strategies. University of California Press

RIDDER, P. 1979: Prozesse sozialer Macht. Bindende Entscheidungen in Organizationen (Processes of social power. Binding decisions in organizations). Ernst Reinhardt. Muenchen

ROYAL SWEDISH ACADEMY OF SCIENCES 2000: The scientific contributions of James Heckman and Daniel McFadden. Advanced information on the Bank of Sweden Prize in Economic Sciences in Memory of Alfred Nobel. Stockholm

RUDZIO, W. 1996: Das politische System der Bundesrepublik Deutschland (The political system of the Federal Republic of Germany). Lest und Budrich. Opladen

SABATIER, P. 1998: The Advocacy Coalition Framework: Revisions and relevance for Europe. In: Journal of European Public Policy, 5/1998, pp. $98-130$

SCHARPF, F. 1997: Games real actors play: Actor-centered Institutionalism in policy research. Boulder, CO: Westview Press

SCHUBERT, K. 1989: Interessenvermittlung und staatliche Regulation (Interest intermediation and state regulation). Westdeutscher Verlag. Opladen.

SCHWARZER, D. 1996: Arbeitsbeziehungen im Umbruch gesellschaftlicher Strukturen. Bundesrepublik Deutschland, DDR und neue Bundesländer (Working relations in radical change of social structures. Federal Democracy of Germany, DDR and new federal states). Steiner, Stuttgart.

SIMON, H. 1981: Entscheidungsverhalten in Organizationen (Decisionmaking behavior in organizations). Berlin

SIMON, H. 1978: Rational decision-making in business organizations. Nobel Memorial Lecture. Stockholm 
SKVORETZ, J./ WILLER, D. 1993: Exclusion and Power: A test of four theories of Power in Exchange Networks. In: American Sociological Review. 58, 801-818

STONE, C.N. 1980: Systemic power in community decision-making: A restatement of stratification theory. In: The American Political Science Review, V.74, 1980, 978-90

STRAUCH, M. 1993: Lobbying- die Kunst des Einwirkens (Lobbying: the Art of influencing). In: Lobbying. Wirtschaft und Politik im Wechsel. (Hrsg.) M. Strauch. Wiesbaden. 17-60

TUERK, K. 1995: Die Organisation der Welt. Herrschaft und Organisation in der modernen Gesellschaft (The organization of the world. Dominance and Organization in the moderne society). Westdeutscher Verlag. Opladen

VOGT, J. 1997: Vertrauen und Kontrolle in Transaktionen. Eine institutionenoekonomische Analyze (Trust and control in transactions. An institutional-economic analysis). Betriebswirtschaftlicher Verlag. Wiesbaden

WAARDEN, F.V. 1992: Dimensions and types of policy networks. In: European Journal of Political Research 21:29-52

WANG, S./ VAN KOOTEN, G. 2001. Forestry and the New Institutional Economics. An application of contract theory to forest silvicultural investment. Ashgate. England

WAPNER, P. 1996: Environmental activism and world civic politics. State University of New York Press.

WEAVER, R.K./ ROCKMAN, B.A. 1993: Do Institutions Mater?: Government Capabilities in the United States and Abroad. DC: Brookings Institution. Washington

WEBER, M. 1922: Wirtschaft und Gesellschaft (Economy and Society). 5. Aufl. besorgt v. J. Winckelmann. Tübingen: Mohr, 1972

WEBER, N. 2002: Tendencies towards privatization of international politics and their implications for the forest sector. In: Proceedings of the 
international conference 'Privatization in Forestry", Rankovic, N, Nonic, D. (eds.), V.2. Belgrade, p. 49-64

WEINGEIST, B. 1996: Institutional Theory. A new handbook of political science. (Ed.) R.E. Goodin, H.-D. Klingemann, Oxford University Press

WILLIAMSON, O. 1985: The economic institutions of capitalism. New York. Free Press

WILLIAMSON, O./ OUICHI, W. 1981: The markets and hierarchies program of research: origins, implication, prospects. In: Perspectives on organizational design and behavior. Ed. A. van de Ven, W.E. Joyce. New York. Wiley-Interscience

WINDHOFF-HERITIER, A. 1987: Policy-Analyze. Eine Einführung (Policy-Analysis. An introduction). Campus Studium Bd. 570 Campus Verlag

YAMAGUCHI, K. 1996: Power in networks of substitutable and complementary exchange relations: A rational-choice model and an analysis of power centralization. In: American Sociological Review. 61, 308-332 


\section{Lebenslauf von Nikolaos D. Hasanagas}

Geburtsdatum: 17.02.1974

Geburtsort: Thessaloniki, Griechenland

Staatsangehörigkeit: Griechisch

\section{Bildungsgang:}

1991- 97: Diplom Forst- und Umweltwissenschaft. Fachrichtung Planung und Entwicklung von natürlichen Ressourcen. Geotechnische Fakultät. Aristoteles Universität von Thessaloniki

1999- 2004: MA in Sozialwissenschaften (Hauptfach: Soziologie, Nebenfächer: Politikwissenschaft, Ethnologie). Universität Göttingen

Seit 1998: Promotionsstudium. Universität Göttingen

\section{Curriculum Vitae of Nicolas D. Hasanagas}

Birthday: $17^{\text {th }}$ February 1974

Birthplace: Thessaloniki, Greece

\section{Educational background:}

1991-97: MEng. eq. in Planning and Development of Natural Resources. Dept. of Forest Science and Natural Environment. Geo-technical Faculty. Aristotle University of Thessaloniki. Greece

1999-2004: MA in Social Sciences (Major subject: Sociology, Minor subjects: Political Science and Ethnology). Goettingen University. Germany

Since 1998: PhD. Goettingen University 


\section{GEORG-AUGUST-UNIVERSITÄT GÖTTINGEN \\ INSTITUT FÜR FORSTPOLITIK, FORSTGESCHICHTE UND NATURSCHUTZ}

Institut für Forstpolitik und Naturschutz, Büsgenweg 5, 37077 Göttingen

\author{
Büsgenweg 5 \\ D-37077 Göttingen \\ Tel.: +49-551-393412 \\ Fax: +49-551-39 3415 \\ Vorstand: \\ Prof. Dr. Renate Bürger- \\ Arndt \\ Prof. Dr. Max Krott
}

20. Mai 2004

\section{Erklärung}

Ich versichere, dass ich die eingereichte Dissertation

„Power factor typology through organisational and network analysis - Using environmental policy networks as an illustration "

selbständig und ohne unerlaubte Hilfsmittel verfasst habe. Anderer als der von mir angegebenen Hilfsmittel und Schriften habe ich mich nicht bedient. Alle wörtlich oder sinngemäß den Schriften anderer Autoren entnommenen Stellen habe ich kenntlich gemacht.

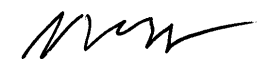

(Nikolaos.D.Hasanagas) 


\section{Acknowledgments:}

I would like to thank Prof. M. Krott for his intensive supervision, interesting discussions and multifaceted support as well as Prof. S. Gissendanner

(Goettingen University) and Prof. V. Mueller-Benedict (Leipzig University) for their helpful comments and my research companion, Ms Alejandra Real (Goettingen University), for her irreplaceable assistance.

Also, I would like to thank Prof. P. Efthymiou and Prof. N. Stamou for their support and especially Prof. A. Papastavrou (Aristotle University of Thessaloniki) for his decisive help and the sound introduction into the Policy Analysis that I received as an undergraduate student.

Finally, I would like to thank my parents and the following friends and associates for their tireless cooperation:

- Mr Athanasios Karagiannis (Aristotle University of Thessaloniki, Greece)

- Ms Binnie Feierabend (Goettingen University, Germany)

- Mr Esteban Voehringer (Goettingen University, Germany)

- Ms Christina Popi (Kassel University, Germany)

- Mr Konstantinos Tsimonis (Panteion University of Athens, Greece)

- Mr Marios Skembis (Goettingen University, Germany)

- Ms Natalia Kyriakidi (Goettingen University, Germany)

- Ms Tatiana Wert (Goettingen University, Germany) 
ibidem-Verlag

Melchiorstr. 15

D-70439 Stuttgart

info@ibidem-verlag.de

www.ibidem-verlag.de

www.edition-noema.de

www.autorenbetreuung.de 